\title{
DISSERTATION
}

\section{THE EARLY PATHOGENESIS OF FOOT-AND-MOUTH DISEASE IN CATTLE AFTER AEROSOL INOCULATION}

\author{
Submitted by \\ Jonathan Arzt \\ Department of Microbiology, Immunology, and Pathology
}

In partial fulfillment of the requirements

For the Degree of Doctor of Philosophy

Colorado State University

Fort Collins, Colorado

Summer 2010 
COLORADO STATE UNIVERSITY

July 6,2010

WE HEREBY RECOMMEND THAT THE DISSERTATION PREPARED UNDER OUR SUPERVISION BY JONATHAN ARZT ENTITLED THE EARLY PATHOGENESIS OF FOOT-AND-MOUTH DISEASE IN CATTLE AFTER AEROSOL INOCULATION BE ACCEPTED AS FULFILLING IN PART REQUIREMENTS FOR THE DEGREE OF DOCTOR OF PHILOSOPHY.

$\underline{\text { Committee on Graduate work }}$

\begin{tabular}{c}
\hline Anthony Knight \\
\hline Luis Rodriguez \\
\hline Barbara Powers \\
\hline Advisor: Gary Mason \\
\hline Department Head: Edward Hoover
\end{tabular}




\section{ABSTRACT OF DISSERTATION \\ THE EARLY PATHOGENESIS OF FOOT-AND-MOUTH DISEASE IN CATTLE AFTER AEROSOL INOCULATION}

The goal of the efforts described in this dissertation was to characterize the early pathogenesis of foot-and-mouth disease (FMD) in cattle after simulated natural infection. More specifically, emphasis was placed upon two critical knowledge gaps: identification of the primary site(s) of infection of FMD virus (FMDV) and the mechanism of establishment of viremia. In order to investigate these processes, novel systems were developed for (1) consistent experimental aerosol infection of steers, (2) molecular and virological detection of FMDV in bovine tissues, and (3) microscopic localization of FMDV antigens in bovine tissues. These novel tools were then applied to a thorough, prospective, time-course analysis of bovine FMD.

Screening of antemortem samples indicated that establishment of primary infection in the respiratory tract was detectable between 4 - 6 hours post aerosol inoculation (hpa); establishment of viremia was detectable between 24 - 48 hpa. Examination of tissue samples collected postmortem demonstrated that in previremic steers, FMDV was most consistently localized to nasopharyngeal tissues by all detection methods indicating this region as the most important site of primary viral replication. The earliest site of microscopic localization of FMDV antigens was the lymphoid 
follicle-associated epithelium of the pharyngeal mucosa - associated lymphoid tissue (PALT) of the nasopharynx. At early time points after aerosol inoculation, viral antigens colocalized with cytokeratin-positive pharyngeal epithelial cells; intraepithelial, FMDVnegative, MHCII/CD11c-double positive dendritic cells were present in close proximity to FMDV-positive cells. Onset of viremia coincided with marked increase of viral loads in pulmonary tissues and substantial decrease of viral detection in nasopharyngeal tissues. These data indicate that subsequent to aerogenous exposure to FMDV, the temporally defined critical pathogenesis events are (1) primary replication in epithelial cells of the PALT crypts, (2) subsequent widespread replication in pneumocytes in the lungs which coincides with (3) the establishment of sustained viremia.

This body of work is unique for its breadth and depth of investigation of FMD in cattle; the importance of the conclusions described herein may be separated into three tiers. The detailed characterization of the early virus-host interactions provides a greater level of understanding of the pathogenesis of this important disease and thus directly contributes to basic science knowledge. Additionally, the novel techniques described herein may be applied to a wide range of subsequent pathogenesis studies which will further elucidate FMDV-host interactions in various species and stages of infection. However, the translational implications of the findings are likely to, ultimately, have greatest significance by contributing to the development of rationally designed FMDV vaccines and biotherapeutics. Specifically, the data described in the chapters which 
follow strongly suggest that improved mucosal immunity (particularly in the nasopharynx) should be a high-priority goal of "next generation" FMDV prophylaxis.

Jonathan Arzt Department of Microbiology, Immunology, and Pathology Colorado State University Fort Collins, CO 80523

Summer 2010 


\section{Acknowledgments}

Various forms of non-financial support have come from various individuals over the course of the realization of this work. Firstly, Luis Rodriguez must be recognized both for conceiving the notion of this endeavor and for allowing the author sufficient independence to pursue its fulfillment unencumbered. Gary Mason has supported the author with invaluable confidence and encouragement which spanned from early in residency until completion of this Ph.D. Juan Pacheco and Meghan Tucker have provided extensive practical contributions without which completion of this work would likely have been delayed by a handful of years. Funding for this work came from the Agricultural Research Service, United States Department of Agriculture, CRIS project number 1940-32000-052-00D. Lastly, the author must acknowledge Sholom Arzt who instilled in his only son at a young age a dedication to the scientific thought process, but sadly did not survive long enough to see the fruits of that encouragement. 


\section{Preface}

The work described herein was performed between September, 2006 - January, 2010 at the Plum Island Animal Disease Center within the Foreign Animal Disease Research Unit, Agricultural Research Service, United States Department of Agriculture. The individual chapters were each originally generated as separate manuscripts for publication in scholarly, peer-reviewed journals. At the time of submission of this dissertation these manuscripts are in varying states of progression through the publication process. Though these works have been stylistically adapted to ensure that this dissertation is a unified and integrated work, the original content has been preserved.

Chapters 2 and 3 present some novel pathogenesis data, but are both essentially technique papers which describe the development of the requisite tools for the work described in Chapter 4. Chapter four builds upon the first three chapters and clearly represents the culmination of the cumulative effort described herein. As the chapter was originally written as a stand-alone manuscript, some relevant material (particularly as related to technique) from the previous chapters has been repeated. 
Table of Contents

Chapter 1, page 1

A review of the current understanding of the pathogenesis of foot-and-mouth disease

Chapter 2, page 45

Development of a novel aerogenous inoculation system for the experimental investigation of the pathogenesis of foot-and-mouth disease in cattle

Chapter 3, page 68

Development of novel immunolocalization techniques for the experimental investigation of the pathogenesis of foot-and-mouth disease in cattle

Chapter 4, page 103

A time-course investigation of the early pathogenesis of foot-and-mouth disease in cattle utilizing novel aerosol inoculation and immunolocalization techniques

Conclusions, page 143 


\title{
Chapter 1
}

\section{A review of the current understanding of the pathogenesis of foot-and-mouth disease}

\begin{abstract}
In 1898 foot-and-mouth disease (FMD) earned a place in history as the first disease of animals shown to be caused by a virus. Yet, despite over a century of active investigation and elucidation of many aspects of FMD pathogenesis, critical knowledge about virus-host interactions is still lacking. The aim of this review is to provide a comprehensive overview of FMD pathogenesis spanning from the earliest works to recently acquired insights emphasizing pathogenesis in natural hosts (predominantly cattle and swine) infected by methodologies most closely resembling natural infection (predominantly aerosol or direct/indirect contact). The 3 basic phases of FMD pathogenesis in vivo will be dissected and characterized as: (1) previremia characterized by infection and replication at the primary replication site(s), (2) sustained viremia with generalization and vesiculation at secondary infection sites, and 3)

postviremia/convalescence including resolution of clinical disease that may result in long-term persistent infection. Additionally, molecular pathogenesis mechanisms characterized in vitro will be considered in relationship to pathogenesis in live animals. Critical evaluation of the current status of understanding will be used to identify knowledge gaps to guide future research efforts
\end{abstract}




\section{Introduction}

Foot-and-mouth disease virus (FMDV; family Picornaviridae; genus Aphthovirus) causes an acute disease of cloven-hoofed animals characterized by fever, lameness, and vesicular lesions of the feet, tongue, snout, and teats. These debilitating effects, rather than high mortality rates, are responsible for severe productivity losses associated with foot-and-mouth disease (FMD). The highly contagious nature of the virus and severity of economic impacts associated with the disease, determine FMD's status as the most important disease limiting trade of animals and animal products throughout the world.

The earliest recognition of the clinical entity of FMD is generally credited to Fracastorius's observations in the $16^{\text {th }}$ century ${ }^{45}$; however, the first step towards understanding the pathogenesis of FMD was Loeffler and Frosch's landmark demonstration that the disease was caused by a filterable agent (i.e. virus) ${ }^{78}$. In the years since that discovery, investigation of the pathogenesis of FMD has been conducted in various manners and has been reviewed relatively recently ${ }^{3,55}$. However, progress in understanding the mechanisms of this important disease has been impaired by two substantial obstacles: 1) the biosecurity requirements for working with the virus have limited research to only a handful of institutions worldwide and 2) the seven serotypes and myriad strains of the virus have proven to often be as dissimilar as they are similar, thus limiting the ability to extrapolate findings from many studies to understanding of FMDV in general.

It is generally accepted that FMDV spreads predominantly by direct or indirect contact with infected animals, their secretions, or contaminated food products. It is also 
known that under certain circumstances the virus travels over extensive distances to cause incursions at previously virus-free premises (reviewed in ${ }^{8}$ ). Though airborne dissemination of infectious aerosols is often implicated, the contributory roles of humans (fomites), wildlife, and waterborne spread are often not easily discerned. It is widely accepted that natural infection of cattle occurs via the respiratory route by aerosolized virus ${ }^{37}$, whereas pigs are more commonly infected by consumption of viruscontaminated food or through skin lesions while in contact with infected animals or their secretions ${ }^{5}$. However, despite many years of research, the basic events and mechanisms utilized by the virus to infect, cause disease within one animal, and disseminate to other animals remain incompletely elucidated.

Much of the basic knowledge about FMDV virus-host interactions is derived from in vitro studies under controlled cell culture conditions. These studies, while important, cannot fully address the complexity of the virus-host interaction at the tissue, organ, and systemic levels in the natural hosts. Of particular interest are the identification and characterization of sites of primary viral infection in the host and the pathways, mechanisms, host factors, and viral factors that determine generalization (i.e. viremia) and spread of the virus.

The importance of elucidating the previremic events is that it is these steps which must be targeted by vaccines and biotherapeutic agents; if viremia occurs, the battle (at the individual animal level) has been lost. Thus, improving the understanding of FMD pathogenesis is more than an exercise in basic science research. Rather, it is an effort that surely will be the basis for rational design of the next generation of vaccines and biotherapeutic agents. These products may target the following closely related, yet 
distinct aspects of FMD: establishment of primary viral infection, prevention of generalization (viremia), mitigation of clinical disease, and prevention of viral persistence in ruminants. Of these issues, persistence has a unique significance. The infectivity of persistently infected ruminants to naïve animals is believed to be low under most circumstances; yet, it is not completely negligible. That perceived threat of contagion from carriers is one of the factors that dictate trade policies of FMD-free nations. And, it is these policies which drive the cost-benefit analyses that determine FMD response strategies; most models indicate that without a "vaccinate to live" policy, the economically favored control strategy in most scenarios is "stamping out" (i.e. mass depopulation $)^{15,135}$. Since persistence is a consequence of the other stages of FMDV infection, it follows that improved understanding and mitigation of the various stages of FMD (i.e. pathogenesis), ultimately, is a requisite path to decreasing the need for mass depopulations.

The goals of this review are to provide a comprehensive overview of the field of FMDV virus-host interactions and to identify important knowledge gaps that remain in the understanding of this important disease. As pathogenesis in cattle has been most thoroughly investigated, this body of work will be described at length and used as a basis of comparison for understanding virus-host interactions in other species. Descriptions of viral pathways in vivo will be followed by a review of the molecular mechanisms characterized in vitro which suggest explanations of pathogenesis in live animals.

\section{Stages of FMD Pathogenesis}

The terms "previremia", "viremia", and "postviremia" have generally accepted definitions in the description of stages of FMD pathogenesis. However, other terms such 
as "early" and "persistent" have been used variably in the published literature and have led to some confusion. While authors will, likely, continue to use terminology to suit their needs and preferences, for the purposes of this review, the stages of FMD pathogenesis are defined as:

1. Previremia: the period from which an animal is first infected with FMDV until virus is first detected within the intravascular (i.e. blood) compartment with a sustained and quantitatively increasing trend (defined by VI or rRT-PCR). Previremia may include a passive and transient presence of virus in the blood in the period immediately following first exposure to FMDV.

2. Establishment of viremia: not a true stage, but rather the transition between previremic and viremic stages. However, because of the importance of this transition it will be treated as a distinct event.

3. Viremia: the period during which FMDV can be detected within the intravascular compartment with kinetics suggestive of active viral replication (defined by VI or rRTPCR). Viremia may be undetectable in some infected animals even when they develop secondary lesions. However, if replication has occurred at secondary sites, viremia must have occurred, and failure of detection in such instances may be attributed to insufficient frequency of sampling and/or inadequate detection threshold.

4. Post viremia: the period following viremia starting with the first negative assay on blood (defined by VI or rRT-PCR) which includes:

i. Clinical phase and convalescence 
ii. persistent infection (carrier state): the period after 28dpi in which infectious FMDV may be detected on at least one of multiple esophageal-pharyngeal samples (as defined by OIE)

iii. persistent / non-infectious: a recently described condition in which FMDV antigens and/or RNA, but not infectious virus may be detected in tissues subsequent to resolution of viremia (a condition which may exist in continuity with the conventional carrier state)

\section{Previremia and primary sites of infection in cattle}

FMD pathogenesis has been most thoroughly investigated in cattle, less so in swine, and minimally in other species. Yet despite several decades of investigation of the bovine pathogenesis, a clear consensus still does not exist regarding many basic aspects of virus-host interaction. Basic events of early infection, such as tissue sites and cellular characteristics of primary infection and replication, are not clearly established. Contradictions exist in the scientific literature which are likely due to multifactorial differences across studies including virus strains used, methods of virus detection, techniques used for animal exposure, tissues examined, and variability among small numbers of experimental animals. Despite the relevance of all of these factors, strainspecific viral properties have likely created the most substantial challenge to generating a consensus understanding of the pathogenesis of FMD. Amongst the myriad strains of FMDV, there surely are aspects of tropism and virulence which are strain-specific; however, conclusions regarding these factors can not be adequately documented unless different strains are examined in vivo in studies in which all other experimental 
techniques remain constant. Such studies are rarely performed due to constraints of cost and logistics, and as such the conclusions from most pathogenesis studies are only directly applicable to a single FMDV strain. Overall, upon examination of the complete breadth of the FMD pathogenesis literature, one is best advised to accept that the seemingly contradictive conclusions across studies are most likely a reflection of systems-dependent factors.

It is often stated that early investigators considered the natural routes of infection by FMDV to be via the upper gastrointestinal tract ${ }^{28,74,126}$. However, as early as 1952 the susceptibility of cattle to respiratory tract inoculation was experimentally investigated ${ }^{59}$. Korn's 1957 work is often cited as the earliest demonstration that the respiratory tract provides the site of primary infection; however in that work, the author cites two earlier studies which described infection of cattle via aerosol ${ }^{46}$ or intranasal deposition ${ }^{96}$. The remainder of the following discussion of previremia will focus upon contact and direct respiratory tract inoculation as these are considered to closely simulate natural exposure in cattle; however, it is acknowledged that cattle are (likely) less commonly naturally infected by direct transepithelial penetration and ingestion and this might result in different primary replication sites and distinct patterns of viral dissemination.

Korn infected cattle with FMDV by moist gauze deposition on the nasal planum and euthanized animals at various times after inoculation ${ }^{74}$. By performing virus isolation (VI) on various tissues, this work demonstrated that in previremic animals, FMDV was more frequently retrieved from nasal mucosae and nasopharynx than stratified squamous epithelial sites within the oral cavity. This work is also noteworthy in 
providing the only documentation of microvesiculation at a primary replication site (nasal mucosa).

Following Korn's tissue-specific work, much of the investigation of FMD pathogenesis was conducted in studies utilizing virus isolation from various clinical samples with an emphasis on esophageal-pharyngeal fluid (OP, "probang samples") and/or serum as a means of detecting "pharyngeal" FMDV replication and viremia, respectively $26,29,90,92,127$. Though these early works are informative, they clearly have limitations. The probang cup, while useful as a diagnostic instrument, provides a crude specimen for pathogenesis investigation. Though a VI-positive OP sample is surely indicative of the presence of infectious virus, it is insufficient to discern the origin of virus from amongst esophagus, pharynx, oral cavity, lung, or nasal cavity; each, individually, containing numerous distinct tissue and cell types. Regardless, in 1968, Burrows and colleagues demonstrated the presence of FMDV in OP samples prior to development of vesicles ${ }^{26}$, and somewhat later confirmed previremic "pharyngeal" replication by demonstrating that OP VI-positivity occurred prior to detection of virus in blood subsequent to contact exposure ${ }^{29,127}$. However, within approximately the same time period, Eskildsen brought into question the notion that VI-positive probang samples were necessarily indicative of pharyngeal FMDV replication by demonstrating that deposition of FMDV directly into the lung via tracheostomy consistently resulted in generalized disease ${ }^{42}$. Thus, the relative contributions of upper and lower respiratory tract to FMD pathogenesis were already in question.

The previremic viral dynamics in the bovine respiratory tract were more precisely defined in subsequent experiments which demonstrated that primary replication of 
FMDV could be detected in OP fluid within 2-6 hours of intranasal deposition depending upon viral strain and dose administered ${ }^{90,92}$. These experiments also demonstrated that the onset of viremia occurred at or near the peak of FMDV detection from OP samples (16$72 \mathrm{hpi}$ ) and that the lag (eclipse) time between inoculation and OP positivity was inversely related to the FMDV dose inoculated.

The first comprehensive examination of distribution of FMDV in numerous distinct tissues during acute infection of cattle was reported in $1981^{28}$. By returning to the strategy of dissecting and screening tissues individually, this work provided compelling evidence that in the previremic phase, FMDV-positive OP samples, likely, largely represented pharyngeally replicated FMDV. Additionally, the use of several routes of exposure and 3 different viruses broadened the implications of this work. Overall, amongst previremic cattle, dorsal soft palate, pharynx (precise region not indicated), and retropharyngeal lymph node were the tissues most frequently found to be VI-positive and had the highest mean FMDV titers. These experiments found other tissues including lungs, tonsils, and nasal mucosae to be involved in previremic FMD with lower frequency and at generally lower viral titers.

Theoretically, microscopic localization of FMDV during previremic infection should provide the most definitive information regarding the primary site(s) of infection; however the combinatorial data from a handful of studies is less than completely congruous. Microscopic localization of previremic FMDV has been performed by in situ hybridization (ISH) ${ }^{21,23,60}$ and immunohistochemistry ${ }^{13,107}$. Brown and colleagues inoculated cattle using an improvised aerosol chamber and examined several tissues by ISH at various times post exposure. The overall conclusion was that the lungs were the 
most likely primary infection site based on localization of FMDV RNA to respiratory bronchioles in (presumed) previremic steers. However, viewed retrospectively, both works from this group have perplexing findings. In the earlier work ${ }^{21}$, the strongest ISH signal at 6hpe was detected at the lesion predilection sites of the feet with weaker signal seen in tongue and carpus (all unexpected in previremic animals). This could be explained either by the occurrence of a transient, low grade, undetected viremia or by preexisting (non-FMD-related) lesions which became FMDV-contaminated at the time of aerosol inoculation. The latter hypothesis is unlikely since the finding was similarly repeated in several animals within the study, and the former cannot be addressed as blood was not collected from the animals euthanized at early time points (discussed further below). Additionally, it is unfortunate that tissues of the pharynx and nasal cavity were not examined within that study ${ }^{21}$ to address the earlier indications that such tissues were important primary replication sites ${ }^{28,74}$. The later work from this group did examine the soft palate which was FMDV ISH-negative at 24hpi, however only a single (presumed) previremic animal was included for each virus used in this study ${ }^{23}$.

Chapters 2 and 4 of this dissertation will describe novel investigations of the early pathogenesis of bovine FMD in an aerosol inoculation model ${ }^{13,107}$. These studies have surpassed earlier works in intensiveness of sampling (time points examined, number of animals per time point, and number of tissues per animal). Additionally, the unique use of trimodal (VI, rRT-PCR, immunomicroscopy) detection systems for FMDV provides novel insights into pathogenesis by allowing discrimination of the presence of infectious virus, viral RNA, and viral antigen. Within this system, bovine FMDV infection initiated at the crypt regions of the follicle associated epithelia at MALT regions of the 
nasopharynx. Shortly thereafter, FMDV was detected within the pulmonary alveolar septa. At both pharyngeal and pulmonary sites, FMDV colocalized with cytokeratin indicating that the infected cells were of epithelial histogenesis. Furthermore, these works demonstrated a trend that as viremia approached, FMDV became more prominent within the lungs and less apparent in the pharyngeal tissues.

Lastly, various studies have directly demonstrated or indirectly suggested that FMDV may enter the systemic circulation and disseminate to distant sites during the previremic period (i.e. primary or passive viremia). There are sporadic reports of detection of transient, low titer (trace) viremia in cattle following contact-infection or exposure to FMDV aerosols ${ }^{60,89,130}$. Additionally, in calves exposed to aerosolized virus, the detection of FMDV RNA in pedal and oral epithelia at six hours post-infection, before the onset of "true" viremia and clinical signs is best explained by hematogenous spread ${ }^{21}$. FMDV has also been isolated from the pharynx in cattle as early as four hours after virus was instilled into mammary tissue, before the onset of viremia ${ }^{29}$. It is feasible that low titers of cell-free or cell-associated virus were present in the circulation in these animals but were undetectable by current methodologies due to the large volume of the circulatory system ${ }^{129}$. Overall, the consistency and the mechanisms by which this proposed primary viremia occurs remain to be elucidated, and the significance to overall understanding of FMD pathogenesis remains unknown.

\section{Establishment of viremia in cattle}

Understanding the mechanism by which FMDV enters the systemic circulation and maintains high-titer viremia is of critical importance to basic scientific understanding 
of the pathogenesis, but also to control efforts. Effective abrogation of viremia markedly decreases severity of clinical disease and extent of shedding, and thus the economic impact of incursion into naïve herds or flocks. Indeed, current vaccines likely function by preventing viremia not primary infection. Despite this elevated importance, very few pathogenesis studies have specifically addressed how viremia is established, and the "conventional wisdom" on the subject is derived almost entirely from speculation. In order to suggest that an organ or tissue may serve as a "portal" for establishment of viremia, certain requirements should be met individually or, ideally, in combination: 1) FMDV should be detected in that tissue prior to detection of viremia, 2) experimental exposure of that tissue (in isolation) should be shown to result in viremia, and 3) a cellular/molecular mechanism for movement of FMDV from the interstitium to the intravascular compartment should be demonstrated (or sensibly projected).

Though category 3 is the most elusive at present given the incomplete elucidation of FMDV-host molecular interactions in vivo (discussed below), several studies have met categories 1 and 2. As discussed above (previremia section), several studies have demonstrated the presence of FMDV in the respiratory tract prior to viremia $13,26,28,74,90,130$. However, pursuit of further defining the viremia portal (upper vs. lower repiratory tract) is complicated by the fact that these regions are interconnected, and in live animals air flow (and hence aerogenous FMDV) passes freely between the external environment, nasal cavity, pharynx, and all levels of lungs. This complexity was elegantly addressed by Sutmoller and McVicar by placement of tracheostomy tubes in steers as a means of isolating the upper and lower respiratory tracts for examination of viral dissemination under variable exposure conditions ${ }^{130}$. By demonstrating similar 
FMDV kinetics in blood between tracheostomized cattle inoculated either intranasally or by contact this work concluded that either the upper or lower respiratory tract may individually serve as portals of FMDV entrance to the systemic circulation. Further evidence supporting the importance of the nasopharynx in establishing viremia came from Burrows work which demonstrated that lungs of aerogenously infected cattle were often (but not exclusively) VI-negative unless the animals were viremic; this suggested that the virus had to reach some other site (presumably nasopharynx) to establish viremia which then could be detected in lung. However, more recent work has shown that in the period in which viremia is established, substantially greater quantities of FMDV are detectable in the lungs as compared to the pharynx suggesting a pulmonary portal ${ }^{13}$.

The notion that FMDV viremia is established at regional lymph nodes draining sites of primary replication is intuitively reasonable, but has not been supported by the primary literature. At least two important pathogenesis studies have suggested this mechanism while acknowledging that it was speculative in nature ${ }^{74,130}$. However Korn's data, by demonstrating absence of FMDV in lymph nodes of previremic cattle contradicted this notion. Conversely, previremic cattle in Burrows' work had relatively high prevalence and titer of FMDV in retropharyngeal lymph nodes, yet this author did not speculate viremia was established by the lymphoid route ${ }^{28}$. A more recent study concluded that lymphoid organs were not the portal for viremia based upon low frequency of detection of FMDV in tonsils and lymph nodes of previremic cattle ${ }^{13}$. Though there surely is room for FMDV strain-specificity as an explanation, it should be noted that afferent lymphatics draining the pharynx and lungs pass through the highly vascular regional MALT prior to reaching primary lymph nodes. As such, if one chose to 
favor establishment of viremia via lymphoid tissue, the MALT/BALT must be included either as precedent to lymph node involvement or as a direct route to the systemic circulation.

\section{Viremia}

Experimental contact challenge experiments in cattle, sheep and pigs have demonstrated that viremia, as determined by VI or qRT-PCR, is readily detectable from 1 to 2 days prior to the onset of pyrexia or other clinical signs ${ }^{2,5,10,13}$. Viremia results in widespread distribution of FMDV to various tissues and organs, including epithelia, endocrine glands and across the blood-brain barrier ${ }^{28,44}$. Furthermore, all excretions and secretions can contain virus during the viremic phase or clinical disease ${ }^{8}$. Early viremia is characterized by the onset of the non-pathognomonic FMD hallmark of vesiculation and erosion of various epithelial sites including the mouth, feet, prepuce, teats, and pillars of the rumen ${ }^{3,124}$. Progression of vesiculation extends beyond the period of viremia. Infrequently, gross lesions are associated with other secondary predilection sites which include the myocardium ${ }^{56,117,133}$.

The anatomic and cellular source of the high titers of virus detected in the blood during viremia remains one of the important knowledge gaps regarding FMD. Typically only vesicles have greater quantities of FMDV than viremic blood which suggests a vesicular source; except that viremia can precede vesicular lesions for several hours or days and in some cases viremia is present in the absence of vesicular lesions. Also it is unlikely that several minute vesicles could maintain the high viremic titers of FMDV given the large bovine blood volume. However, microscopic vesicles have been 
described in the tongue and haired skin of cattle in the absence of macroscopic lesions ${ }^{48,124,137}$. Despite the absence of gross lesions, it has been shown that bovine haired skin can contain relatively high titers of virus, approaching but not exceeding the amount detected in the blood at the peak of viremia ${ }^{49}$. Thus virus replicating within non-lesional epithelial sites (i.e. skin) could contribute to the high titer viremia detected in animals in the absence of macroscopic lesions ${ }^{22,98}$. Additionally, it has recently been suggested that FMDV replication in the lungs of cattle may substantially contribute to maintenance of high-titer viremia ${ }^{13}$. Detection of high quantities of viral RNA, antigen, and infectious virus in pulmonary tissues starting at the onset of viremia combined with the large mass of the lungs supports this notion.

Several studies have reported tissue-specific viral loads in viremic cattle ${ }^{13,28,138}$. However, such data must be reviewed cautiously as it is impossible to accurately determine the contribution to a tissue's "viral load" from blood-borne virus. The common approach to correct this complication by subtracting the blood titer from the tissue titer is an imperfect solution as it falsely assumes similar blood volumes in all tissues examined. Bearing this limitation in mind, it is still noteworthy that the highest viral loads reported in these studies (excluding vesicles) were lymph nodes and myocardium ${ }^{28}$, lungs ${ }^{13}$, and vesicle-free lesion predilection sites ${ }^{138}$.

There is no significant evidence for replication or transport of FMDV in peripheral blood mononuclear cells (PBMC) in cattle ${ }^{6,138}$. A transient lymphopenia has been reported during the early stages of infection in swine which may be a consequence of early infection of T cells ${ }^{16,34}$. However, the susceptibility of porcine PBMC to FMDV infection may depend on the serotype of challenge virus. PBMC isolated from serotype C 
infected swine were shown to be infected during viremia, coinciding with depletion of $\mathrm{T}$ cells in lymph nodes and the spleen ${ }^{34}$. In contrast, PBMC isolated from serotype O infected swine were not infected ${ }^{16,132}$. It is clear that FMDV can interact with bovine and porcine lymphocyte populations in vitro ${ }^{58,69,128}$ but the role of these interactions in vivo during viremia remains to be determined.

Dendritic cells have a central role in the induction of innate and adaptive immune responses, yet their role in FMD pathogenesis is poorly understood. This is particularly relevant in the presence of anti-FMDV antibodies which lead to a shift in affinity and uptake of antibody-opsinised virus by $F_{c}$ receptor expressing cells. This shift in affinity may also be partly responsible for early localization of FMDV to the germinal centre light zone, as detected in mandibular lymph nodes of cattle as early as 3 to 4 days post intradermolingual challenge ${ }^{71}$. An effective immune response against FMDV, leading to clearance of viremia and tissue viral loads, is characterized by the rapid induction of specific antibody and is thought to be dependent on the interaction between antibodyvirus complexes and the phagocytic cells of the reticuloendothelial system ${ }^{70,85-87}$. Although FMDV structural and non-structural proteins have been detected in lymph nodes of cattle at 4 days post-infection, FMDV proteins have not been detected in the spleen or liver and it is not clear if FMDV undergoes productive replication at these $\operatorname{sites}^{71}$.

\section{Post viremia}

It is well established that in the convalescent period, subsequent to clearance of viremia, FMDV continues to be present in very high titers at the lesion predilection sites. 
Additionally, after clearance of virus from lesion sites, FMDV persists in certain tissues for prolonged times and a subset of FMDV-infected ruminants develop chronic asymptomatic infection referred to as persistence or the carrier state ${ }^{6,119}$. Though various trends have been described regarding tissues affected, species susceptibility, and viral genomic alterations associated with persistence, much remains unknown. A noteworthy knowledge gap is the poor understanding of the extent of the threat posed by carriers to naïve animals. However, global trade policy is intimately tied to FMD persistence and two inescapable realities are (1) that the concern of transmission from asymptomatic carriers is the main reason why FMD-free nations restrict imports from enzootic regions or regions with freedom with vaccination and (2) one of the main reasons that FMD-free nations depopulate when confronted with FMDV incursion is due to failure of vaccination to prevent the carrier state.

The historic recognition of FMDV persistence in ruminants has been reviewed extensively ${ }^{7,9,55,121}$. Briefly, the recovery of infectious FMDV from convalescent cattle was first convincingly demonstrated by Van Bekkum and colleagues in $1959^{134}$. Reports of similar findings from various investigators established the notion that FMD persistence (defined as recovery of live virus at more than $28 \mathrm{dpi}$ ) is a common sequel to infection of ruminants, and that roughly $50 \%$ (with substantial variability across studies) of ruminants become persistent carriers. Another landmark was Burrows' demonstration of tissuespecific localization of persistence with dorsal soft palate and dorsal pharynx implicated as the most frequent sites of recovery of FMDV from post-viremic cattle ${ }^{25,27}$. Yet, the sites within which FMDV persists and the origin of virus detected by probang sampling still remains incompletely elucidated. Burrows had additionally recovered FMDV from 
several other tissues of carrier animals including the esophagus, ventral soft palate, pharynx, glosso-epiglottic space and tonsillar sinuses. These early studies were somewhat limited in that they detected FMDV by virus isolation, a technique which is compromised in carrier animals by the presence of high titers of neutralizing antibody. Donn et. al. highlighted the limitations of applying conventional virus isolation techniques for detecting the carrier state in tissue samples and the benefits of detecting viral RNA by the polymerase chain reaction. Viral RNA was readily detected in the tonsil, ventral and dorsal soft palate and cranial esophagus of contact challenged cattle, however, all the tonsillar and esophageal samples were negative by virus isolation ${ }^{38}$. However, this type of application of RT-PCR also has limitations in that it gives no indication whether or not detected RNA was derived from infectious virus.

More recently, detailed time course experiments have characterized clearance of FMDV RNA from tissues during the immediate post-acute period in cattle ${ }^{139}$. This work demonstrated that viral RNA was detectable in various tissues for up to two days after cessation of viremia, but was largely cleared from most tissues of cattle at 14 days post challenge. However, the same study demonstrated detection of FMDV RNA in pharyngeal tissues (carrier and non-carriers) and lymph nodes (carriers only) up to $72 \mathrm{dpi}$. Notably, only one tissue (dorsal soft palate) contained FMDV viral RNA in every animal with a $\mathrm{VI}(+)$ probang specimen suggesting a dorsal palatal source of virus detected via probang. Other works have similarly described that viral RNA is detectable in pharyngeal tissues beyond 28 days ${ }^{7,9,121}$. Similarly, in sheep, viral RNA has been detected in tonsil, dorsal soft palate and nasopharynx up to 43 days post needle or contact challenge ${ }^{62}$. A 
recent study in sheep showed that by $10 \mathrm{dpi}$, the only tissues where FMDV still replicates were the tonsil and soft palate ${ }^{117}$.

Microscopy studies utilizing in situ hybridization in bovine tissues have provided further support for the importance of pharyngeal tissue in the convalescent $(5-17 \mathrm{dpi})^{113}$ and persistent (42-82dpi) ${ }^{143}$ periods. Both of these studies described intraepithelial localization of FMDV RNA within dorsal and ventral soft palate and pharynx with the strongest ISH signal detected in the basal and deep spinous regions. Though the phenotypes of infected cells were not investigated in these works, the signal distribution is most consistent with epithelial cells. Strong ISH signal was also identified within tonsillar lymphoid follicles at $14 \mathrm{dpi}^{113}$. Microscopic localization of FMDV antigens in these regions from carrier animals has not been published; however, recent work has suggested that FMDV structural and non-structural antigens are present in pharyngeal tissues with a more limited distribution compared to that described by ISH (Arzt, unpublished data).

Recently, Juleff et al analyzed pharyngeal tissue samples harvested from cattle 38 days post-contact challenge using a combination of different techniques to detect viral RNA and protein ${ }^{71}$. These investigators readily detected FMDV genome, using laser capture microdissection and quantitative rRT-PCR, in germinal centers within the dorsal soft palate, pharyngeal tonsil, palatine tonsil, lateral retropharyngeal lymph node and mandibular lymph node. In contrast to earlier ISH studies, viral RNA was not identified within the overlying epithelia. These findings were confirmed by in situ hybridization studies and by immunohistochemistry using a monoclonal antibody specific for conformational, non-neutralizing epitopes on the FMDV capsid. FMDV capsid antigen 
(but not non-structural proteins) was detected in mandibular lymph node germinal centers of 22 animals examined between 29 to 38 days post-contact infection, irrespective of the carrier status at the time of euthanasia. These novel findings have provided evidence for a previously undescribed stage of FMD in cattle in which it is presumed that the virus persists in a non-replicative form. Since this condition was observed in carriers and noncarriers, it is proposed that it may occur as a normal sequel to infection or may exist interchangeably with conventional persistence.

The detection of FMDV antigens in germinal centers, potentially as an extracellular reservoir of immune complexed infectious virus, has important implications for understanding both the mechanism of viral persistence and the ability of FMDV infection to stimulate long-lasting antibody responses ${ }^{71}$. Another recent study showed the low ratios of positive to negative strand viral RNA transcript in the mandibular lymph node of lambs, indicating viral replication at this site ${ }^{117}$. Thus it remains to be elucidated whether FMDV in pharyngeal lymphoid tissues exists in a replicative, non-replicative, or semi-replicative state. Additionally, it is unclear if these virus depots contribute to viral repopulation of epithelia with replication and release of FMDV.

Various mechanisms have been proposed to explain establishment and maintenance of FMDV persistence (reviewed in ${ }^{6,121}$ ); however further elucidation is clearly required. The hypothesis that immune mechanisms play a role in supporting persistent infection in ruminants is supported by the early observations by that infected vaccinated cattle present a more stable host-virus relationship compared to unvaccinated cattle ${ }^{91}$ and observations by Ilott et al, that dexamethasone treatment suppresses the ability to detect FMDV and the secretory IgA response in probang samples ${ }^{64}$. One study 
compared cytokine and toll-like receptor RNA levels in dorsal soft palate lymphoid tissues between carrier and non-carrier cattle at 64dpi with only TNF-a having significantly elevated levels in persistently infected animals ${ }^{141}$. By contrast, all other genes investigated (IFN $\alpha, \beta, \gamma$, IL1a, 2, TLR-3, 4) had similar expression between carrier and non-carrier tissues. In a separate report it was described that IFN- $\gamma$ treatment of persistently FMDV-infected cells resulted in marked decrease of detection of viral antigens and RNA suggesting that this cytokine might play a role of clearance of infection in vivo ${ }^{142}$.

Few studies have demonstrated that FMDV mutation with associated antigenic variation can occur during persistent infection in vitro ${ }^{36,61,80}$ and in vivo ${ }^{51,67,120}$. It has been suggested that the failure of high levels of IgA in esophageal-pharyngeal fluid to clear FMDV in carrier cattle may be partly due to this antigenic variation. Recently, Horsington et al demonstrated that a substitution change in the B-C loop of VP2 may be associated with persistent FMDV infection in cattle ${ }^{62}$. Antigenic sites of FMDV VP2 are of high immunological importance and mutations within these sites have been shown to affect antigenicity $^{72}$. Though such works raise intriguing questions regarding mechanisms of persistence, much work remains to be performed.

\section{Pathogenesis in swine}

Compared to cattle, relatively little pathogenesis investigation has been conducted in other species; however, swine are the second most commonly studied subjects for FMD research. Recent and historic reviews have supported the notions that compared to cattle, pigs are more refractory to aerogenous infection, more susceptible to infection via 
the gastrointestinal route, and generate greater quantities of aerosolized virus ${ }^{3,125,126}$. Yet, the pathophysiological explanations for these differences remain poorly defined. The main explanation for this knowledge gap is that only two reports on porcine FMD pathogenesis have examined tissues from previremic FMDV-infected pigs ${ }^{98,131}$. Thus, viral dynamics in tissues and blood during viremia have been well characterized, but primary sites of replication and mechanisms of establishment of viremia remain elusive.

In 1972 Terpstra reported experimental infection of pigs with FMDV via 3 distinct routes and found that in previremic animals the tissue-specific distribution of progeny virus was highly dependent upon the route of exposure ${ }^{131}$. In that study aerosolinoculation resulted in high-titer FMDV replication in the lungs which was followed by systemic dissemination at $72 \mathrm{hpi}$; by contrast, oral inoculation led to primary infection of the palatine tonsil followed by spread to regional lymph nodes. Additionally, this work, contrary to conventional wisdom, documented a lower minimal infectious dose when FMDV was administered to pigs via aerosol as compared to oral instillation. A more recent study which quantitated viral loads in tissues in previremic pigs reported that at 24 hours post contact-infection, viral RNA was detected in coronary band epithelium, liver, tongue, soft palate, pharynx, spleen and mandibular lymph node prior to viremia which was not detected until 48 hpe ${ }^{98}$. These authors proposed that virus may have disseminated to these tissues via the lymphatic system; however, such extensive dissemination is inconsistent with solely lymphatic distribution. An alternative (and seemingly inescapable) explanation is that virus did enter the intravascular (blood) space prior to $48 \mathrm{hpe}$, but was below the threshold of detection. The great lingering question from this study, and regarding porcine FMD pathogenesis in general, is whether FMDV 
enters the vasculature via the respiratory, gastrointestinal, or transcutaneous (biting) route.

Subsequent to contact exposure, pigs have been demonstrated to become viremic at $24-48$ hpe and develop vesicles at $48-72 \mathrm{hpe}{ }^{4,5,98}$. Additionally, it has been suggested that the high quantity of FMDV shed by pigs is generated in the upper respiratory tract; this was based upon higher quantities of viral RNA recovered from soft palate, trachea, and nasal mucosa as compared to lung in one study ${ }^{4}$. In situ hybridization and RT-PCR based studies have demonstrated that abundant FMDV RNA may be detected in various epithelial sites in viremic pigs, regardless of the presence of vesicular lesions ${ }^{4,22}$. This suggests that the high-titer viremia may be maintained by FMDV replication in various peripheral tissues as well as within the respiratory tract. However, direct comparison of FMDV load in tissues vs. blood in viremic pigs indicates that only lesional lingual and pedal epithelia have substantially higher quantity of viral RNA than blood $^{4,98}$.

Microscopic localization of FMDV in pigs has been limited to characterization of the viremic state ${ }^{12,22,40}$. One study found that FMDV RNA could be localized in all strata of all epithelia examined from viremic pigs with greatest signal intensity (inconsistently) within the stratum basale ${ }^{22}$. More recent works have characterized FMDV RNA ${ }^{40}$ or antigen ${ }^{12}$ distribution in developing vesicles, and have similarly indicated that lesions are initiated with infection of basal cells overlying dermal papillae or deep dermo-edipermal junctions. Lack of detection of FMDV in dermal cells or vascular endothelial cells suggests that in the morphogenesis of vesiculation, virus transits from the intravascular space to (pre)vesicular epithelium via a cell-independent mechanism. Additionally, 
Murphy et al observed in pigs that vesicle development continued after viral loads in tissue started to decline and suggested that the immune response and viral replication play a role in vesicle formation ${ }^{98}$.

It is generally accepted that persistent FMDV infection does not occur in pigs; however, one publication provides support (RT-PCR evidence only) for FMDV carriers in this species ${ }^{93}$. Additionally, Zhang et al determined that viral RNA was detectable in the tonsils, mandibular and cervical lymph nodes from both needle and contact challenged pigs at 28 days post infection ${ }^{140}$. This study highlights the delayed clearance of viral RNA from pharyngeal and lymphoid tissue compared to the skin and mouth epithelia, which contained the highest levels of viral RNA during the acute stage of infection. However, since infectious virus was not isolated from animals in either of these studies the significance of the findings remains uncertain.

It is noteworthy that pigs are reported to clear FMDV within 3 to 4 weeks postinfection. In addition, FMDV infection in pigs induces neutralizing titers of antibody that are only detectable for a few months post-infection, with a reported half-life of 1 week ${ }^{9}$. This is an unusual host response to a highly immunogenic and cytopathic virus like FMDV $^{57,79}$, sanctioning further investigation in order to understand the post-viremic localization of virus in pigs. Additionally, improved understanding of the porcine ability to resist persistent infection may suggest strategies to prevent or cure persistence in cattle.

\section{FMD molecular pathogenesis}

Much investigation has been conducted in vitro to characterize FMDV molecular pathobiology and virus-host interactions, and this body of work has been thoroughly 
reviewed ${ }^{55,83}$. The in vitro works have provided numerous, invaluable insights which could not possibly have been achieved by studies in live animal. Some of these results have been confirmed to be relevant in vivo; however, as is often the case, translation of findings from in vitro works to improved understanding of natural infection of live animals is often less than straightforward. The in vitro works can be broadly divided into two main topic categories: interaction of viral structural proteins with host receptors and intracellular mechanisms involving viral non-structural proteins and host factors.

Interaction of viral structural proteins with host receptors.

FMDV contains a single-stranded positive-sense RNA genome of approximately 8500 nucleotides surrounded by an icosahedral capsid composed of 60 copies each of four structural proteins VP1, 2, 3, and 4 (also termed 1D, 1B, 1C, and 1A) (5, $^{5516}$. Covalently linked to the 5' end of the genome is the viral genome linked protein VPg $(3 \mathrm{~B})^{54,122}$. The three dimensional structure of a number of FMDV serotypes has been determined by X-ray crystallography ${ }^{1}$. The structural proteins VP1, VP2, and VP3 fold into eight-stranded $\beta$ barrels which fit together to form the majority of the virus particle (reviewed in ${ }^{55}$ ). The VP4 protein is buried on the inside of the capsid. The $\beta$ barrel strands of VP1, 2, and 3 are connected by loops which form the outer surface of the virus particle. Of particular interest regarding the tropism of FMDV is a prominent surface loop connecting the $\beta \mathrm{G}$ and $\beta \mathrm{H}$ strands (G-H loop) of VP1. This surface exposed G-H loop contains the highly conserved sequence arginine-glycine-aspartic acid (RGD) which directly interacts with host cell integrins (receptors) resulting in virus binding to cells followed by penetration and uncoating ${ }^{55}$. 
This RGD sequence has been shown to be a recognition sequence for the integrin family of cell surface receptors ${ }^{110,111}$. Integrins are type I heterodimeric membrane proteins consisting of an $\alpha$ and $\beta$ subunit and are involved in cell adhesion, signaling, cell migration, and thrombosis ${ }^{63}$. Of the 24 known integrins, only 8 bind the RGD tripeptide recognition sequence. Research utilizing infectious FMDV cDNA clones with mutated or deleted RGD sequences gave rise to virions that were non-infectious in tissue culture and could not cause disease in susceptible animals ${ }^{76,88,114}$. Although the RGD motif is highly conserved in the G-H loop of VP1 of FMDV field isolates, recently, a serotype A virus isolated from cattle was shown to possess a SGD sequence in place of $\mathrm{RGD}^{115}$. The "SGD virus" showed strong preference for utilization of the $\alpha_{V} \beta_{6}$ receptor and exhibited a selective advantage to initiate infection in cattle relative to the RGD-containing virus counterpart.

The integrins $\alpha v \beta 1, \alpha v \beta 3, \alpha v \beta 6$ and $\alpha v \beta 8$, which recognize and bind the RGD tripeptide appear to be the major receptors for FMDV in cell culture ${ }^{19,39,65,66,99,100}$. Additionally, recent studies in cattle and sheep have demonstrated that $\alpha v \beta 6$ is expressed constitutively on the surface of epithelial cells at sites which are normally targeted by FMDV, while $\alpha v \beta 3$ was detected at epithelial sites that are not FMDV-permissive and also found in close association with blood vessels in various tissues ${ }^{97,104}$. However, the only integrin detected on FMDV-positive cells in tongue vesicles ${ }^{104}$ and at primary infection sites (Arzt, unpublished data) was $\alpha_{V} \beta_{6}$. These results suggest that $\alpha \mathrm{v} \beta 6$ may be a requisite receptor for FMDV infection of individual cells in vivo and furthermore that this intergrin may be a major determinant of cellular tropism. 
Despite strong evidence for the importance of $\alpha \mathrm{V}$ integrins as FMDV receptors, there is also evidence which strongly suggests that in addition to receptor expression, other cell-specific or tissue-specific host factors are essential co-determinants of tropism $^{136}$. In particular, it has become clear that $\alpha v \beta 6$ is expressed in a variety of bovine and ovine tissues which do not support FMDV replication. Similarly, since the distribution of $\alpha v \beta 6$ integrin in the cornified epithelia is diffuse, it is not clear why FMD vesicles are focal and well delineated. It has been proposed that the distribution of initiation of lesions reflects the pattern of exit of virus from the blood at the predilection sites ${ }^{12,137}$. Yet considering the role of integrins in tropism, the real question is "once the virus initiates a lesion, why doesn't every $\alpha v \beta 6$-positive cell in the region become infected?". Consideration of answers to this question should include the potential roles of facilitating factors within infected cells as well as resistance-determining factors either in adjacent (uninfected) cells or within the extracellular space. While the potential tropismdefining role of $\alpha v \beta 3$ is even less defined than that of $\alpha v \beta 6$, the (peri)vascular distribution makes it attractive to suggest that this integrin may contribute to enabling the virus's ability to enter or exit blood (or lymphatic) vessels.

Recent studies revealed that the viral integrin-binding site is most highly adapted for binding to $\alpha v \beta 6^{24}$ and that virus binding to this integrin occurs in a two step process that involves an initial cation-dependent interaction with the RGD and a second stabilizing or "synergy" interaction that was resistant to EDTA dissociation" ${ }^{35}$. The stabilizing interaction was shown to be dependent on two conserved leucine residues in the $\mathrm{RGD}+1$ and +4 positions and the integrity of a helical structure immediately $\mathrm{C}$ terminal to the RGD sequence. In contrast, stable binding of FMDV to $\alpha_{V} \beta_{3}$ was not 
observed $^{35}$. In studies of viral entry utilizing both biochemical and confocal microscopic assays, it was shown that serotype $\mathrm{A}, \mathrm{O}$ and $\mathrm{C}$ viruses enter early endosomes via clathrinmediated endocytosis, followed by trafficking into recycling endosomes ${ }^{20,103}$. While it was initially believed that viral RNA was released from recycling endosomes, recent results, using dominant-negative rab protein mutants showed that the viral RNA was released primarily from the early endosomes ${ }^{68}$. Why the virus was observed moving into later endosomal compartments is not clear at this point. However, $\alpha v \beta 6$ was also shown to traffic through early and recycling endosomes suggesting that viral pentamers may remain attached to the integrin during the entry process ${ }^{20}$. Taken together, these results provide additional support for the role of $\alpha_{V} \beta_{6}$ integrin as the major viral receptor utilized in susceptible animals.

Recent evidence suggests that FMDV can also potentially utilize non-integrin receptors to cause disease in susceptible animals ${ }^{144}$. This was confirmed when it was shown that FMDV could infect cultured cells via an $\mathrm{F}_{\mathrm{c}}$ receptor-mediated antibody enhancement of infection ${ }^{17,82,84}$. Additionally, multiple passages of type $\mathrm{O}$ viruses in cell culture resulted in viruses capable of utilizing the heparan sulfate (HS) receptor and correlated with selection of viruses containing an extra positive charge on the virion ${ }^{47,118}$. Inoculation of high doses of HS-utilizing viruses into cattle resulted in clinical lesions but the viruses recovered from these animals could only utilize an integrin and not the HS, receptor. These results suggest that only viruses which utilize integrin receptors can cause disease in susceptible animals. In contrast to integrin-binding viruses, HS-binding viruses enter cells via a caveola-mediated mechanism with subsequent virus trafficking to acidic early endosomes. These results have provided novel insights into FMDV 
endocytosis as they demonstrate that FMDV can use multiple entry mechanisms that lead to acidic endosome ${ }^{102}$. Yet the relevance of these mechanisms to naturally occurring FMDV infection in vivo remains to be determined.

There is also evidence supporting the existence of an additional, currently unidentified FMDV receptor that is distinct from integrins, HS, and immunoglobulin/Fcmediated mechanisms ${ }^{14,144}$. Only a small number of viruses appear to infect cells in this way and only one such virus has been reported to establish infection in pigs ${ }^{144}$. The role of these additional receptors in pathogenesis remains speculative and further experiments are required to establish their importance in vivo.

A biochemical feature of FMDV that may contribute to its tropism is the acid lability of the virion. Below $\mathrm{pH} 6.5$ the virus particle dissociates into pentamers presumably as a result of electrostatic repulsion between a cluster of histidine residues at the interface between VP2 and VP3 that are protonated at low $\mathrm{pH}^{31,41}$. This instability at low $\mathrm{pH}$ may be involved in the targeting of productive virus replication to specific tissues and ensures that infectious virus cannot pass beyond the stomach of monogastric hosts or the abomasum of ruminants.

\section{Intracellular molecular pathogenesis}

Upon infection of cells, the FMDV RNA genome is released into the cytoplasm and translation begins via an internal ribosome entry site (IRES) located approximately 1300 bases from the 5 ' end. The RNA is translated as a single long open reading frame (ORF) into a polyprotein which is processed mainly by viral encoded proteinases to initially generate the leader (L) protein and 3 precursor proteins P1-2A, P2 and P3. Subsequent 
processing of the 3 precursor proteins yields the 4 viral structural proteins and 9 additional nonstructural (NS) proteins. As seen in other picornaviruses, some of the intermediate protein products synthesized by FMDV contribute to various viral functions ${ }^{77,94,95}$. However, many of the functions and interactions of FMDV NS proteins with host factors remain unclear. In addition to the ORF, the 5' and 3' untranslated regions of the genome also have significant roles in virus translation as well as replication ${ }^{83}$.

Virus replication occurs in the cytoplasm although some viral NS proteins including $\mathrm{L}$ and $3 \mathrm{D}$ also translocate to the nucleus ${ }^{32,50}$. The NS proteins perform a number of functions during the virus replication cycle that promote virus production and block or limit host responses. These include 1) processing of the viral polyprotein by $\mathrm{L}$ and $3 \mathrm{C}$ proteinases and $2 \mathrm{~A}$, an 18 amino acid peptide, 2) replication of the viral genome by the viral RNA-dependent RNA polymerase, 3D, a process which also requires NS protein $3 \mathrm{~B}$ to initiate RNA synthesis and $2 \mathrm{C}^{123}, 3$ ) cleavage of host translation initiation factor eIF4G by $\mathrm{L}$ resulting in marked down-regulation of host protein synthesis $\left.{ }^{33}, 4\right)$ inhibition of host transcription as a result of nuclear cleavage of transcription factor nuclear factor kappa $\mathrm{B}(\mathrm{NF}-\mathrm{\kappa B})^{32,43,53}$, and 5) inhibition of trafficking of proteins through the endoplasmic reticulum/Golgi secretory pathway by $2 \mathrm{~B}$ and $2 \mathrm{C}$ and/or $2 \mathrm{BC}^{94,95}$. The NS proteins $2 \mathrm{~B}, 2 \mathrm{C}$ and $3 \mathrm{~A}$ also play a role in rearrangement of host cell membranes which become the sites for viral RNA replication and capsid assembly $y^{73,105,108}$. Although some advance has been made in recent years, viral determinants of virulence for FMDV in natural hosts remain undefined. Among the most thoroughly investigated virulence factors is the $\mathrm{L}$ proteinase. Virus constructs lacking the $\mathrm{L}$ sequence 
(leaderless FMDV) have been shown to be avirulent in cattle ${ }^{23}$ and pigs ${ }^{30}$. Cattle exposed to leaderless FMDV by aerosol did not show viremia or clinical signs of FMD, had minimal quantities of viral RNA detected in lungs by ISH and no viral RNA detected in any other tissue. More recently, FMDV mutants with in-frame insertions in L were shown to be markedly attenuated in cattle ${ }^{109}$. These viruses had a more extensive dissemination within the respiratory tract (compared to leaderless FMDV) after aerosol inoculation in cattle; but, similar to the leaderless virus, there was no viremia and no clinical disease. However the multifactorial nature of FMDV virulence was suggested by the finding that some leaderless FMDV constructs retained partial virulence ${ }^{11}$.

A number of studies suggest that NS protein $3 \mathrm{~A}$ may also play a role in virus tropism and host range ${ }^{18,52,101}$. The FMD virus which caused the 1997 outbreak in Taiwan was relatively unique in that it only affected swine and was not virulent to cattle. Molecular characterization of the virus revealed a deletion in the $3 \mathrm{~A}$ coding region and reverse genetics demonstrated that the mutated $3 \mathrm{~A}$ was partially responsible for the porcinophilic phenotype of the virus ${ }^{18}$. Interestingly it had been previously shown that egg-adapted live vaccine candidates of FMDV containing deletions in 3A of similar size and location to the Taiwan virus, were attenuated for cattle but not for swine ${ }^{52}$. Furthermore, it was subsequently shown that a point mutation in $3 \mathrm{~A}$, at a distinct site from the 3A deletion, resulted in adaptation of an FMDV isolate to cause disease in guinea pigs ${ }^{101}$. Collectively, these data indicate that $3 \mathrm{~A}$ contains multiple viral virulence determinants.

Tissue-culture based works have indicated that FMDV also utilizes a number of host proteins to promote various aspects of its replication ${ }^{75,81,112}$. Host cellular proteins 
have been found to interact with both viral RNA and viral proteins and enhance viral translation and replication. Recently Lawrence and Rieder demonstrated that RNA helicase A, a methylated nuclear protein, is redistributed in a non-methylated form to the cytoplasm during FMDV infection and interacts with NS proteins $2 \mathrm{C}$ and $3 \mathrm{~A}$ as well as with the 5' end of the FMDV genome to promote virus replication ${ }^{75}$. This interesting observation provides a clear example of FMDV targeting a specific host cell protein and altering both its subcellular localization and biochemical composition for its own benefit. Additionally, canonical and non-canonical host translation factors have been shown to be involved in FMDV IRES-mediated translation (reviewed in ${ }^{106}$ ). At present, FMDV's exploitation of host mechanisms for viral replication and translation have not been fully investigated in vivo.

\section{Discussion}

Cure, prevention, and eradication are the ultimate goals of the study of any disease. Even basic research feeds into a cumulative effort directed towards disease control and eradication. Considering these goals in the context of FMD, the modern investigator may take solace from the accrual of some major accomplishments over the last 100 years; however, much work clearly remains. Various high-priority knowledge gaps have been mentioned throughout the preceding sections and are reiterated in Table 1.1; the bridging of these gaps will, ultimately, contribute to FMD control and eradication.

It may be asserted that the biggest problem overshadowing all of FMD research is that (based upon recent history) incursion of FMDV into FMD-free nations still results in 
massive depopulations of uninfected but "high risk" animals. This practice is based more in policy than science, and is closely related to the inability of currently available vaccines to prevent primary infection and persistence. The rationales behind use of depopulation as the means of control are (1) eliminating any potential acute shedders of large quantities of virus and (2) eliminating potential infectivity amongst carrier (chronic) animals. Thus, development of means to prevent or cure primary infection and the carrier state in ruminants are of utmost importance. However, these lofty goals do not exist in isolation, but rather in a web of interdependence of sources and resolutions of individual contributory knowledge gaps. As such, it seems advantageous for investigators to consider pathogenesis research as the investigation of a continuum rather than a series of isolated events.

Central within the complex web of FMD virus-host interactions lays the ruminant nasopharynx including the dorsal soft palate, nasopharyngeal walls/ceiling, and associated MALT. The last fifty years of FMD research have repeatedly implicated these tissues for their importance in primary infection and in persistence. Given that nasopharyngeal tissues have well-documented roles in acute and chronic stages of infection, it seems likely (though has not been demonstrated) that a gradual transition occurs between these stages of disease. Interestingly, infection of these tissues is also morphologically quite distinct from the more dramatic lesions at secondary replication sites. Unlike the classic pathological changes seen in vesicles, FMDV infection in the nasopharynx is predominantly non-cytolytic, induces minimal inflammation, and does not induce acantholytic degeneration. Yet, by a still unknown mechanism, these epithelia are uniquely susceptible to primary and persistent FMDV infection. It is a natural 
corollary to question what it is about these tissues that determines their differential FMDV-host interactions. Foremost amongst numerous potential explanations are the exceedingly broad categories of unique cellular characteristics and immunological (innate and/or adaptive) factors. A more thorough understanding of these processes ultimately may lead to effective modulation of such cellular and immune responses for the benefit of preventing or resolving infection.

Recent advances in FMD pathogenesis have highlighted the benefits of integrative approaches to answering such questions rather than viewing these subjects distinctly as acute disease, persistent disease, immunology, and vaccinology. Similarly, successful research groups have demonstrated the advantages of drawing upon the complementary contributions of teams of scientists with distinct skill sets including clinical veterinary medicine, immunology, molecular biology, pathology, bioinformatics, and vaccinology. It seems likely that the next generation of "rationally designed" FMD vaccines and biotherapeutics will have to more directly integrate recent and ongoing advances in pathogenesis and immunology in order to affect implementation of major improvements in FMD control. 


\section{Chapter 1 Tables}

Table 1.1. Critical knowledge gaps in current understanding of the pathogenesis of foot-and-mouth disease.

1. What are the sites of primary infection (tissue and cellular understanding; multiple serotypes \& host species)?

2. What are the sites and mechanisms of establishment of viremia?

3. What are the sites of high-titer replication responsible for maintenance of viremia?

4. What are the host determinants of tropism beyond integrins?

5. How can understanding of tropism and primary infection be manipulated to generate "rational design" vaccines?

6. What innate and adaptive immune factors contribute to tropism?

7. Which innate and adaptive immune factors are subverted by FMDV and by what mechanisms?

8. What are the roles of dendritic cells during the various stages of infection?

9. What are the viral and host determinants of establishing persistence at the species and individual animal levels?

10. Why are ruminants, but not swine susceptible to persistent FMDV infection?

11. To what extent are persistently infected ruminants a threat to naïve animals? 


\section{Chapter 1 References}

1. Acharya R, Fry E, Stuart D, Fox G, Rowlands D, Brown F: The three-dimensional structure of foot-and-mouth disease virus at 2.9 A resolution. Nature 337:709-716, 1989 2. Aggarwal N, Zhang Z, Cox S, Statham R, Alexandersen S, Kitching RP, Barnett PV: Experimental studies with foot-and-mouth disease virus, strain $\mathrm{O}$, responsible for the 2001 epidemic in the United Kingdom. Vaccine 20:2508-2515, 2002

3. Alexandersen S, Mowat N: Foot-and-mouth disease: host range and pathogenesis. Curr Top Microbiol Immunol 288:9-42, 2005

4. Alexandersen S, Oleksiewicz MB, Donaldson AI: The early pathogenesis of foot-andmouth disease in pigs infected by contact: a quantitative time-course study using TaqMan RT-PCR. J Gen Virol 82:747-755, 2001

5. Alexandersen S, Quan M, Murphy C, Knight J, Zhang Z: Studies of quantitative parameters of virus excretion and transmission in pigs and cattle experimentally infected with foot-and-mouth disease virus. J Comp Pathol 129:268-282, 2003

6. Alexandersen S, Zhang Z, Donaldson AI: Aspects of the persistence of foot-andmouth disease virus in animals--the carrier problem. Microbes Infect 4:1099-1110, 2002 7. Alexandersen S, Zhang Z, Donaldson AI: Aspects of the persistence of foot-andmouth disease virus in animals-the carrier problem. Microbes Infect 4:1099-1110, 2002 8. Alexandersen S, Zhang Z, Donaldson AI, Garland AJ: The pathogenesis and diagnosis of foot-and-mouth disease. J Comp Pathol 129:1-36, 2003

9. Alexandersen S, Zhang Z, Donaldson AI, Garland AJM: The pathogenesis and diagnosis of foot-and-mouth disease. J Comp Pathol 129:1-36, 2003

10. Alexandersen S, Zhang Z, Reid SM, Hutchings GH, Donaldson AI: Quantities of infectious virus and viral RNA recovered from sheep and cattle experimentally infected with foot-and-mouth disease virus O UK 2001. J Gen Virol 83:1915-1923, 2002

11. Almeida MR, Rieder E, Chinsangaram J, Ward G, Beard C, Grubman MJ, Mason

PW: Construction and evaluation of an attenuated vaccine for foot-and-mouth disease:

difficulty adapting the leader proteinase-deleted strategy to the serotype O1 virus. Virus Res 55:49-60, 1998

12. Arzt J, Gregg DA, Clavijo A, Rodriguez LL: Optimization of immunohistochemical and fluorescent antibody techniques for localization of Foot-and-mouth disease virus in animal tissues. J Vet Diagn Invest 21:779-792, 2009

13. Arzt J, Pacheco JM, Rodriguez LL: The early pathogenesis of foot-and-mouth disease in cattle after aerosol inoculation: identification of the nasopharynx as the primary site of infection. Vet Path, in press

14. Baranowski E, Sevilla N, Verdaguer N, Ruiz-Jarabo CM, Beck E, Domingo E: Multiple virulence determinants of foot-and-mouth disease virus in cell culture. J Virol 72:6362-6372, 1998

15. Bates TW, Carpenter TE, Thurmond MC: Benefit-cost analysis of vaccination and preemptive slaughter as a means of eradicating foot-and-mouth disease. Am J Vet Res 64:805-812, 2003

16. Bautista EM, Ferman GS, Golde WT: Induction of lymphopenia and inhibition of T cell function during acute infection of swine with foot and mouth disease virus (FMDV). Vet Immunol Immunopathol 92:61-73, 2003 
17. Baxt B, Mason PW: Foot-and-mouth disease virus undergoes restricted replication in macrophage cell cultures following Fc receptor-mediated adsorption. Virology 207:503509, 1995

18. Beard CW, Mason PW: Genetic determinants of altered virulence of Taiwanese footand-mouth disease virus. J Virol 74:987-991, 2000

19. Berinstein A, Roivainen M, Hovi T, Mason PW, Baxt B: Antibodies to the vitronectin receptor (integrin alpha $\mathrm{V}$ beta 3 ) inhibit binding and infection of foot-andmouth disease virus to cultured cells. J Virol 69:2664-2666, 1995

20. Berryman S, Clark S, Monaghan P, Jackson T: Early events in integrin alphavbeta6mediated cell entry of foot-and-mouth disease virus. J Virol 79:8519-8534, 2005

21. Brown CC, Meyer RF, Olander HJ, House C, Mebus CA: A pathogenesis study of foot-and-mouth disease in cattle, using in situ hybridization. Can J Vet Res 56:189-193, 1992

22. Brown CC, Olander HJ, Meyer RF: Pathogenesis of foot-and-mouth disease in swine, studied by in-situ hybridization. J Comp Pathol 113:51-58, 1995

23. Brown CC, Piccone ME, Mason PW, McKenna TS, Grubman MJ: Pathogenesis of wild-type and leaderless foot-and-mouth disease virus in cattle. J Virol 70:5638-5641, 1996

24. Burman A, Clark S, Abrescia NG, Fry EE, Stuart DI, Jackson T: Specificity of the VP1 GH loop of Foot-and-Mouth Disease virus for alphav integrins. J Virol 80:97989810, 2006

25. Burrows R: Studies on the carrier state of cattle exposed to foot-and-mouth disease virus. Journal of Hygiene 64:81-90, 1966

26. Burrows R: Excretion of foot-and-mouth disease virus prior to the development of lesions. Vet Rec 82:387-388, 1968

27. Burrows R: The persistence of foot-and mouth disease virus in sheep. Journal of Hygiene 66:633-640, 1968

28. Burrows R, Mann JA, Garland AJ, Greig A, Goodridge D: The pathogenesis of natural and simulated natural foot-and-mouth disease infection in cattle. J Comp Pathol 91:599-609, 1981

29. Burrows R, Mann JA, Greig A, Chapman WG, Goodridge D: The growth and persistence of foot-and-mouth disease virus in the bovine mammary gland. J Hyg (Lond) 69:307-321, 1971

30. Chinsangaram J, Mason PW, Grubman MJ: Protection of swine by live and inactivated vaccines prepared from a leader proteinase-deficient serotype A12 foot-andmouth disease virus. Vaccine 16:1516-1522, 1998

31. Curry S, Abrams CC, Fry E, Crowther JC, Belsham GJ, Stuart DI, King AM: Viral RNA modulates the acid sensitivity of foot-and-mouth disease virus capsids. J Virol 69:430-438, 1995

32. de Los Santos T, Diaz-San Segundo F, Grubman MJ: Degradation of nuclear factor kappa B during foot-and-mouth disease virus infection. J Virol 81:12803-12815, 2007 33. Devaney MA, Vakharia VN, Lloyd RE, Ehrenfeld E, Grubman MJ: Leader protein of foot-and-mouth disease virus is required for cleavage of the p220 component of the cap-binding protein complex. J Virol 62:4407-4409, 1988 
34. Diaz-San Segundo F, Salguero FJ, de Avila A, de Marco MM, Sanchez-Martin MA, Sevilla N: Selective lymphocyte depletion during the early stage of the immune response to foot-and-mouth disease virus infection in swine. J Virol 80:2369-2379, 2006 35. Dicara D, Burman A, Clark S, Berryman S, Howard MJ, Hart IR, Marshall JF, Jackson T: Foot-and-mouth disease virus forms a highly stable, EDTA-resistant complex with its principal receptor, integrin alphavbeta6: implications for infectiousness. J Virol 82:1537-1546, 2008

36. Diez J, Davila M, Escarmis C, Mateu MG, Dominguez J, Perez JJ, Giralt E, Melero JA, Domingo E: Unique amino acid substitutions in the capsid proteins of foot-andmouth disease virus from a persistent infection in cell culture. J Virol 64:5519-5528, 1990

37. Donaldson AI, Gibson CF, Oliver R, Hamblin C, Kitching RP: Infection of cattle by airborne foot-and-mouth disease virus: minimal doses with O1 and SAT 2 strains. Res Vet Sci 43:339-346, 1987

38. Donn A, Martin LA, Donaldson AI: Improved detection of persistent foot-and-mouth disease infection in cattle by the polymerase chain reaction. J Virol Methods 49:179-186, 1994

39. Duque H, Baxt B: Foot-and-mouth disease virus receptors: comparison of bovine alpha(V) integrin utilization by type A and O viruses. J Virol 77:2500-2511, 2003 40. Durand S, Murphy C, Zhang Z, Alexandersen S: Epithelial distribution and replication of foot-and-mouth disease virus RNA in infected pigs. J Comp Pathol 139:8696,2008

41. Ellard FM, Drew J, Blakemore WE, Stuart DI, King AM: Evidence for the role of His-142 of protein $1 \mathrm{C}$ in the acid-induced disassembly of foot-and-mouth disease virus capsids. J Gen Virol 80 ( Pt 8):1911-1918, 1999

42. Eskildsen M: Experimental pulmonary infection of cattle with foot-and-mouth disease virus. Nord. Vet. Med 21:86-91, 1969

43. Falk MM, Grigera PR, Bergmann IE, Zibert A, Multhaup G, Beck E: Foot-andmouth disease virus protease $3 \mathrm{C}$ induces specific proteolytic cleavage of host cell histone H3. J Virol 64:748-756, 1990

44. Fogedby E: Review of epizootiology and control of foot-and-mouth disease in Europe from 1937 to 1961. European Commission for the control of foot-and-mouth disease, Food and Agricultural Organization of the United Nations, Rome, Italy, 1962 45. Fracastorius H. De alijs differentijs contagionis. In De Sympathia et Antipathia Rerum Liber Unus. De Contagione et Contagiosis Morbis et Curatione (libri iii) In: Heirs of L.A. Junta Book 1. 36-38. 1546

46. Fredorf E: Die verbreitung der maul- und klauenseuche. Berl. Munch. tierarztl. Wschr. 3, 1949

47. Fry EE, Lea SM, Jackson T, Newman JW, Ellard FM, Blakemore WE, AbuGhazaleh R, Samuel A, King AM, Stuart DI: The structure and function of a foot-andmouth disease virus-oligosaccharide receptor complex. Embo J 18:543-554, 1999 48. Gailiunas P: Microscopic skin lesions in cattle with foot-and-mouth disease. Arch Gesamte Virusforsch 25:188-200, 1968

49. Gailiunas P, Cottral GE: Presence and persistence of foot-and-mouth disease virus in bovine skin. J Bacteriol 91:2333-2338, 1966 Jun 
50. Garcia-Briones M, Rosas MF, Gonzalez-Magaldi M, Martin-Acebes MA, Sobrino F, Armas-Portela R: Differential distribution of non-structural proteins of foot-and-mouth disease virus in BHK-21 cells. Virology 349:409-421, 2006

51. Gebauer F, de la Torre JC, Gomes I, Mateu MG, Barahona H, Tiraboschi B, Bergmann I, de Mello PA, Domingo E: Rapid selection of genetic and antigenic variants of foot-and-mouth disease virus during persistence in cattle. J Virol 62:2041-2049, 1988 52. Giraudo AT, Beck E, Strebel K, de Mello PA, La Torre JL, Scodeller EA, Bergmann IE: Identification of a nucleotide deletion in parts of polypeptide $3 \mathrm{~A}$ in two independent attenuated aphthovirus strains. Virology 177:780-783, 1990

53. Grigera PR, Tisminetzky SG: Histone H3 modification in BHK cells infected with foot-and-mouth disease virus. Virology 136:10-19, 1984

54. Grubman MJ: The 5' end of foot-and-mouth disease virion RNA contains a protein covalently linked to the nucleotide pUp. Arch Virol 63:311-315, 1980

55. Grubman MJ, Baxt B: Foot-and-mouth disease. Clin Microbiol Rev 17:465-493, 2004

56. Gulbahar MY, Davis WC, Guvenc T, Yarim M, Parlak U, Kabak YB: Myocarditis associated with foot-and-mouth disease virus type $\mathrm{O}$ in lambs. Vet Pathol 44:589-599, 2007

57. Hangartner L, Zinkernagel RM, Hengartner H: Antiviral antibody responses: the two extremes of a wide spectrum. Nature Reviews Immunology 6:231-243, 2006

58. Harwood LJ, Gerber H, Sobrino F, Summerfield A, McCullough KC: Dendritic cell internalization of foot-and-mouth disease virus: influence of heparan sulfate binding on virus uptake and induction of the immune response. J Virol 82:6379-6394, 2008 59. Henderson WM: A comparison of different routes of inoculation of cattle for detection of the virus of foot-and-mouth disease. J Hyg (Lond) 50:182-194, 1952 60. Hofner MC: A study of foot-and-mouth disease virus pathogenesis in cattle: A thesis presented for the degree of Doctor of Philosophy. University of London. 1995

61. Holguin A, Hernandez J, Martinez MA, Mateu MG, Domingo E: Differential restrictions on antigenic variation among antigenic sites of foot-and-mouth disease virus in the absence of antibody selection. J Gen Virol 78 ( Pt 3):601-609, 1997

62. Horsington J, Zhang Z: Analysis of foot-and-mouth disease virus replication using strand-specific quantitative RT-PCR. J Virol Methods 144:149-155, 2007

63. Hynes RO: Integrins: bidirectional, allosteric signaling machines. Cell 110:673-687, 2002

64. Ilott MC, Salt JS, Gaskell RM, Kitching RP: Dexamethasone inhibits virus production and the secretory IgA response in oesophageal-pharyngeal fluid in cattle persistently infected with foot-and-mouth disease virus. Epidemiology and Infection 118:181-187, 1997

65. Jackson T, Clark S, Berryman S, Burman A, Cambier S, Mu D, Nishimura S, King AM: Integrin alphavbeta8 functions as a receptor for foot-and-mouth disease virus: role of the beta-chain cytodomain in integrin-mediated infection. J Virol 78:4533-4540, 2004 66. Jackson T, Mould AP, Sheppard D, King AM: Integrin alphavbeta1 is a receptor for foot-and-mouth disease virus. J Virol 76:935-941, 2002

67. Jangra RK, Tosh C, Sanyal A, Hemadri D, Bandyopadhyay SK: Antigenic and genetic analyses of foot-and-mouth disease virus type A isolates for selection of 
candidate vaccine strain reveals emergence of a variant virus that is responsible for most recent outbreaks in India. Virus Res 112:52-59, 2005

68. Johns HL, Berryman S, Monaghan P, Belsham GJ, Jackson T: A dominant-negative mutant of rab5 inhibits infection of cells by foot-and-mouth disease virus: implications for virus entry. J Virol 83:6247-6256, 2009

69. Joshi G, Sharma R, Kakker NK: Phenotypic and functional characterization of Tcells and in vitro replication of FMDV serotypes in bovine lymphocytes. Vaccine 27:6656-6661, 2009

70. Juleff N, Windsor M, Lefevre EA, Gubbins S, Hamblin P, Reid E, McLaughlin K, Beverley PC, Morrison IW, Charleston B: Foot-and-mouth disease virus can induce a specific and rapid CD4+ T-cell-independent neutralizing and isotype class-switched antibody response in naive cattle. J Virol 83:3626-3636, 2009

71. Juleff N, Windsor M, Reid E, Seago J, Zhang Z, Monaghan P, Morrison IW, Charleston B: Foot-and-mouth disease virus persists in the light zone of germinal centres. PLoS One 3:e3434, 2008

72. Kitson JD, McCahon D, Belsham GJ: Sequence analysis of monoclonal antibody resistant mutants of type $\mathrm{O}$ foot and mouth disease virus: evidence for the involvement of the three surface exposed capsid proteins in four antigenic sites. Virology 179:26-34, 1990

73. Knox C, Moffat K, Ali S, Ryan M, Wileman T: Foot-and-mouth disease virus replication sites form next to the nucleus and close to the Golgi apparatus, but exclude marker proteins associated with host membrane compartments. J Gen Virol 86:687-696, 2005

74. Korn G: Experimentelle untersuchungen zum virusnachweis im inkubationsstadium der maul-und klauenseuche und zu ihrer pathogenese

Archiv fur experimentelle veterinarmedizin

11:637-649, 1957

75. Lawrence P, Rieder E: Identification of RNA helicase A as a new host factor in the replication cycle of foot-and-mouth disease virus. J Virol 83:11356-11366, 2009

76. Leippert M, Beck E, Weiland F, Pfaff E: Point mutations within the betaG-betaH loop of foot-and-mouth disease virus $\mathrm{O} 1 \mathrm{~K}$ affect virus attachment to target cells. J Virol 71:1046-1051, 1997

77. Leong LE, Cornell CT, Semler BL. Processing determinants and functions of cleavage products of picornavirus polyproteins In: Molecular Biology of Picornaviruses, Semler BL and Wimmer E, eds. 187-199. 2002

78. Loeffler F, Frosch P: Summarischer Bericht ueber der Ergebnisse der Untersuchungen zur Erforschung der Maul- und Klauenseuche. ZentBl. Bakt. Parasitkde 22:257-259, 1897

79. Manz RA, Hauser AE, Hiepe F, Radbruch A: Maintenance of serum antibody levels. Annual Review of Immunology 23:367-386, 2005

80. Martin Hernandez AM, Carrillo EC, Sevilla N, Domingo E: Rapid cell variation can determine the establishment of a persistent viral infection. Proc Natl Acad Sci U S A 91:3705-3709, 1994

81. Martinez-Salas E, Ramos R, Lafuente E, Lopez de Quinto S: Functional interactions in internal translation initiation directed by viral and cellular IRES elements. J Gen Virol 82:973-984, 2001 
82. Mason PW, Baxt B, Brown F, Harber J, Murdin A, Wimmer E: Antibody-complexed foot-and-mouth disease virus, but not poliovirus, can infect normally insusceptible cells via the Fc receptor. Virology 192:568-577, 1993

83. Mason PW, Grubman MJ, Baxt B: Molecular basis of pathogenesis of FMDV. Virus Res 91:9-32, 2003

84. Mason PW, Rieder E, Baxt B: RGD sequence of foot-and-mouth disease virus is essential for infecting cells via the natural receptor but can be bypassed by an antibodydependent enhancement pathway. Proc Natl Acad Sci U S A 91:1932-1936, 1994 85. McCullough KC, Crowther JR, Butcher RN, Carpenter WC, Brocchi E, Capucci L, De Simone F: Immune protection against foot-and-mouth disease virus studied using virus-neutralizing and non-neutralizing concentrations of monoclonal antibodies. Immunology 58:421-428, 1986

86. McCullough KC, De Simone F, Brocchi E, Capucci L, Crowther JR, Kihm U:

Protective immune response against foot-and-mouth disease. J Virol 66:1835-1840, 1992 87. McCullough KC, Parkinson D, Crowther JR: Opsonization-enhanced phagocytosis of foot-and-mouth disease virus. Immunology 65:187-191, 1988

88. McKenna TS, Lubroth J, Rieder E, Baxt B, Mason PW: Receptor binding sitedeleted foot-and-mouth disease (FMD) virus protects cattle from FMD. J Virol 69:57875790, 1995

89. McVicar JW, Eisner RJ: Aerosol exposure of cattle to foot-and-mouth disease virus. J Hyg (Lond) 91:319-328, 1983

90. McVicar JW, J.H. G, Sutmoller P: Growth of foot-and-mouth disease virus in the bovine pharynx. Proceedings of the 74th Annual Meeting of the United States Animal Health Association 230-234, 1970

91. McVicar JW, Sutmoller P: The epizootiological importance of foot-and-mouth disease carriers. II. The carrier status of cattle exposed to foot-and-mouth disease following vaccination with an oil adjuvant inactivated virus vaccine. Arch Gesamte Virusforsch 26:217-224, 1969

92. McVicar JW, Sutmoller P: Growth of foot-and-mouth disease virus in the upper respiratory tract of non-immunized, vaccinated, and recovered cattle after intranasal inoculation. J Hyg (Lond) 76:467-481, 1976

93. Mezencio JM, Babcock GD, Kramer E, Brown F: Evidence for the persistence of foot-and-mouth disease virus in pigs. Vet J 157:213-217, 1999

94. Moffat K, Howell G, Knox C, Belsham GJ, Monaghan P, Ryan MD, Wileman T:

Effects of foot-and-mouth disease virus nonstructural proteins on the structure and function of the early secretory pathway: $2 \mathrm{BC}$ but not $3 \mathrm{~A}$ blocks endoplasmic reticulumto-Golgi transport. J Virol 79:4382-4395, 2005

95. Moffat K, Knox C, Howell G, Clark SJ, Yang H, Belsham GJ, Ryan M, Wileman T: Inhibition of the secretory pathway by foot-and-mouth disease virus $2 \mathrm{BC}$ protein is reproduced by coexpression of $2 \mathrm{~B}$ with $2 \mathrm{C}$, and the site of inhibition is determined by the subcellular location of 2C. J Virol 81:1129-1139, 2007

96. Mohlmann H: Der derzeitige stand der forschung uber das virus der maul- und klauenseuche. Arch. exper. veterinarmed. 8:316-393, 1954

97. Monaghan P, Gold S, Simpson J, Zhang Z, Weinreb PH, Violette SM, Alexandersen $\mathrm{S}$, Jackson T: The alpha(v)beta6 integrin receptor for Foot-and-mouth disease virus is 
expressed constitutively on the epithelial cells targeted in cattle. J Gen Virol 86:27692780,2005

98. Murphy C, Bashiruddin JB, Quan M, Zhang Z, Alexandersen S: Foot-and-mouth disease viral loads in pigs in the early, acute stage of disease. Vet Rec 166:10-14, 2010 99. Neff S, Baxt B: The ability of integrin alpha(v)beta(3) To function as a receptor for foot-and-mouth disease virus is not dependent on the presence of complete subunit cytoplasmic domains. J Virol 75:527-532, 2001

100. Neff S, Mason PW, Baxt B: High-efficiency utilization of the bovine integrin alpha(v)beta(3) as a receptor for foot-and-mouth disease virus is dependent on the bovine beta(3) subunit. J Virol 74:7298-7306, 2000

101. Nunez JI, Baranowski E, Molina N, Ruiz-Jarabo CM, Sanchez C, Domingo E, Sobrino F: A single amino acid substitution in nonstructural protein $3 \mathrm{~A}$ can mediate adaptation of foot-and-mouth disease virus to the guinea pig. J Virol 75:3977-3983, 2001 102. O'Donnell V, Larocco M, Baxt B: Heparan sulfate-binding foot-and-mouth disease virus enters cells via caveola-mediated endocytosis. J Virol 82:9075-9085, 2008 103. O'Donnell V, LaRocco M, Duque H, Baxt B: Analysis of foot-and-mouth disease virus internalization events in cultured cells. J Virol 79:8506-8518, 2005

104. O'Donnell V, Pacheco JM, Gregg D, Baxt B: Analysis of foot-and-mouth disease virus integrin receptor expression in tissues from naive and infected cattle. J Comp Pathol 141:98-112, 2009

105. O'Donnell VK, Pacheco JM, Henry TM, Mason PW: Subcellular distribution of the foot-and-mouth disease virus $3 \mathrm{~A}$ protein in cells infected with viruses encoding wild-type and bovine-attenuated forms of 3A. Virology 287:151-162, 2001

106. Pacheco A, Lopez de Quinto S, Ramajo J, Fernandez N, Martinez-Salas E: A novel role for Gemin5 in mRNA translation. Nucleic Acids Res 37:582-590, 2009

107. Pacheco JM, Arzt J, Rodriguez LL: Early events in the pathogenesis of foot-andmouth disease in cattle after controlled aerosol exposure. Vet J 183:46-53, 2010 108. Pena L, Moraes MP, Koster M, Burrage T, Pacheco JM, Segundo FD, Grubman MJ: Delivery of a foot-and-mouth disease virus empty capsid subunit antigen with nonstructural protein 2B improves protection of swine. Vaccine 26:5689-5699, 2008 109. Piccone ME, Pacheco JM, Pauszek SJ, Kramer E, Rieder E, Borca MV, Rodriguez LL: The region between the two polyprotein initiation codons of foot-and-mouth disease virus is critical for virulence in cattle. Virology 396:152-159, 2010 110. Pierschbacher MD, Ruoslahti E: Cell attachment activity of fibronectin can be duplicated by small synthetic fragments of the molecule. Nature 309:30-33, 1984 111. Pierschbacher MD, Ruoslahti E: Variants of the cell recognition site of fibronectin that retain attachment-promoting activity. Proc Natl Acad Sci U S A 81:5985-5988, 1984 112. Pilipenko EV, Pestova TV, Kolupaeva VG, Khitrina EV, Poperechnaya AN, Agol VI, Hellen CU: A cell cycle-dependent protein serves as a template-specific translation initiation factor. Genes Dev 14:2028-2045, 2000

113. Prato Murphy ML, Forsyth MA, Belsham GJ, Salt JS: Localization of foot-andmouth disease virus RNA by in situ hybridization within bovine tissues. Virus Res 62:6776, 1999

114. Rieder E, Berinstein A, Baxt B, Kang A, Mason PW: Propagation of an attenuated virus by design: engineering a novel receptor for a noninfectious foot-and-mouth disease virus. Proc Natl Acad Sci U S A 93:10428-10433, 1996 
115. Rieder E, Henry T, Duque H, Baxt B: Analysis of a foot-and-mouth disease virus type A24 isolate containing an SGD receptor recognition site in vitro and its pathogenesis in cattle. J Virol 79:12989-12998, 2005

116. Rueckert RR, Wimmer E: Systematic nomenclature of picornavirus proteins. J. Virol. 50:957-959, 1984

117. Ryan E, Horsington J, Durand S, Brooks H, Alexandersen S, Brownlie J, Zhang Z: Foot-and-mouth disease virus infection in young lambs: pathogenesis and tissue tropism. Vet Microbiol 127:258-274, 2008

118. Sa-Carvalho D, Rieder E, Baxt B, Rodarte R, Tanuri A, Mason PW: Tissue culture adaptation of foot-and-mouth disease virus selects viruses that bind to heparin and are attenuated in cattle. J Virol 71:5115-5123, 1997

119. Salt J. Persistence of foot-and-mouth disease In: Foot and mouth disease; current perspectives, Sobrino F and Domingo E, eds. 103-144. Horizon Bioscience, Norfolk, 2004

120. Salt JS: The carrier state in foot and mouth disease--an immunological review. $\mathrm{Br}$ Vet J 149:207-223, 1993

121. Salt JS. Persistence of foot-and-mouth disease In: Foot and mouth disease: current perspectives. 103-143. Horizon Bioscience, 2004

122. Sangar DV, Rowlands DJ, Harris TJ, Brown F: Protein covalently linked to footand-mouth disease virus RNA. Nature 268:648-650, 1977

123. Saunders K, King AM: Guanidine-resistant mutants of aphthovirus induce the synthesis of an altered nonstructural polypeptide, P34. J Virol 42:389-394, 1982

124. Seibold HR: A Revised Concept of the Lingual Lesions in Cattle with Foot-andMouth Disease. Am J Vet Res 24:1123-1130, 1963

125. Sellers R, Gloster J: Foot-and-mouth disease: a review of intranasal infection of cattle, sheep and pigs. Vet J 177:159-168, 2008

126. Sellers RF: Quantitative aspects of the spread of foot and mouth disease. The Veterinary Bulletin 41:431-439, 1971

127. Sellers RF, Burrows R, Mann JA, Dawe P: Recovery of virus from bulls affected with foot-and-mouth disease. Vet Rec 83:303, 1968

128. Summerfield A, Guzylack-Piriou L, Harwood L, McCullough KC: Innate immune responses against foot-and-mouth disease virus: current understanding and future directions. Vet Immunol Immunopathol 128:205-210, 2009

129. Sutmoller P, McVicar JW: Pathogenesis of foot-and-mouth disease: clearance of the virus from the circulation of cattle and goats during experimental viraemia. J Hyg (Lond) 77:245-253, 1976

130. Sutmoller P, McVicar JW: Pathogenesis of foot-and-mouth disease: the lung as an additional portal of entry of the virus. J Hyg (Lond) 77:235-243, 1976

131. Terpstra C: Pathogenesis of foot-and-mouth disease in experimentally infected pigs. Bull Off Int Epizoot 77:859-874, 1972

132. Toka FN, Nfon C, Dawson H, Golde WT: Natural killer cell dysfunction during acute infection with foot-and-mouth disease virus. Clin Vaccine Immunol 16:1738-1749, 2009

133. Tunca R, Sozmen M, Erdogan H, Citil M, Uzlu E, Ozen H, Gokce E: Determination of cardiac troponin I in the blood and heart of calves with foot-and-mouth disease. J Vet Diagn Invest 20:598-605, 2008 
134. Van Bekkum JG, Frenkel HS, Frederiks HHJ, Frenkel S: Observations on the carrier state of cattle exposed to foot-and-mouth disease virus. Tijdschr. Diergeneeskd 84 1159-1164, 1959

135. Ward MP, Highfield LD, Vongseng P, Graeme Garner M: Simulation of foot-andmouth disease spread within an integrated livestock system in Texas, USA. Prev Vet Med 88:286-297, 2009

136. Whitton JL, Cornell CT, Feuer R: Host and virus determinants of picornavirus pathogenesis and tropism. Nat Rev Microbiol 3:765-776, 2005

137. Yilma T: Morphogenesis of vesiculation in foot-and-mouth disease. Am J Vet Res

41:1537-1542, 1980 Sep

138. Zhang Z, Alexandersen S: Quantitative analysis of foot-and-mouth disease virus RNA loads in bovine tissues: implications for the site of viral persistence. J Gen Virol 85:2567-2575, 2004

139. Zhang Z, Alexandersen S: Quantitative analysis of foot-and-mouth disease virus RNA loads in bovine tissues: implications for the site of viral persistence. Journal of General Virology 85:2567-2575, 2004

140. Zhang Z, Bashiruddin JB: Quantitative analysis of foot-and-mouth disease virus RNA duration in tissues of experimentally infected pigs. Vet J 180:130-132, 2009 141. Zhang Z, Bashiruddin JB, Doel C, Horsington J, Durand S, Alexandersen S: Cytokine and Toll-like receptor mRNAs in the nasal-associated lymphoid tissues of cattle during foot-and-mouth disease virus infection. J Comp Pathol 134:56-62, 2006 142. Zhang ZD, Hutching G, Kitching P, Alexandersen S: The effects of gamma interferon on replication of foot-and-mouth disease virus in persistently infected bovine cells. Arch Virol 147:2157-2167, 2002

143. Zhang ZD, Kitching RP: The localization of persistent foot and mouth disease virus in the epithelial cells of the soft palate and pharynx. J Comp Pathol 124:89-94, 2001 144. Zhao Q, Pacheco JM, Mason PW: Evaluation of genetically engineered derivatives of a Chinese strain of foot-and-mouth disease virus reveals a novel cell-binding site which functions in cell culture and in animals. J Virol 77:3269-3280, 2003 


\title{
Chapter 2
}

\section{Development of a novel, aerogenous inoculation system for the experimental investigation of the pathogenesis of foot-and-mouth disease in cattle}

\begin{abstract}
The goal of this study was to develop a consistently repeatable method for simulated natural (aerogenous) inoculation of cattle with foot-and-mouth disease virus (FMDV). Two novel systems (aerosol nebulization and intranasal instillation) were compared for efficacy and repeatability in a "proof of concept" manner. Efficacy was assessed as the ability of each system to allow the identification of early replication sites by real-time reverse transcriptase-polymerase chain reaction (rRT-PCR), virus isolation (VI), and immunohistochemistry (IHC). Virus distribution at $24 \mathrm{~h}$ post inoculation was compared between the two systems. Aerosol inoculation of FMDV consistently resulted in virus detection by rRT-PCR, VI, and IHC in the nasopharynx, and lungs. Additionally, aerosol exposure resulted in typical clinical signs of FMD when animals were kept alive long enough to develop disease. The aerosol infection method was highly reproducible regarding inoculum dose and volume, and allowed the detailed study of early events in FMDV-infected cattle. The intranasal instillation method resulted in FMDV infection of all inoculated animals, but was considered inferior due to poor consistency of tissue distribution of FMDV. The extensive postmortem sampling and trimodal virus detection
\end{abstract}


system allowed a more precise determination of FMDV localization than previously reported.

\section{Introduction}

Foot-and-mouth disease (FMD) is a highly contagious picornaviral disease affecting domestic and wild cloven-hoofed animals. Inhalation of aerosolized foot-andmouth disease virus (FMDV) is generally considered to be the most important route of transmission within and between herds of cattle so that under appropriate environmental conditions virus-laden droplets may travel vast distances whilst maintaining infectivity. ${ }^{1,10}$

Over the course of more than 100 years of investigation of FMD, numerous animal models have been developed to investigate the pathogenesis of the disease. The goals of these models were to closely simulate naturally occurring disease and to be reproducible across experimental subjects. In cattle, FMD has been experimentally reproduced by exposing animals to virus via direct or indirect contact with infected animals, via injection by various routes, by intra-tracheal aerosol infection, by intrapulmonary implantation, or via respired aerosol. ${ }^{1,17}$ Injection infection models, though highly consistent, bypass the respiratory tract ${ }^{1}$, and thus, preclude the possibility of investigating early events in pathogenesis. Contact exposure closely simulates natural infection, but has the intrinsic limitations of inability to quantitate viral dose or precisely standardize exposure conditions across infected animals. Direct introduction of virus to the bovine respiratory tract offers the advantages of standardization of viral dose and simulation of the natural route of transmission, while preserving the capacity to examine early events in pathogenesis. As such, this infection method has been widely used. ${ }^{17}$ 
Early bovine FMD models utilizing respiratory exposure achieved infection by depositing virus in the nasal cavity of cattle with a latex tube mounted to a syringe (intranasal instillation). ${ }^{13,14}$ Later models utilized improvised containment chambers enclosing the heads of cattle while introducing virus suspensions aerosolized with deVilbiss nebulizers. ${ }^{2,3,12}$ Using such a technique, $76 \%$ of mean aerosolized particles within the exposure chamber were $<3 \mu \mathrm{m}$ and $7 \%$ were $>6 \mu \mathrm{m}$ immediately after shutting off the nebulizer. ${ }^{12}$ Consideration of nebulized particle size is important since this influences the anatomical distribution of the aerosol. Particles $<3 \mu \mathrm{m}$ are more likely to progress to the lungs, whereas particles $>6 \mu \mathrm{m}$ are likely to lodge in the upper respiratory tract. During natural aerosol infection of cattle it is likely that particles $<3 \mu \mathrm{m}$ predominate ${ }^{12}$ whereas those $<6 \mu \mathrm{m}$ are most likely to be responsible for long-distance transmission. ${ }^{8}$

Variable exposure conditions, virus strains, detection methods, and tissues examined confound comparison of results across published FMD pathogenesis studies. Despite abundant effort to elucidate the early events of infection, a clear consensus still does not exist regarding the natural portal of FMDV infection. The purpose of this work was to investigate the early, pre-viremic events of FMD in cattle using a highly reproducible infection model that closely simulated natural exposure.

\section{Materials and methods}

Experimental animals, virus, and inoculation systems

Eleven 9-12 month-old Holstein steers weighing 300-400 kg were obtained from an experimental-livestock provider (Thomas-Morris Inc.). Animals were housed in individual rooms in a BSL-3 animal facility from inoculation until time of necropsy. 
Seven steers were inoculated with FMDV either by aerosolization (animals 66, 670, 671, 760 ) or by intranasal instillation (animals $67,672,673$ ) of FMDV. Prior to inoculation, steers were sedated with xylazine given intramuscularly $(0.22 \mathrm{mg} / \mathrm{kg})$ so as to maintain sternal recumbency for the duration of the procedure. Upon completion of the inoculation procedure, sedation was reversed by giving tolazine slowly IV $(2-4 \mathrm{mg} / \mathrm{kg})$. One steer inoculated by aerosolization (animal 760) was euthanized 10 days post inoculation (dpi) in order to characterize the course of clinical disease and viremia. The other six animals were euthanized and necropsied $24 \mathrm{hpi}$ for tissue collection.

The challenge virus consisted of clarified macerated tongue epithelium harvested from two steers experimentally infected with the FMDV strain O1 Manisa as previously described. ${ }^{9}$ The macerate was pooled, aliquoted and stored at $-70{ }^{\circ} \mathrm{C}$. Challenge virus was titrated in the tongue of a steer to determine $50 \%$ bovine tongue infectious doses $\left(\mathrm{BTID}_{50}\right)$. All animals were inoculated with $10^{7} \mathrm{BTID}_{50}$ either in $1 \mathrm{~mL}$ of minimum essential medium (MEM) for the first steer infected in each group or in $2 \mathrm{~mL}$ for the remaining steers.

The inoculum titer is expressed in $\mathrm{BTID}_{50}$ as we have determined this method is the most sensitive for quantifying this bovine-adapted strain. We tested LFBK cells, a previously described cell line of bovine origin ${ }^{18}$, and found that an inoculum containing $10^{7} \mathrm{BTID}_{50} / \mathrm{mL}(\mathrm{Ct}=13$ by rRT-PCR $)$ yielded a titer of $10^{6}$ in LFBK cells ${ }^{4}$, as compared to $10^{1}$ in BHK-alphaVbeta6 cells ${ }^{7}$ and $10^{0}$ in BHK or primary lamb kidney cells. Aerosol inoculation was performed with a jet nebulizer (Whisper Jet, Marquest Medical Products) attached to a commercially available aerosol delivery system (Equine Aeromask, Medium Size, Trudell Medical). The delivery mask, although originally 
designed for horses, fitted the muzzles of the cattle sufficiently well to ensure complete delivery of the inoculum. This nebulizer generates particles with an average size of $5 \mu \mathrm{m}$ that distribute throughout the upper and lower respiratory tract. ${ }^{11}$ Compressed air, at 25 psi, is used to jet-nebulize the inoculum directly into the holding chamber. Upon inspiration, the nebulized inoculum is inhaled through a one-way valve into the delivery mask which covers the distal portion of the muzzle including the nares.

Intranasal instillation was performed with Accuspray (DB brochure, http://www.bd.com/pharmaceuticals/pdfs/accuspray-brochure.pdf), an intranasal delivery system designed for use in humans. This device's droplet size distribution, as reported by the manufacturer, is $85 \%$ of particles of 10 to $150 \mu \mathrm{m}$ in diameter and $4 \%$ of particles $<$ $10 \mu \mathrm{m}$. This ensures that the instillation is delivered predominantly to the upper respiratory tract and not the lungs. For each inoculation, the device was inserted into both nostrils and the syringe plunger compressed with a single brisk motion. Inoculation volume for instillation was $0.5 \mathrm{~mL}$ (animal 67) or $1.0 \mathrm{~mL}$ (animals 672 and 673) per nostril. In both cases the infectious dose was $10^{7} \mathrm{BTID}_{50}$.

A preliminary infection was carried out to confirm that the course of clinical FMD after aerosolization was comparable with that seen after direct inoculation or contact exposure. In brief, two steers (animals 624 and 625) were placed in a single room and inoculated via intra-dermolingual injection with $10^{4}$ BTID of the same FMDV O1 Manisa inoculum administered to the aerosolized and instillated steers. After $24 \mathrm{~h}$, two naïve steers (animals 626 and 627) were introduced into the same room and the four animals remained in direct contact until $10 \mathrm{dpi}$. 


\section{Sample collection}

For the aerosolized and instillated cattle, oral and nasal swabs and serum samples were collected at 0,6 and $24 \mathrm{hpi}$. At 24 hpi animals 66, 67, 670,671, 672, and 673 were euthanized by IV injection of Fatal Plus (barbiturate), and 35 anatomically distinct tissue samples were collected from the: oral cavity, nasal cavity, soft palate, pharynx, larynx, trachea, and lungs (Table 2.1). Sample collection was based upon previously published reports of the relevance of particular tissues in the pathogenesis of FMD. Gross and microscopic anatomic characteristics were used to identify and subdivide the samples. All tissues (excluding lung and tonsils) were collected as specimens with a full-thickness epithelium with 1-3 mm of associated subjacent stroma. Palatine and pharyngeal tonsil samples were collected as wedge specimens including the luminal aspect of these structures. Lung samples were all from the right lung. For each lung lobe, samples were designated: 'proximal' (included bronchial epithelium only); 'mid' (included bronchial epithelium and adjacent pulmonary parenchyma); and 'distal' (included pulmonary parenchyma only). Primary bronchial samples were mucosal specimens collected at the level of the tracheal bifurcation. For all specimens with 'cranial' and 'caudal' designations, the tissue was bisected at the midpoint of the cranio-caudal axis and the sample collected from the middle segment of the bisected specimen. For each anatomically defined specimen, two $30 \mathrm{mg}$ tissue samples were aliquoted into separate screw-cap $1.5 \mathrm{~mL}$ tubes and frozen immediately in liquid nitrogen for transfer, within $2 \mathrm{~h}$ to a $-70{ }^{\circ} \mathrm{C}$ freezer until time of processing.

An adjacent tissue specimen from each tissue was placed in a cryomold, embedded in optimal cutting temperature compound (OCT) (Sakura Finetek), frozen on 
liquid nitrogen, and stored at $-70{ }^{\circ} \mathrm{C}$ for immunohistochemistry. In the case of animal 760 , swabs were collected at $24 \mathrm{~h}$ intervals for the duration of the experiment and serum was sampled at $1 \mathrm{~h}$ intervals for the first $6 \mathrm{hpi}, 6 \mathrm{~h}$ intervals from $6-78 \mathrm{hpi}$, and $24 \mathrm{~h}$ intervals from $78-240$ hpi (10 dpi) when euthanasia and tissue sampling was performed. Serum was collected at $24 \mathrm{~h}$ intervals from animals 624, 625, 626 and 627. All animals allowed to survive beyond 24 hpi $(624,625,626,627$, and 760$)$ were sedated daily for clinical evaluation.

\section{Foot and mouth disease virus RNA detection}

Two sample containers of each tissue listed in Table 2.1 per animal were thawed and immediately macerated by adding two $5 \mathrm{~mm}$ stainless steel beads (Qiagen, catalogue No. 69989) and $0.9 \mathrm{~mL}$ of MEM-25 mM Hepes, and shaken in a TissueLyser bead beater (Qiagen) for $2 \mathrm{~min}$ at a frequency of $22 / \mathrm{s}$. After maceration, $50 \mu \mathrm{L}$ of sample was transferred to 96-well plates (King Fisher No. 97002540) containing $150 \mu \mathrm{L}$ lysis/binding solution. RNA was then extracted using Ambion's MagMax-96 Viral RNA Isolation Kit (Ambion, catalogue number 1836) on a King Fisher-96 Magnetic Particle Processor (Thermo Electron Corp.). Briefly, after the initial 5 min lysis/binding step, the RNA sample underwent a series of four washing steps, a drying step, and a final elution step. RNA was eluted in a final volume of $25 \mu \mathrm{L}$. At each of the above steps, RNA was magnetically bound to the beads contained in the lysis/binding solution and was transferred to the different extraction solutions. Once extracted, the RNA was analyzed by rRT-PCR using $2.5 \mu \mathrm{L}$ of RNA on the ABI 7000 as previously described (Callahan et al., 2002). Samples were considered positive when $\mathrm{Ct}$ values were $<40$. The remaining 
macerated tissue was clarified $\left(1000 \mathrm{~g}\right.$ for 2 min at $4{ }^{\circ} \mathrm{C}$ ) and the supernatant was cleared of bacterial contamination using centrifuge tube filters (Spin-X, Costar). Clarified and cleared samples were stored at $-70^{\circ} \mathrm{C}$ until virus isolation (VI) was performed.

\section{Virus isolation}

After $48 \mathrm{~h}$, flasks seeded with $1 \times 10^{6}$ LFBK cell monolayers ${ }^{18}$ were rinsed with serumfree media and inoculated with $100 \mu \mathrm{L}$ of sera, swabs or clarified and filtered samples obtained from the tissues. After $1 \mathrm{~h}$ of adsorption, $5 \mathrm{~mL}$ of media with $1 \%$ serum was added to the flasks. Due to the potential toxicity of the swab samples, the inoculum was removed and $5 \mathrm{~mL}$ of media containing $1 \%$ serum was added. To avoid a high concentration of sera in flasks that received serum samples, the inoculum was removed and replaced with $5 \mathrm{~mL}$ of media with $1 \%$ serum. Inoculated flasks were incubated 3 to 5 days at $37^{\circ} \mathrm{C}$ on a rocking platform. Upon detection of a cytopathic effect (CPE), samples were confirmed as FMDV-positive by rRT-PCR. Samples in which no CPE was observed were amplified through three complete blind passages and the supernatants tested by rRT-PCR before they were deemed negative.

\section{Immunohistochemistry}

Samples for immunohistochemistry (IHC) were OCT-embedded, cryosectioned at $4 \mu \mathrm{m}$ onto electrostatically charged glass slides (Superfrost Plus, Fisher Scientific), fixed for $10 \mathrm{~min}$ in acetone at $-20{ }^{\circ} \mathrm{C}$, and air-dried at $20^{\circ} \mathrm{C}$. These sections were blocked for 2 h at $20{ }^{\circ} \mathrm{C}$ with PBST containing $6 \%$ mixed serum and $2 \%$ powdered non-fat milk. A mouse monoclonal primary antibody designated 12AF4.2.3 (Stave et al., 1986) targeting 
the FMDV 12S fraction (VP 1, 2, 3) was diluted in blocking buffer and applied to tissue sections for $18 \mathrm{~h}$ at $4{ }^{\circ} \mathrm{C}$. Specific anti-FMDV immunoreactivity was detected with a commercial kit (Vectastain ABC-AP, Vector Laboratories). The manufacturer's protocol was modified in that secondary antibody was applied diluted with $20 \%$ mixed serum to decrease background staining. An alkaline phosphatase substrate (Vector Red, Vector Laboratories) was applied and allowed to develop for $15 \mathrm{~min}$. Slides were counterstained with Gill's hematoxylin and coverslipped using routine methods. For each test section, a duplicate, negative-control serial section treated with a mouse monoclonal anti-VSVIndiana antibody of similar concentration was prepared. Additional negative control tissue sections from a steer that received a virus-free aerosol inoculum and killed at 24 hpi were included. Most tissues were additionally screened by IHC using a primary monoclonal antibody against the FMDV RNA polymerase 3D. ${ }^{19}$

Immunohistochemical labeling was considered positive when there was an intense cell-associated signal within the tissue with the absence of such staining in the negative controls.

\section{Results}

\section{Clinical profiles of FMDV-infected cattle}

Clinical signs of FMD (vesiculation, lameness, increased salivation, loss of appetite or fever) were not detected in the six animals euthanized at 24 hpi subsequent to either aerosolization or intranasal instillation with FMDV. Virus isolation and rRT-PCR data from sera and swab samples are presented in Table 2.2. All serum samples $(0,6$, and 24 hpi) from these animals were negative for FMDV by both VI and rRT-PCR indicating 
all six were non-viremic up to time of necropsy regardless of route of virus exposure. Given the importance of this data, the rRT-PCR detection procedure was repeated on $\geq 10$ replicates per sample and VI was run in triplicate to confirming the negative results.

Virus was not isolated at any time from nasal or oral (saliva) swabs in three aerosolized animals with only viral RNA detectable at 6 and 24 hpi in oral and nasal swabs. Virus was isolated only from two nasal swab specimens from instillated steers at 24 hpi, but several saliva and nasal samples were positive for viral RNA at 6 and 24 hpi.

In order to confirm that aerosol exposure would produce typical FMD, one steer (animal 760) was aerosol-inoculated and allowed to survive for 10 days by which time clinical signs and viremia have ceased (Fig. 2.1). In this animal disease progression was characterized by fever from 3 to $4 \mathrm{dpi}$, virus in sera at 2 and 3 dpi as determined by VI, and from 1 to 5 dpi as determined by rRT-PCR, and vesicles on all four feet and on the tongue first detected $2 \mathrm{dpi}$ and of maximum severity at $5 \mathrm{dpi}$. These clinical signs are similar to those in steers infected by the intradermal-lingual route and by contact exposure with this FMDV strain (Fig. 2.1).

Tissue-specific localization of FMDV by VI and rRT-PCR.

Thirty-five tissues were collected and processed by VI and rRT-PCR from each of the six steers euthanized at 24 hpi. Using both techniques, virus was most frequently detected in the soft palate, pharynx, larynx, and lungs and few positive samples were found from the oral or nasal cavity or from the trachea (Table 2.1). Of the 105 specimens from aerosol-exposed cattle, 39 (37.1\%) had detectable FMDV RNA and 23 (21.9\%) contained viable FMDV. Among comparable tissues from instillated steers, 10 (9.5\%) 
had detectable FMDV RNA and 8 (7.6\%) contained viable FMDV. Thus, both detection techniques indicated a greater dissemination of FMDV in aerosolized animals.

\section{Oral and nasal cavities}

Most samples from the oral cavity of both aerosolized and instillated steers were negative $(50 / 54,92.6 \%)$ for virus and viral RNA (Table 2.1). In aerosolized steers FMDV was detected in the oral cavity in just three samples: from the lower lip of two steers (one by rRT-PCR and one by VI); and one from the cranial tongue of one steer (by rRT-PCR only). A sample from the palatine tonsil was the only positive sample from the instillated steers and this was for viral RNA. Similar results were obtained from nasal tissue samples, of which most were negative $(21 / 24,87.5 \%)$. Only one aerosolized steer was positive for viral RNA and by VI in the caudal turbinate and only one instillated steer was VI positive at this site.

\section{Soft palate}

For aerosolized steers the ventral soft palate (cranial and caudal), was positive by VI and/or rRT-PCR in 2/3 animals. The cranial dorsal soft palate was positive by both rRT-PCR and VI in 2/3 steers, whereas the caudal dorsal soft palate was positive by both rRT-PCR and VI in all three animals. For instillated steers only three positive results were obtained. This included a caudal dorsal soft palate sample positive by both rRTPCR and VI in one steer. The cranial segment of ventral soft palate was positive by rRTPCR in another animal but was negative by VI (Table 2.1 ).

\section{Pharynx}

For aerosolized steers all specimens of cranial and caudal dorsal nasopharynx were VI-positive and all but one specimen (cranial dorsal pharynx of animal 670) were 
positive for viral RNA. For instillated steers, only the cranial dorsal nasopharynx of one steer was positive by both rRT-PCR and VI and caudal dorsal nasopharynx and pharyngeal tonsil from another animal was positive for RNA only (Table 2.1).

Larynx

For aerosolized steers, epiglottis and ventral larynx were positive by rRT-PCR and/or VI in the three steers. For the instillated steers, only the epiglottis of one steer was positive by both rRT-PCR and VI, and ventral larynx of another by VI (Table 2.1). Lungs and trachea

For aerosolized steers, 53.3\% (16/30) of lung specimens were positive for viral RNA, but virus was isolated only from five specimens from animal 66. All lung specimens from animal 671 were negative by both detection techniques with the exception of the primary bronchus where viral RNA was detected. Only one instillated steer had five positive lung samples by rRT-PCR of which only one was VI-positive. Tracheal specimens from three distinct levels were uniformly negative for virus and viral RNA from all steers (Table 2.1).

Immunohistochemical localization of FMDV antigens

Tissues positive by VI and rRT-PCR were further examined by IHC using monoclonal antibodies directed against structural and non-structural viral proteins. In general there was good correlation with IHC indicating tissue viral replication was occurring. All rRT-PCR and VI-negative tissues were also negative using IHC. In lung samples, cells with strong cytoplasmic anti-FMDV immunoreactivity were infrequently identified individually or in small clusters within the pulmonary parenchyma (Fig. 2.2A). 
Within the alveoli, immunoreactive cells were morphologically consistent with alveolar macrophages. Within alveolar walls, similar immunoreactivity was observed in cells suspected to be pneumocytes or intra-vascular macrophages. In tissues from the dorsal soft palate, nasopharynx, and larynx, anti-FMDV immunoreactivity was infrequently identified in the pseudostratified columnar, stratified squamous, and attenuated epithelial regions and in the lymphofollicular, interfollicular, and stromal regions of the submucosa. In some instances, immunoreactive intra-epithelial cells appeared morphologically similar to adjacent epithelial cells. Specific anti-FMDV immunoreactivity was rarely identified in attenuated epithelial cells overlying lymphoid follicles (Fig. 2.2C), cells interpreted as possible M-cells. Sloughed lingual vesicular epithelium from animal 760 at 4 dpi contained abundant immunoreactive keratinocytes within the necrotic stratum spinosum (Fig. 2.2E) confirming that clinically visible vesicles occurred in association with the presence of FMDV.

\section{Discussion}

Donaldson et al. ${ }^{6}$ highlighted the respiratory tract as the most susceptible natural portal of FMD virus entry for cattle and that the only infection route that approached this in terms of infectivity was intradermal (IDL) inoculation of the tongue. Though IDL inoculation has great utility in terms of repeatability of infecting dose and location of inoculum delivery, it is a minor route of infection in cattle that likely by-passes many of the early phases of natural infection. ${ }^{6}$

In order to study early events in FMDV pathogenesis, we compared the distribution of virus in tissues of animals inoculated using the Accuspray device, a direct 
nasal instillation device and using the Aeromask pulmonary nebulization system. Given their size, the delivery of particles produced by the Accuspray device would be limited to the upper respiratory tract whereas particles produced by the nebulizer system, designed for intra-pulmonary drug deposition, would be expected to deposit in the lungs and in the upper respiratory tract. Standardizing the size of infectious particles is critical to an early pathogenesis model as it dictates the transmission distances and anatomical distribution of the infectious aerosol thus influencing the relevance of the model system. Aerosolized particles $<6 \mu \mathrm{m}$ in diameter are minimally affected by gravity and can therefore transmit virus over long distances. ${ }^{8}$ Additionally, only particles in this size range can reach the lower respiratory tract. ${ }^{8}$ Those $>6 \mu \mathrm{m}$ in diameter are likely to only transmit FMDV over short distances and to deposit in the upper or middle regions of the respiratory tract. ${ }^{1,8,12}$

In the current study, cattle exposed to FMDV via intranasal instillation had substantially fewer positive tissues relative to aerosolized animal. Considering that both groups received the same quantity of virus and that the delivery of inoculum by nasal instillation should be limited to the upper respiratory tract, animals infected by this method were anticipated to have more FMDV infection of the pharynx, larynx and soft palate than were aerosolized animals. However, in contrast, aerosolized animals had more FMDV-positive tissues in all regions except the palatine tonsil. Our extensive postmortem sampling protocol determined more precisely the localization of FMDV than did previous studies. The detection of FMDV and viral RNA in palatine, pharyngeal, laryngeal, and pulmonary samples from animals inoculated with the nebulizer system suggests that all levels of the respiratory tract were exposed to viral inoculum, a situation similar to that occurring in naturally occurring aerosol transmission. Thus the evidence 
suggests nebulization to be a superior infection model system and the remainder of this discussion focuses on the data generated from animals inoculated using this method.

The rRT-PCR, VI and IHC results strongly suggest that FMDV is replicating primarily in the upper respiratory tract of the aerosolized steers at 24 hpi. Furthermore, the fact that most oral and nasal swab samples remained negative suggests that the inoculum is rapidly removed from oral and nasal secretions.

The tissue distribution data of FMDV O1 Manisa in aerosol-inoculated cattle provides novel insights into the pathogenesis of bovine FMD. Although many of the tissues sampled in this work have been examined previously, the further anatomical subdivision of the sampled sites provides more detail and precision in characterizing virus distribution and disease pathogenesis. The data generated from animals at $24 \mathrm{hpi}$ is largely in agreement with previous FMD early pathogenesis studies in that the dorsal soft palate and nasopharynx, and to a lesser extent the lungs, are strongly implicated sites of early infection. The finding that laryngeal tissues are frequently FMDV-positive is novel, but, likely, reflects the fact that these tissues have not previously been specifically examined. The finding that almost all exterior and oral cavity samples were negative on VI is consistent with previous evidence that intact keratinized epithelia are resistant to primary FMDV infection. ${ }^{5}$ The few rRT-PCR-positive, VI-negative findings in these regions most likely represent viral RNA deposited on the epithelial surfaces from other locations.

The use of IHC to localize FMDV within tissues during early bovine FMD has not been previously reported. The localization of FMDV antigens within alveolar macrophages and within alveolar walls is consistent with previous studies that reported 
similar findings using in situ hybridization (ISH) in an aerosol-inoculation model. ${ }^{2,3}$ However, the previous ISH-based work did not localize FMDV to the soft palate or respiratory-associated lymph nodes until 72 hpi in contrast to our findings of viral RNA, infectious virus and FMDV immunoreactivity within pharyngeal tissues at 24 hpi. This difference may be due to differences in: aerosolization technique; the sensitivity of detection; tissues sampled; strain-specific viral tissue tropism. Foot-and-mouth disease virus has been detected in bovine pharyngeal and palatine tissues at later stages of infection using ISH. ${ }^{16,20}$ The current findings are in agreement with these studies in suggesting that pharyngeal and palatine tissues are involved in FMD pathogenesis. However, the time of onset of FMDV replication in these tissues, and thus their role as primary versus secondary sites of replication remains unresolved. Our preliminary IHC data suggests that early in FMDV infection of cattle, replication occurs in the upper respiratory tract within respiratory-associated lymphoid tissue. However, it remains unclear if infection at these sites proceeds directly to systemic disease.

Our tissue-specific data demonstrates good correlation between the detection of viable FMDV by VI and of FMDV RNA by rRT-PCR with agreement between the two techniques of $77.1 \%(81 / 105)$ between specimens from the aerosolized cattle. The finding of viral RNA but no infectious virus in a number of samples (20/105) was expected since virus could be inactivated yet the RNA could still be detectable. The fact that 15 such samples were from lung may indicate that pulmonary tissue is poorly permissive to FMDV replication. The few instances (4/105) when infectious virus but no viral RNA was detected suggests the presence of minute quantities of virus that required multiple passages in culture and/or that rRT-PCR inhibitors were present. The greater quantity of 
tissue macerate used to inoculate cells for VI compared to that used to extract RNA for rRT-PCR may also have contributed to this finding. Alternatively, the patchy distribution of FMDV infection ${ }^{15}$ might explain why adjacent tissue did not contain similar quantities of infected cells. The almost $100 \%$ correlation in finding viral RNA and infectious virus in only the caudal dorsal soft palate, caudal dorsal nasopharynx and ventral larynx suggests these are primary viral replication sites.

We confirmed that aerosolization simulated clinical FMD, by infecting, examining and sampling one animal for 10 days post inoculation. Work at our laboratory with the FMDV O1 Manisa and A24 Cruzeiro strains using this and other infection systems has resulted in the development of a similar clinical picture, so that cattle euthanized at 24 hpi can be considered pre-viremic and pre-clinical and would have gone on to develop clinical FMD.

Overall, the results of this study identify specific regions of the respiratory tract as primary sites of FMDV replication in aerosolized cattle. The aerosolization infection method used, the detailed tissue sampling protocol, and the trimodal virus detection methodology employed have allowed us to pinpoint the tissue distribution of FMDV in greater detail than previously. This well defined, repeatable model will facilitate the future investigation of FMD pathogenesis (as described in Chapter 4) and, in contrast to earlier models, the equipment required is commercially available. This experimental system has the potential to better define how localized primary infection progresses to systemic disease and to be used in the assessment of FMDV vaccines and other control measures to minimize the impact of this disease. 


\section{Chapter 2 Tables}

Table 2.1 The distribution of foot-and-mouth disease virus strain O1 Manisa as determined by rRT-PCR and virus isolation (VI) in tissues collected postmortem from cattle inoculated by aerosol or nasal instillation.

\begin{tabular}{|c|c|c|c|c|c|}
\hline \multirow[b]{2}{*}{ Anatomical region } & \multirow[b]{2}{*}{ Tissue sub-division } & \multicolumn{2}{|c|}{$\begin{array}{c}\text { Aerosol inoculation } \\
\text { Animals } 66,670 \text {, and } 671 \\
\end{array}$} & \multicolumn{2}{|c|}{$\begin{array}{c}\text { Nasal instillation } \\
\text { Animals } 67,672 \text {, and } 673 \\
\end{array}$} \\
\hline & & rRT-PCR & VI & rRT-PCR & VI \\
\hline \multirow[t]{9}{*}{ Oral cavity } & lower lip (mucosa) & -+- & +-- & $-\cdots$ & $-\cdots$ \\
\hline & dental pad & - - - & - - - & $-\ldots$ & - \\
\hline & cranial tongue & -+ & - - - & $-\ldots$ & $\ldots$ \\
\hline & mid tongue & - - - & - - - & - - - & $-\cdots$ \\
\hline & lingual torus & - - - & - - - & $-{ }_{-}$ & - \\
\hline & lingual tonsil &.- & - - - & $\ldots$ & $\ldots$ \\
\hline & cranial hard palate & - - - & - - - & $\ldots$ & $\ldots$ \\
\hline & caudal hard palate & $-\ldots$ & - - - & - & - \\
\hline & palatine tonsil & - - & - - - & $+\ldots$ & $-\ldots$ \\
\hline \multirow[t]{4}{*}{ Nasal cavity / exterior } & nasal planum & - - - & - - - & - - - & $-\cdots$ \\
\hline & alar fold & +-- & - - - & - - & - \\
\hline & cranial turbinates & - - - & - - - & - & $\ldots$ \\
\hline & caudal turbinates & - . - & $+\ldots$ & $-\ldots$ & $-{ }_{-}+$ \\
\hline \multirow[t]{4}{*}{ Soft palate } & cranial ventral soft palate & ++- & +- & +- & - \\
\hline & caudal ventral soft palate & ++- & +- & $\ldots$ & $\ldots$ \\
\hline & cranial dorsal soft palate & +-+ & +-+ & -- & $-\cdots$ \\
\hline & caudal dorsal soft palate & +++ & +++ & --+ & --+ \\
\hline \multirow[t]{3}{*}{ Pharynx } & cranial dorsal nasopharynx & + - + & +++ & $-{ }_{-}^{+}$ & $-{ }_{-}^{+}$ \\
\hline & caudal dorsal nasopharynx & +++ & +++ & - - - & +- \\
\hline & pharyngeal tonsil & $+\ldots$ & - - - & - & +- \\
\hline \multirow[t]{2}{*}{ Larynx } & cranioventral epiglottis & ++- & --+ & +-- & +-- \\
\hline & ventral larynx & +++ & ++- & - . - & $-{ }_{-}+$ \\
\hline \multirow[t]{3}{*}{ Trachea* } & trachea $10 \mathrm{~cm}$ & -- & - - - & - - & - \\
\hline & trachea $20 \mathrm{~cm}$ & - & - - - & - & - \\
\hline & trachea $30 \mathrm{~cm}$ & $-\ldots$ & - - - & $\ldots$ & $\ldots$ \\
\hline \multirow[t]{10}{*}{ Lungs } & primary bronchus & -++ & - - - & $-{ }_{-}^{+}$ & - \\
\hline & cranial lobe, proximal & ++- & - - & --+ & -+ \\
\hline & cranial lobe, mid & +-- & +-- & --+ & -- \\
\hline & cranial lobe, distal & +-- & +- & - - - & - \\
\hline & middle lobe, proximal & ++- & +- & - & - \\
\hline & middle lobe, mid & +- & +- & --+ & -- \\
\hline & middle lobe, distal & ++- & +- & --+ & $-\ldots$ \\
\hline & caudal lobe, proximal & ++- & - - - & .. - & $\ldots$ \\
\hline & caudal lobe, mid & -+- & - - - & $-\ldots$ & $\ldots$ \\
\hline & caudal lobe, distal & ++- & - - - & $-\ldots$ & $\ldots$ \\
\hline
\end{tabular}

* Trachea 10, 20 and 30 correspond to samples of trachea taken 10,20 and $30 \mathrm{~cm}$ aboral to the larynx, respectively. 
Table 2.2 The distribution of foot-and-mouth disease virus strain O1 Manisa as determined by rRT-PCR and virus isolation (VI) in samples collected antemortem from cattle inoculated by aerosol or nasal instillation.

\begin{tabular}{|c|c|c|c|c|c|}
\hline \multirow[b]{2}{*}{ Sample } & \multirow[b]{2}{*}{ Time post-inoculation (h) } & \multicolumn{2}{|c|}{$\begin{array}{c}\text { Aerosol inoculation } \\
\text { Animals } 66,670 \text {, and } 671 \\
\end{array}$} & \multicolumn{2}{|c|}{$\begin{array}{c}\text { Nasal instillation } \\
\text { Animals } 67,672 \text {, and } 673 \\
\end{array}$} \\
\hline & & rRT-PCR & VI & rRT-PCR & VI \\
\hline \multirow{3}{*}{ Serum } & 0 & $-\ldots$ & $-\ldots$ & $-\ldots$ & $\ldots$ \\
\hline & 6 & $-\ldots$ & $-\ldots$ & $-\ldots$ & $\ldots$ \\
\hline & 24 &.- & $-\ldots$ & $-\ldots$ & $-\ldots$ \\
\hline \multirow[t]{3}{*}{ Saliva } & 0 & $\ldots$ & $\ldots$ & $\ldots$ & $\ldots$ \\
\hline & 6 & +- & $-\ldots$ & ++- & $\ldots$ \\
\hline & 24 & --+ & $-\ldots$ & +- & $\ldots$ \\
\hline \multirow[t]{3}{*}{ Nasal Swab } & 0 & - . - & $\ldots$ & $\ldots$ & $\ldots$ \\
\hline & 6 & $+\ldots$ & . . - & $+\ldots$ & $\ldots$ \\
\hline & 24 & --+ & $\ldots$ & +++ & +-+ \\
\hline
\end{tabular}




\section{Chapter 2 Figures}

(A) Direct inoculation, animal numbers 624 and 625
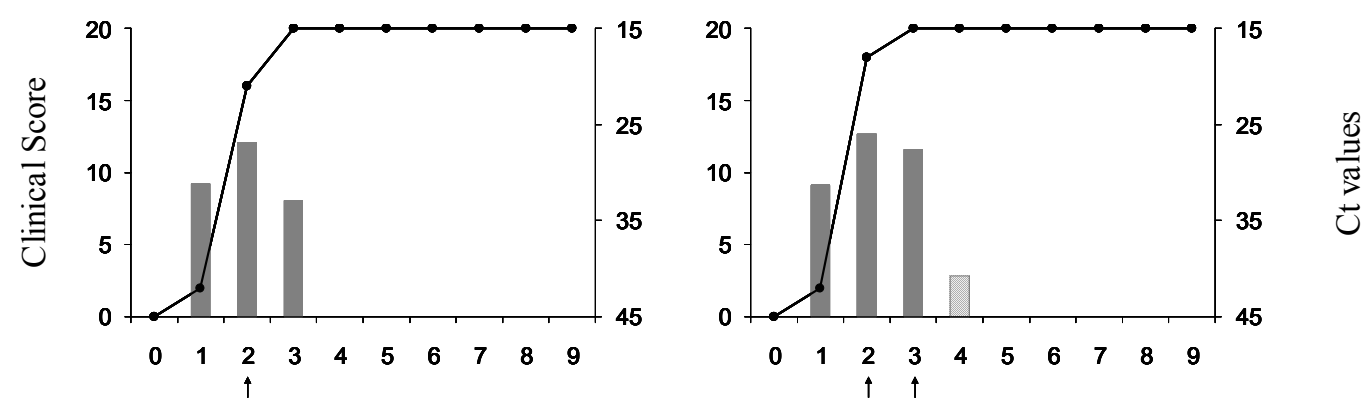

Days postinoculation

(B) Contact inoculation, animal numbers 626 and 627

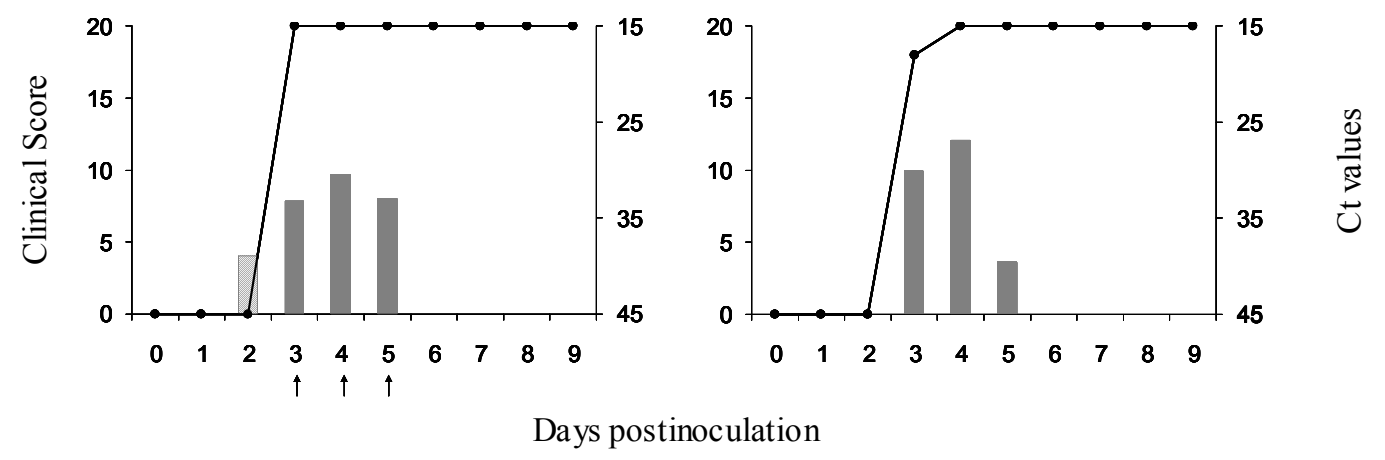

(C) Aerosol inoculation, animal number 760

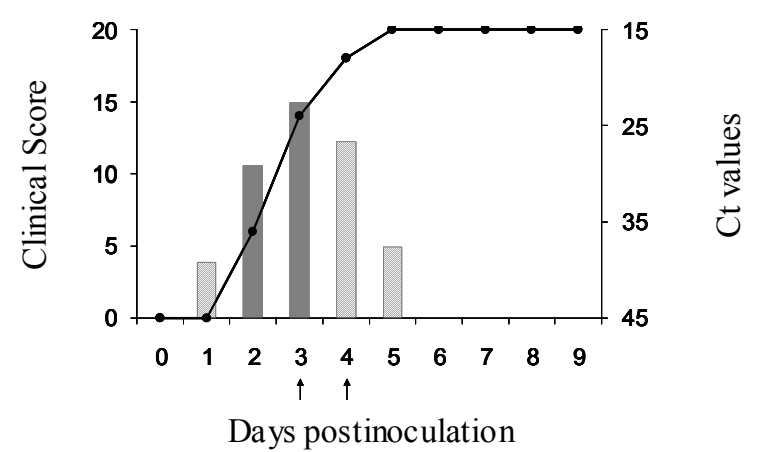

Fig. 2.1 Graphs illustrating the time course of infection in cattle: directly inoculated (intradermolingually) with foot-and-mouth virus strain O1 Manisa (A); in contact with directly inoculated cattle (B); or inoculated by aerosol exposure (C). Time on the $\mathrm{x}$-axes is in days post-inoculation/contact. The left y-axes represent the clinical scores $(\bullet)$ which are based on number and size of vesicles in the oral cavity and/or on the feet. Bars indicate $\mathrm{Ct}$ values of viral RNA detection in serum (Ct scale on right y-axes). Solid gray and hatched bars represent samples positive and negative on virus isolation respectively. Arrows denote that the animals were pyrexic $\left(\geq 40^{\circ} \mathrm{C}\right)$. 



$2.2 \mathbf{E}$

$2.2 \mathrm{~F}$
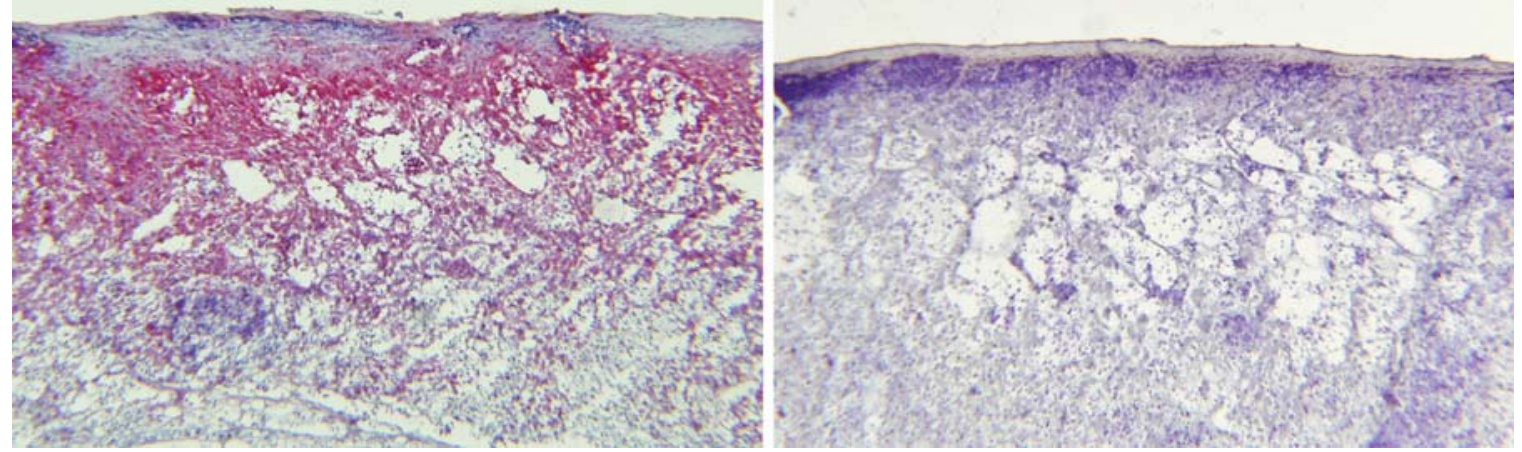

Fig. 2.2 Foot-and-mouth disease virus (FMDV) antigen (red staining) in cryosections from animals 24 (A-D) and 96 (E-F) h post aerosol infection with FMDV. Antibodies against FMDV VP-1, 2, 3 (A, C, and E) and VSV-Indiana (B, D, and F) were used: (A) proximal cranial lung tissue from animal 670 illustrating alveolar macrophages (arrow) cells in the alveolar wall (arrowheads) with cytoplasmic immunoreactivity (6x, inset 40x); (B) negative control for (A) (6x); (C) caudal dorsal nasopharynx from animal 66 exhibiting several attenuated surface epithelial (M-like) cells (arrows) and a few paracortical cells with cytoplasmic immunoreactivity. There is a subjacent lymphoid follicle (arrowheads) (16x, inset 40x); (D) negative control for (C) (6x); (E) sloughed lingual vesicular epithelium from animal 760 illustrating numerous immunoreactive keratinocytes within the stratum spinosum ( 6x); (F) negative control for (E)(6x). Immunohistochemical stain for FMDV antigen with haematoxylin counterstain. 


\section{References}

1. Alexandersen S, Zhang Z, Donaldson AI, Garland AJ: The pathogenesis and diagnosis of foot-and-mouth disease. J Comp Pathol 129:1-36, 2003 Jul

2. Brown CC, Meyer RF, Olander HJ, House C, Mebus CA: A pathogenesis study of foot-and-mouth disease in cattle, using in situ hybridization. Can J Vet Res 56:189-193, $1992 \mathrm{Jul}$

3. Brown CC, Piccone ME, Mason PW, McKenna TS, Grubman MJ: Pathogenesis of wild-type and leaderless foot-and-mouth disease virus in cattle. J Virol 70:5638-5641, 1996 Aug

4. Callahan JD, Brown F, Osorio FA, Sur JH, Kramer E, Long GW, Lubroth J, Ellis SJ, Shoulars KS, Gaffney KL, Rock DL, Nelson WM: Use of a portable real-time reverse transcriptase-polymerase chain reaction assay for rapid detection of foot-and-mouth disease virus. J Am Vet Med Assoc 220:1636-1642, 2002

5. Cottral GE, Patty RE, Gailiunas P, Scott FW: Sensitivity of cell cultures, cattle, mice, and guinea-pigs for detection of nineteen foot-and-mouth disease viruses. Bull Off Int Epizoot 63:1607-1625, 1965

6. Donaldson AI: Foot-and-mouth disease: the principal features. Irish Veterinary Journal 41:325-327, 1987

7. Duque H, LaRocco M, Golde WT, Baxt B: Interactions of foot-and-mouth disease virus with soluble bovine alphaVbeta3 and alphaVbeta6 integrins. J Virol 78:9773-9781, 2004

8. Gloster J, Blackall RM, Sellers RF, Donaldson AI: Forecasting the airborne spread of foot-and-mouth disease. Vet Rec 108:370-374, 1981 Apr 25

9. Golde WT, Pacheco JM, Duque H, Doel T, Penfold B, Ferman GS, Gregg DR, Rodriguez LL: Vaccination against foot-and-mouth disease virus confers complete clinical protection in 7 days and partial protection in 4 days: Use in emergency outbreak response. Vaccine 23:5775-5782, 2005

10. Grubman MJ, Baxt B: Foot-and-mouth disease. Clin Microbiol Rev 17:465-493, 2004 Apr

11. Hess D, Fisher D, Williams P, Pooler S, Kacmarek RM: Medication nebulizer performance. Effects of diluent volume, nebulizer flow, and nebulizer brand. Chest 110:498-505, 1996

12. McVicar JW, Eisner RJ: Aerosol exposure of cattle to foot-and-mouth disease virus. J Hyg (Lond) 91:319-328, 1983 Oct

13. McVicar JW, J.H. G, Sutmoller P: Growth of foot-and-mouth disease virus in the bovine pharynx. Proceedings of the 74th Annual Meeting of the United States Animal Health Association 230-234, 1970

14. McVicar JW, Sutmoller P: Growth of foot-and-mouth disease virus in the upper respiratory tract of non-immunized, vaccinated, and recovered cattle after intranasal inoculation. J Hyg (Lond) 76:467-481, 1976 Jun

15. Monaghan P, Simpson J, Murphy C, Durand S, Quan M, Alexandersen S: Use of confocal immunofluorescence microscopy to localize viral nonstructural proteins and potential sites of replication in pigs experimentally infected with foot-and-mouth disease virus. J Virol 79:6410-6418, 2005 
16. Prato Murphy ML, Forsyth MA, Belsham GJ, Salt JS: Localization of foot-andmouth disease virus RNA by in situ hybridization within bovine tissues. Virus Res 62:6776,1999

17. Sellers R, Gloster J: Foot-and-mouth disease: a review of intranasal infection of cattle, sheep and pigs. Vet J 177:159-168, 2008

18. Swaney LM: A continuous bovine kidney cell line for routine assays of foot-andmouth disease virus. Vet Microbiol 18:1-14, 1988

19. Yang M, Clavijo A, Li M, Hole K, Holland H, Wang H, Deng MY: Identification of a major antibody binding epitope in the non-structural protein 3D of foot-and-mouth disease virus in cattle and the development of a monoclonal antibody with diagnostic applications. J Immunol Methods 321:174-181, 2007

20. Zhang ZD, Kitching RP: The localization of persistent foot and mouth disease virus in the epithelial cells of the soft palate and pharynx. J Comp Pathol 124:89-94, 2001 


\title{
Chapter 3
}

\section{Development of novel immunolocalization techniques for the experimental investigation of the pathogenesis of foot-and-mouth disease in cattle}

\begin{abstract}
Immunohistochemical (IHC) and immunofluorescent (IF) techniques were optimized for the detection of foot-and-mouth disease virus (FMDV) structural and nonstructural proteins in frozen and paraformaldehyde-fixed paraffin embedded (PFPE) tissues of bovine and porcine origin. Immunohistochemical localization of FMDV was compared with seven detection systems, eight primary antibodies, and eleven epitope retrieval techniques. All serotypes tested (O, A, Asia, C for cryosection / O, A, Asia for PFPE) were localized in association with mature vesicles. Multi - label IF was used in conjunction with IHC and conventional histopathology to characterize vesicle maturation in four steers and two pigs experimentally infected with FMDV. At the edge of advancing vesicles, a consistent finding was acantholytic degeneration of basal keratinocytes surrounding dermal papillae with suprabasilar clefts and microvesiculation. Progression of microvesiculation led to coalescence with the expanding vesicle - proper. Cells at the leading edge of vesicles were positive for FMDV antigens by IHC and IF. Cell marker profile of these cells by IF was consistent with keratinocytes (i.e. cytokeratin
\end{abstract}


(CK) - positive, S100 - negative, MHC-II - negative). Rarely, CK-negative, MHC-II positive, FMDV - positive cells (presumptive dendritic cells or macrophages), were identified within dermis subjacent to vesicles.

\section{Introduction}

Foot-and-mouth disease virus (FMDV) is the etiological agent of foot-and-mouth disease (FMD), the most economically significant veterinary disease worldwide which has been investigated using numerous laboratory techniques. Though FMDV has been microscopically localized in tissues by wide field immunofluorescence (IF) ${ }^{31}$ and IFconfocal microscopy (CFM) ${ }^{14,17-19}$ and FMDV RNA has been localized by in situ hybridization (ISH) $)^{3,4,7,14,22,32}$, the only description in the scientific literature of localization of FMDV antigens by immunohistochemistry (IHC) in domestic species is a recent, limited description from our laboratory. ${ }^{21}$ The only other published anti-FMDV immunohistochemical technique provides one image of the technique applied to cervid tissue..$^{30}$ In that study, the two anti-structural protein monoclonal antibodies described are demonstrated to recognize all seven serotypes of FMDV in an ELISA assay; however, positive IHC detection of FMDV antigens is only demonstrated for one monoclonal antibody against one FMDV serotype. Anti-FMDV monoclonal antibodies have been generated against viral structural ${ }^{2,27,30}$ and non-structural proteins ${ }^{18,29}$ and have been used in a variety of diagnostic applications.

Immunohistochemistry has been used to identify a variety of viruses in animal tissues including West Nile virus ${ }^{5}$, bovine viral diarrhea virus ${ }^{12}$, vesicular stomatitis virus $^{6}$, and African swine fever virus ${ }^{11}$. Advantages of IHC over ISH and CFM, 
respectively, are the relative simplicity of protocols and the ability to screen far greater quantities of tissues. Historically, most IHC techniques have taken advantage of the affinity of (strept)avidin for biotin (avidin-biotin complex, ABC) by using either 1) biotinylated primary antibody followed by avidin - reporter enzyme conjugate or 2) nonbiotinylated primary antibody, biotinylated secondary antibody, then avidin - reporter enzyme conjugate. ${ }^{24}$ More recently micropolymer-based assays ${ }^{23,25}$ have been developed which claim better sensitivity than conventional $\mathrm{ABC}$ systems while avoiding the specificity failures associated with background biotin $^{24}$. However, comparisons across polymer system kits and between polymer and $\mathrm{ABC}$ systems are not readily available.

Tissue fixation and epitope (antigen) retrieval are critical components of a successful immunohistochemical technique and have recently been thoroughly reviewed. ${ }^{24}$ Formaldehyde is the most commonly used tissue fixative in veterinary pathology and is routinely used as a $10 \%$ buffered aqueous solution, neutral buffered formalin (NBF). Paraformaldehyde (PFA) fixation has been used predominantly in research applications when less protein and nucleic acid cross-linking is desired; paraformaldehyde - periodate - lysine (PLP) ${ }^{15}$ fixation was originally described for electron microscopy, but has been reported to be a superior fixative for immunohistochemical techniques due to the ability to use lower concentration of PFA and thus induce less crosslinking. ${ }^{13}$ Detection of FMDV RNA by in situ hybridization has been reported in PFA-fixed ${ }^{22,28}$ and NBF-fixed ${ }^{32}$ tissues. Antigen retrieval techniques from aldehyde-fixed tissues vary widely according to target antigen and operator preference, but generally consist of heat-induced epitope retrieval (HIER), enzymatic antigen retrieval, or a combination of both. ${ }^{24}$ 
The hallmark gross pathological lesions of FMD are the vesicles most commonly occurring in tongue, interdigital skin and coronary band and less commonly associated with rumenal pillars, snout, and other sites. The histological characteristics of FMD vesicles have been thoroughly described in the recent ${ }^{16,20}$ and historic ${ }^{8,10,26,31}$ literature. However, the histogenesis of cells involved in the morphogenesis of vesiculation has not been thoroughly examined. Moreover, elucidation of the mechanism of transfer of FMDV from the systemic circulation to lesional epithelium remains elusive.

We provide the first thorough description of immunohistochemical detection of FMDV antigens in frozen and fixed animal tissues including serotype specific efficacies of eight monoclonal antibodies, comparisons of four polymer-based detection systems and eleven epitope retrieval techniques. Using these optimized techniques, we characterized FMD vesicles by immunohistochemical localization of viral antigens and multichannel immunofluorescence with the overall conclusions that as vesicles progress laterally within the epithelium, microvesiculation by FMDV-positive dermal papillary basal cells leads to coalescence with, and expansion of, the maturing vesicle.

\section{Materials and methods}

Animal inoculations and tissue collection / processing

All work described herein was performed within the biosafety level 3 containment facility at Plum Island Animal Disease Center with adherence to animal use protocols. All animals were included in other experiments in our laboratory and will be described in greater detail in subsequent manuscripts. Briefly, cattle were $400-800 \mathrm{lb}$ Holstein steers. Pigs were Yorkshire barrows aged four - six months. Two steers were inoculated with 
FMDV via intraepithelial lingual injection (IEL); steer B6100 was infected with FMDV strain A24-Cruzero, 1.0(10) ${ }^{4}$ TCID $_{50}$-BHK-21 and steer B732 was infected with 3.0(10) ${ }^{5}$ bovine tongue infectious doses $\left(\mathrm{BTID}_{50}\right)$ of FMDV strain 01-Manisa. Twenty four hours after IEL inoculations each steer was euthanized by intravenous barbiturate overdose. Typical, multifocal, primary injection site vesicles $(0.5-2.0 \mathrm{~cm}$ diameters $)$ were apparent at the time of euthanasia. Steers B762 and B7200 were aerosol inoculated via a previously described technique ${ }^{21}$ with $1.0(10)^{7} \mathrm{BTID}_{50}$ of FMDV - 01-Manisa and euthanized 48 hours post-inoculation (HPI). At euthanasia, each aerosolized steer had a single vesicle of the interdigital cleft skin. A grossly detected focal region of pallor of lingual torus of B7200 was identified microscopically as an early vesicle. Both aerosolized steers were febrile and viremic at the time of euthanasia.

Pigs were inoculated with FMDV via intraepithelial injection of the heel bulb. Pig \#18566 received $5.3(10)^{5}$ TCID $_{50}$ of FMDV-Asia1-A1 and was euthanized five days post inoculation (DPI). Pig \#871 received 3(10) ${ }^{4} \mathrm{TCID}_{50}$ of FMDV-C3-Resende and was found dead at six DPI. Necropsy and routine histopathology indicated severe myocardial necrosis as the cause of death. Both pigs had extensive mature intact and ruptured vesicles of tongue and all four coronary bands and interdigital clefts. Pig 18566 additionally had a $2.0 \times 1.0 \mathrm{~cm}$ intact vesicle of the dorsal aspect of the snout.

Immediately subsequent to euthanasia, vesicles were dissected from each animal and either 1) immediately fixed in either 10\% neutral buffered formalin (NBF)or $2 \%$ PFA $(\mathrm{PLP})^{15}$ or 2) placed in a cryomold, embedded in Optimal Cutting Temperature Compound (OCT) $)^{\text {a }}$, frozen in a metal pan over a bath of liquid nitrogen, and stored at $70^{\circ} \mathrm{C}$ until used for cryomicrotomy. Fixed tissues were processed by routine methods. 
Fixed and frozen specimens were sectioned at $4-5 \mu$ on to electrostatically charged Superfrost Plus ${ }^{\mathrm{b}}$ glass slides. Cryosections were fixed for 10 minutes in acetone at $-20^{\circ} \mathrm{C}$, air-dried at room temperature, and stored at $-20^{\circ} \mathrm{C}$ until use.

\section{Antigen Retrieval}

Post - fixation retrieval of target antigens was performed by HIER and enzymatic techniques (Table 3.1). Humid heating was performed in a commercially available rice cooker; humid pressurized heating was performed in a typical sterilization autoclave. For both techniques slides were deparaffinized and hydrated by a series of changes of xylene, ethanol, and distilled water. Slides were then placed in loosely closed coplin jars containing target retrieval solutions which were subsequently placed in a water bath during heating. Antigen retrieval solutions evaluated were citrate ${ }^{\mathrm{c}} \mathrm{pH}$ 6.0, 6.2, 9.0, $\operatorname{Diva}^{\mathrm{TM}, \mathrm{d}}$, and Reveal ${ }^{\mathrm{TM}, \mathrm{d}}$ (Table 3.1). Each heating system - retrieval solution combination was evaluated at durations of 5,15 , and 25 minutes.

Enzymatic retrieval was performed with pronase, trypsin, and pepsin epitope retrieval kits ${ }^{\mathrm{d}}$ and with proteinase- $\mathrm{K}^{\mathrm{e}}$ (Table 3.1). Kits were used per manufacturers' recommendations with similar variation in digestion time as for HIER. Proteinase-K was applied at $20 \mathrm{ug} / \mathrm{ml}$ in Tris $\mathrm{pH} 8.0,0.05 \%$ Tween- 20 at $37^{\circ} \mathrm{C}$. For comparison of antigen retrieval techniques, a semi - quantitative retrieval quality score $(-,+,++,+++,++++)$ was assigned to each technique based upon sensitivity and intensity of staining. Scores were defined as: (-) no staining detectable, $(+)$ rare individual positive cells with weak intensity, $(++)$ moderate quantity of individual (or clusters of) positive cells with weak moderate intensity, $(+++)$ regionally extensive detection with moderate - strong intensity, 
$(++++)$ diffuse immunoreactivity within the expected region (vesicle) with strong intensity.

\section{Anti-FMDV antibodies}

Antibodies to FMDV used in these studies and their specificities are described in Table 3.2. Antibodies directed to structural (capsid) proteins were elicited with purified viral particles (140S) or subviral capsid components (12S) and recognize antigens present in the viral particle. ${ }^{2,27,30}$ Conventional anti-capsid antibodies were predominantly serotype specific and reactive only against the eliciting serotype used., ${ }^{27}$ Two antibodies were previously generated and characterized with the goal of serotype-independent FMDV detection (serotype - independent, structural antibodies).$^{30}$ Antibodies directed to the viral non-structural protein FMDV-3D (RNA-dependent RNA polymerase) were elicited against purified 3D protein as previously described. ${ }^{29}$ Presence of intracellular FMDV-3D reactivity was interpreted as suggestive of active viral replication in infected cells.

Immunohistochemistry

Each antibody was evaluated in cryosections from vesicles from animals inoculated with FMDV strains $\mathrm{O}_{1}$-Manisa, $\mathrm{A}_{24}$, Asia1-A1, and $\mathrm{C}_{3}$-Resende (one virus strain per animal). Anti-FMDV-3D and serotype-independent anti-structural antibodies were evaluated in PLP-fixed, paraffin-embedded tissues from animals inoculated with FMDV strains $\mathrm{O}_{1}$-Manisa, $\mathrm{A}_{24}$, and Asia1-A1. Numerous serotype-specific anti-structural antibodies were screened in PLP-fixed, paraffin-embedded tissues, but none were found 
to have adequate signal to noise ratio $(\mathrm{S} / \mathrm{N})$ for use. In order to assess the effect of fixative on retrieval of antigen, duplicate specimens from select tissues from the same lesions were fixed in either NBF or PLP and compared through similar epitope retrieval protocols.

Frozen and depariffinized fixed tissue sections were blocked for two hours at room temperature with phosphate - buffered saline, $0.05 \%$ tween- $20,6 \%$ mixed serum, $2 \%$ powdered non-fat milk. Anti-FMDV mouse monoclonal primary antibodies $2,27,29,30$ generated as crude supernatants of hybridoma cell lines (Table 3.2) were diluted in blocking buffer and applied to tissue sections for 18 hours at $4{ }^{\circ} \mathrm{C}$.

Anti-mouse immunoglobulin detection kits consisted of a conventional ABC alkaline phosphates kit $^{\mathrm{f}}$, two micropolymer alkaline phosphatase kits ${ }^{\mathrm{g}, \mathrm{h}}$, an ABC peroxidase kit ${ }^{\mathrm{i}}$, and two micropolymer peroxidase kits ${ }^{\mathrm{g}, \mathrm{j}}$. All detection kits were utilized per manufacturers' protocols. Various detection substrates were compared; red chromogens provided excellent sensitivity and good contrast to hematoxylin counterstain. A single substrate ${ }^{k}$ consistently provided superior sensitivity and specificity for alkaline phosphatase systems, whereas for peroxidase-based detection two substrates ${ }^{1, \mathrm{~m}}$ had similar properties. Chromogen substrates were applied per manufacturers suggested protocols with the exception that levamisole ${ }^{\mathrm{i}}$ was added to substrate solutions at $5 \mu \mathrm{l} / \mathrm{ml}$ for all slides receiving alkaline phosphatase detection systems. Slides were observed during substrate development and substrate reactions were terminated when signal was considered to be of adequate strength. Slides were counterstained with Gill's hematoxylin and coverslipped by routine techniques. 
For each section examined, a duplicate, negative control slide contained a serial section which received identical treatment with the exception that primary antibody consisted of a mouse, monoclonal anti-VSV-Indiana antibody applied at similar concentration. An additional negative control was included with each IHC run consisting of slides containing similar tissues from a mock-aerosolized steer which was treated identically to the other aerosol-inoculated animals but received a virus-free inoculum; these slides were treated identically to experimental specimens.

Determination of a positive IHC result required the presence of a strong cellassociated signal within the tissue in question with no similar signal present on either of the negative controls from the same run. For antibody and detection system comparisons, sensitivity was graded $(-,+,++,+++,++++)$ based upon distribution of antigen detection within the expected region; intensity was similarly graded according to the relative strength of immunopositivity within antigen-positive cells.

\section{Immunofluorescence assays}

Multi - label immunofluorescence was performed on cryosections similarly to IHC with few exceptions. All primary antibodies were collectively diluted in blocking buffer and simultaneously incubated on tissues at $4{ }^{\circ} \mathrm{C}$ for 18 hours. Mouse monoclonal antibodies used to label cell markers were anti-pancytokeratin plus (pCK) ${ }^{\mathrm{d}}$, anticytokeratin-14(CK-14) ${ }^{\mathrm{d}}$, anti-MHCII (CAT82A $)^{\mathrm{n}}$, and anti-S100 ${ }^{\mathrm{e}}$. Goat, anti-mouse, isotype-specific, fluorescently labeled secondary antibodies ${ }^{\circ}$ were diluted collectively in blocking buffer and applied to slides for 30 minutes at $37^{\circ} \mathrm{C}$. For most stains, virus was detected with Alexa Fluor (AF) -594 and cell markers were labeled with AF-488. In some 
multi-label experiments conformation to this strategy could not be maintained due to availability of secondary antibodies; in such instances, signal colors were digitally reassigned such that for all images included, virus appears as red signal. For double stains, nuclei (DNA) were counterstained with 4',6 diamidino-2-phenylindole (DAPI) ${ }^{\mathrm{p}}$.

Slides were evaluated with a wide-field epifluorescence microscope and images captured with an Olympus DP70 digital camera. Individual images were captured in each detection channel and subsequently adjusted for brightness and contrast and merged in Adobe Photoshop CS2 software. Isotype controls were included with each experiment and were used to establish camera sensitivity settings. Tissues from mock infected animals incubated with anti-FMDV antibodies were also included as negative controls.

\section{Results}

Cryosection immunohistochemistry

In cryosection stainings the anti-3D antibodies provided excellent sensitivity with minimal background for all tissues and serotypes examined with the exception of poor reactivity of antibody F19-6 against FMDV-C 3 (Fig. 3.1, Table 3.2). Negative control serial sections receiving mouse monoclonal anti-VSV antibodies had no corresponding signal. Similar tissues from mock-infected animals also had no detectable signal. Antibody F19-51 had slightly superior sensitivity in most tissues, but also, inconsistently, had greater background at similar dilutions relative to F19-6. Background staining with F19-51 consisted of regional chromogen deposition within vascular basement membranes and smooth muscle and perineurial sheaths. Antibody F19-6 could be used at lower titrations to achieve similar sensitivity without development of background and overall 
provided a superior signal -to - noise ratio. Anti - 3D immunoreactivity within vesicles was predominantly limited to the cytoplasm of acantholytic keratinocytes within the stratum spinosum and intact cells of the stratum basale (presumptive basal cells). Rarely, immunoreactivity was identified within cytoplasm of perivascular mononuclear cells in the dermis.

Numerous conventional anti-structural antibodies were screened, and for each FMDV serotype examined, at least one antibody was found to be efficacious (Table 3.2). Minimal cross-serotype immunoreactivity was occasionally identifiable, but was substantially weaker than signal generated from application to homologous serotype viruses. Antibody $6 \mathrm{HC} 4$ was unusual in this category in that substantial signal was detected against multiple serotypes. Serotype-independent anti-structural antibodies provided excellent sensitivity and specificity against all serotypes examined with the exception that antibody F21140SO had weak reactivity against FMDV-C 3 . Distribution of signal from structural and non-structural antibodies was consistently similar.

\section{Paraffin embedded tissues}

Choice of fixative was found to have minimal effect on overall efficacy of IHC detection of FMDV antigens with PLP and NBF fixation each having superior sensitivity against some serotypes with some antibodies. Tissue morphology and background were also similar with both fixatives. Paraformaldehyde (PLP) - fixed tissues were utilized for subsequent technique optimization due to theoretical superiority based upon decreased cross-linking of proteins and nucleic acids. 
Epitope retrieval technique had a substantial effect on sensitivity of detection (Table 3.1). Overall, the best retrieval of FMDV-3D antigen was achieved with the DIVA $^{\mathrm{TM}, \mathrm{d}}$ solution with 5 or 15 minute autoclave treatment. Citrate solution (pH 6.2) with 15 minute treatment was only slightly inferior. Heat retrieval at ambient pressure (rice cooker) was consistently ineffective, regardless of retrieval solution, with antigen barely detectable at 25 minutes. Of the four enzymatic epitope retrieval techniques evaluated, pepsin provided the best signal and was only slightly inferior to the optimized HIER. Pronase digestion provided moderate retrieval of FMDV antigens; trypsin and proteinase-K were ineffective at all conditions evaluated. Tissue sections were lost from slides less frequently with all enzymatic epitope retrieval combinations relative to HIER. Additionally, within these comparisons, enzymatic epitope retrieval induced less distortion of morphology. However, due to the slightly superior sensitivity achievable with the optimized HIER, this technique is favored for most applications.

\section{Detection systems}

Multiple detection systems were compared in frozen and fixed tissues (Table 3.3). In general, the micropolymer-based systems had greater sensitivity and similar or less background relative to $\mathrm{ABC}$ systems in both peroxidase and alkaline phosphatase platforms. In paraffin-embedded tissues, the one step, peroxidase micropolymer detection $\mathrm{kit}^{\mathrm{J}}$ was preferred due to excellent sensitivity, specificity, and ease of use. Minimal endogenous peroxidase reactivity was observed in erythrocytes and polymorphonuclear leukocytes, but was easily distinguished from the true (specific) signal. By contrast, endogenous peroxidase reactivity in similar cells within frozen sections was substantial 
enough to be prohibitive for many applications. Peroxidase blocking was attempted with hydrogen peroxide and phenylhydrazine at various reaction conditions; however substantial elimination of background without loss of specific signal was not achieved. Rather, a micropolymer alkaline phosphatase system was adopted for routine use in frozen sections due to favorable signal/noise ratio. Phosphatase blocking with levamisole was not necessary in the tissues shown herein, but was crucial to decreasing background in other work in our laboratory examining mucosal tissues and lungs.

\section{Histologic and immunohistochemical characterization of vesicles}

Lesions chosen for immunohistochemical characterization of FMDV antigen distribution were grossly and histologically classic, early - mature vesicles with varying extents of intra- and extracellular edema, keratinocyte acantholytic degeneration, and mixed leukocyte infiltration (Figs. 3.1.-.3.2). Vesicular cavities contained variable quantities of fibrin and necrotic cellular debris. All vesicles had subjacent superficial perivascular dermatitis characterized by mild to moderate, predominantly mixed mononuclear infiltrates with fewer neutrophils. Selected vesicles were all grossly intact (not ruptured); microscopic rupture was observed only in the coronary band lesion of P18566 (Fig. 3.1J - L). This lesion also had the unusual characteristic that the vesicle extended beyond coronary band to supracoronary haired skin. Multifocally, supracoronary hair follicles had segmental mural folliculitis and furunculosis. This consisted of neutrophilic infiltration and disruption of isthmic follicular epithelium with mural epithelial acantholysis, abscesses and microvesiculation (Fig. 3.1 J inset). 
Particular attention was focused on dermal papillae and surrounding basal keratinocytes at the periphery of vesicles as these were considered to comprise regions of progression of vesiculation (Fig. 3.2). Regional groups of these papillae often had a continuum of pathologic changes which included acantholytic degeneration with cytoplasmic hypereosinophilia of suprapapillary basal cells, segmental - circumferential suprabasilar clefts, and neutrophil infiltration. More severely affected papillae were cavitated with accumulations of necrotic debris and coalesced to become continuous with the leading edge of the vesicle-proper (Fig 3.2b).

Immunohistochemical detection of FMDV antigens was typically limited to regions of morphologic vesiculation (Fig. 3.1 - 3.2). For all tissues, distribution of structural and non-structural FMDV antigens was essentially similar. For tongue (B7200, B6100) and snout (P18566) specific immunoreactivity spanned strata basale and spinosum with strongest intensity of staining in basal cells or suprabasal keratinocytes of stratum spinosum (Fig. 3.1). At the junction of lesional and normal epithelium, immunoreactivity was identified in individual, or small clusters of, basal cells lining dermal papillae. Rare antigen-positive cells were seen centrally within dermal papillae (Fig. 3.1C, 3.1F) and perivascularly within superficial dermis.

Within the coronary band / haired skin junctional lesion of pig P18566, antigen detection was largely limited to superficial stratum spinosum and follicular epithelium. Within the affected follicles of this pig, anti- FMDV - $3 \mathrm{D}$ immunoreactivity was present in degenerate epithelial cells spanning internal and external root sheaths but not within neutrophils (Fig. 3.1L). 


\section{Immunofluorescent characterization of vesicles}

In order to examine the histogenesis of cells involved in vesicle propagation, immunofluorescent labeling of FMDV was performed in conjunction with labeling of one or more cell markers. Epithelial cells were identified with anti-pancytokeratin or anticytokeratin-14. Within the tissues examined, similar stainings with anti-S100 and antiMHC-II on serial sections were considered specific for dendritic cells or macrophages. As expected, within vesicles FMDV predominantly colocalized with cytokeratin confirming that $\mathrm{FMDV}+/ \mathrm{CK}+$ cells were keratinocytes (Fig. 3.3 - 3.9). Tissues from the mock infected steer and serial sections of vesicles incubated with isotype control antibodies had no corresponding FMDV-specific signal. At the periphery of vesicles, FMDV antigens were distributed in a similar pattern to that seen in IHC stainings with few FMDV-positive cells within or surrounding dermal papillae (Fig. 3.3D, 3.4B, 3.4C, 3.5F). However, in contrast to the IHC stainings, IF multi-labeling allowed the determination that these FMDV-positive cells within papillary spaces, were also CKpositive and were in varying stages of dissociation from overlying epithelium (Fig. 3.3F, 4B). This corresponds to the acantholytic degeneration and microvesiculation detectable by light microscopy. Though basement membrane was not specifically visualized, the regional collapse of epithelial cells into the dermal papillae was interpreted as regional ulceration (ulcer in situ) (Fig. 3.3F, 3.4B). Additionally, comparison of the periphery of lingual vesicles from aerosol inoculated (Fig. 3.3A-F) and IEL-inoculated (Fig. 3.4A-C) steers indicated essentially similar morphologic and phenotypic characteristics. Double labeling with structural and non-structural antibodies indicated that populations of cells 
containing either structural or non-structural antigen were identifiable independently, or as double positives (Fig. 3.5G-H).

Cells labeled for S100 and MHC-II had consistent and similar distributions with clusters of positive cells within the deep dermis and dermal papillae (Fig. 3.5A-F, 3.6AB). FMDV antigen rarely localized in close proximity to $\mathrm{S} 100$ (Fig. 3.6B inset) and in few additional fields CK-negative, FMDV positive cells were identified within the dermis 50 - 200 microns distant from lesion margins (Fig. 3.7 - 3.8). Examination of the interdigital vesicle of B762 by multilabel immunofluorescence indicated multisegmental discontinuity of the basement membrane at the deep stratum basale (Fig. 3.9A). In these regions of ulceration, clusters of cytokeratin - negative, FMDV capsid - positive, MHCII positive cells were identified within the superficial dermis. These cells were morphologically and phenotypically consistent with dendritic cells (Fig 3.9B). Similar colocalization of FMDV capsid antigens with MHC-II in (presumed) dendritic cells was observed subjacent to ulcerated vesicles at other sites, and was distinct from the failure to identify such colocalization at regions of vesicle progression (dermal papillae).

\section{Discussion}

Modern diagnostic laboratories and research institutions have numerous options for detection of FMDV in animal tissues. Though reverse transcription polymerase chain reaction (RT - PCR) and virus isolation (VI) are preferred for many applications due to their relative ease of standardization and high throughput, these techniques are inadequate for providing information regarding microscopic viral localization to specific anatomic tissue regions or individual cell types. When such data is required or desired, 
investigators may utilize IHC, IF, ISH, or CFM. Of these techniques, IHC is the fastest, most readily adaptable, and requires the least sophisticated laboratory equipment. IHC and ISH are similarly advantageous in that, once the slides are generated, they allow the most efficient screening of relatively large regions of tissues. Though light microscopy, chromogenic detection of multiple antigens (or nucleic acids) is feasible, fluorescent techniques are more routinely applied for multi-label localization. Wide - field IF allows nearly similar screening efficiency as IHC and ISH with the added advantage of allowing precise co-location of multiple antigens.

Though we have used the anti-FMDV IHC and IF as tools for pathogenesis investigation, they could also be effective ancillary diagnostic procedures, particularly when post-mortem tissues might be the only available samples. Precise diagnosis of FMD is of utmost importance due to the severe economic impact associated with detection of the disease. Definitive diagnosis is rarely made with a single modality of testing. Rapidity of diagnosis is crucial as small delays in detection can lead to rapid geographic dissemination through movement of animals and aerosolization of infectious droplets. The cryosection IHC technique described herein is a sensitive, specific, and extremely rapid modality of detection of FMDV, and thus could be an extremely useful ancillary diagnostic test. The entire protocol may be completed within two hours of obtaining fresh tissue specimens. Application of the technique with anti-FMDV-3D or serotypeindependent anti-FMDV-structural antibodies further enhances the utility of this technique as a simple, single method to detect numerous strains of FMDV.

The IHC efficacies of conventional anti - structural antibodies described herein were generally limited to the serotype against which antibodies were elicited. This is 
consistent with virus neutralization data published as part of the original characterization of the antibodies. ${ }^{2,27}$ The ability of antibody $6 \mathrm{HC} 4$ to recognize FMDV serotypes A, Asia 1, and C suggests that this antibody is specific for an epitope conserved across these serotypes. The serotype - independent anti - structural antibodies had excellent efficacy of FMDV detection by IHC across all serotypes tested; the conserved epitopes for which these antibodies are specific have been desdcribed. ${ }^{30}$ The broad serotype efficacy of the anti - FMDV 3D antibodies was not surprising given that this protein, RNA - dependent, RNA polymerase, is highly conserved across serotypes. ${ }^{29}$

The characterization of efficacies of various antigen retrieval and secondary detection systems will be useful to investigators developing IHC protocols for FMDV or other antigens in bovine tissues. Such comparisons are scarcely available in the published literature. Our finding that HIER and proteolytic retrieval techniques are effective for IHC of FMDV antigens will allow flexibility in the adaptation of the techniques we have described.

Our observations that FMD vesicles progress peripherally via infection of basal cells surrounding dermal papillae is consistent with earlier work ${ }^{31}$ which concluded that these regions serve as the sites of initiation of lesions and a recent report ${ }^{7}$ which indicated that these regions are strongly (FMDV) ISH-positive in mature lesions. However, the notion that dermal mononuclear cells serve as "virus-carrying cells", transporting FMDV from the blood to the epithelium presented in a previous work ${ }^{31}$ is not supported by the present study. The rarity with which we identified virus-positive, cytokeratin- negative cells in the papillae suggests that these cells (presumptive dendritic cells) do not have a significant or consistent role in vesicle maturation. The disparity of results between our 
study and that earlier work ${ }^{31}$ may be explained by technical and/or study design differences between the two investigations. Aspects of the earlier work which could explain this disparity include the different strain of FMDV used and the strategy within that study of examining lesion predilection sites before any lesions were grossly detected. ${ }^{31}$

Our IHC and IF techniques do identify virus-positive cells within the dermal papillae. But, the double and triple IF stains indicate that these cells are of epithelial origin, and are, in fact, acantholytic keratinocytes rather than dermal mononuclear cells. Examination using a single, virus-only label visualization system might have lead to misidentification of these cells as dermis-derived. Overall, our conclusion is that under the conditions of these studies, FMDV moves from the vasculature to basal keratinocytes in a cell-free manner. Furthermore, the finding that microvesicles occur surrounding dermal papillae distant from developing vesicles suggests that a single vesicle is often formed through multiple transfer events of virus from blood to epithelium. The rare findings of FMDV-3D and capsid antigen positivity in dermal cytokeratin-negative cells supports the notion that a population of non-epithelial cells becomes infected as lesions progress. But, the role of these cells is unclear. It is possible that despite the rarity of detection of such cells, they do play a significant role in vesicle maturation. Additionally, since these cells are identified near mature lesions, it is not possible to discern whether the FMDV antigens contained within these cells came from the vasculature or the adjacent vesicle.

As dermal papillary microvesiculation proceeds to cavitation, the basal lamina is necessarily breached exposing the dermis; hence, each such occurrence, technically, is an 
ulceration (ulcer in situ). However this process is morphologically distinct from the true ulceration of the deep basal lamina occasionally seen in advanced vesicles. The finding of relative abundance of FMDV / MHCII - double positive cells subjacent to disrupted basement membranes in regions of true ulceration also is distinct from the characteristics of vesicle maturation described above (ulcer in situ). It is likely that in such instances the observed viral antigens are contained within dermal phagocytic cells which are engaged in the elimination of foreign material and necrotic cellular debris. These cells are more likely involved in resolution of the lesion rather than progression. However, it has been suggested that in early FMDV infection, the major systemic viral amplification occurs in various epithelial sites. ${ }^{1}$ This hypothesis is not definitively ruled out by our current work.

In the characterization of FMD vesicles, authors commonly describe affected regions of skin and oral cavity using nomenclature which is appropriate for typical epithelia with uniformly lamellar strata (i.e strata basale, spinosum, granulosum, corneum). However, the typical FMD lesion sites (interdigital skin, coronary band, tongue, and snout) all are comprised of an epithelium which is anatomically complicated by the interdigitation of long dermal papillae with epithelial pegs. This arrangement presumably provides greater resistance to abrasion through a greater surface area of adhesion between basal cells and dermis. The complication arises in that the dermal papillae insert dermal tissue outwardly to regions which are superficial to subjacent regions of epidermis. This leads to the similarly awkward arrangement of basal cells surrounding dermal papillae which (in two dimensions) are superficial to apparently subjacent spinous keratinocytes. This concept is more than just semantic in that our observation that vesicles propagate initially through infection of peripapillary basal cells 
suggests that these cells have increased susceptibility to FMDV infection relative to adjacent spinous cells. This may be a biological vulnerability due to differential expression of virus receptors ${ }^{17,19}$ or other factors or simply a physical characteristic purely associated with proximity to virus exiting dermal capillaries.

The finding of supracoronary hair follicle mural microabscesses with identification of FMDV antigens is novel, but not surprising. Sub-gross ${ }^{10}$ and grossly detectable ${ }^{20}$ lesions of haired skin have been reported in FMDV-infected livestock and, FMDV has been isolated from the non-lesional haired skin of cattle. ${ }^{9,10}$ Localizing FMDV to porcine follicular epithelium has implications to understanding of FMD pathogenesis as it suggests that these cells have biological qualities which confer a susceptibility to infection similar to keratinocytes of classic lesion sites.

The IHC and IF techniques we have described will facilitate various aspects of FMDV investigation. With more thorough examination of sensitivity and specificity, rapid and effective diagnostic tests could easily be validated which could readily be utilized by laboratories lacking resources for diagnosis through PCR or VI. As research tools, these techniques have allowed precise localization of FMDV in various stages of infection which will be described in greater detail in Chapter 4 . 


\section{Chapter 3 Tables}

Table 3.1 Comparison of epitope retrieval techniques for unmasking of FMDV immunoreactivity in paraformaldehyde-fixed bovine tissues. ${ }^{*}$

\begin{tabular}{|c|c|c|c|}
\hline \multirow{2}{*}{ Heat-induced epitope retrieval } & \multirow[b]{3}{*}{+} & \multirow[b]{2}{*}{ 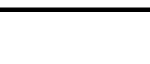 } & \multirow[b]{3}{*}{+} \\
\hline & & & \\
\hline autoclave in Reveal $^{\mathrm{TM}, \mathrm{d}}$ & & ++ & \\
\hline autoclave in Diva ${ }^{\mathrm{TM}, \mathrm{d}}$ & ++++ & +++ & ++ \\
\hline autoclave, citrate $(\mathrm{pH} 6.0)^{\mathrm{c}}$ & + & ++ & + \\
\hline autoclave, citrate $(\mathrm{pH} \mathrm{6.2})^{\mathrm{c}}$ & ++ & +++ & + \\
\hline autoclave, citrate $(\mathrm{pH} 9.0)^{\mathrm{c}}$ & + & + & + \\
\hline rice cooker, citrate $(\mathrm{pH} 6.2)^{\mathrm{c}}$ & - & - & + \\
\hline rice cooker, citrate $(\mathrm{pH} \mathrm{6.0})^{\mathrm{c}}$ & - & - & - \\
\hline Enzymatic epitope retrieval & $5 \mathrm{~min}$ & $10 \min$ & $30 \mathrm{~min}$ \\
\hline $\operatorname{trypsin}^{d}$ & - & - & - \\
\hline pepsin $^{d}$ & + & ++++ & +++ \\
\hline pronase $^{d}$ & - & +++ & - \\
\hline proteinase- $\mathrm{K}^{\mathrm{e}}$ & - & - & - \\
\hline
\end{tabular}




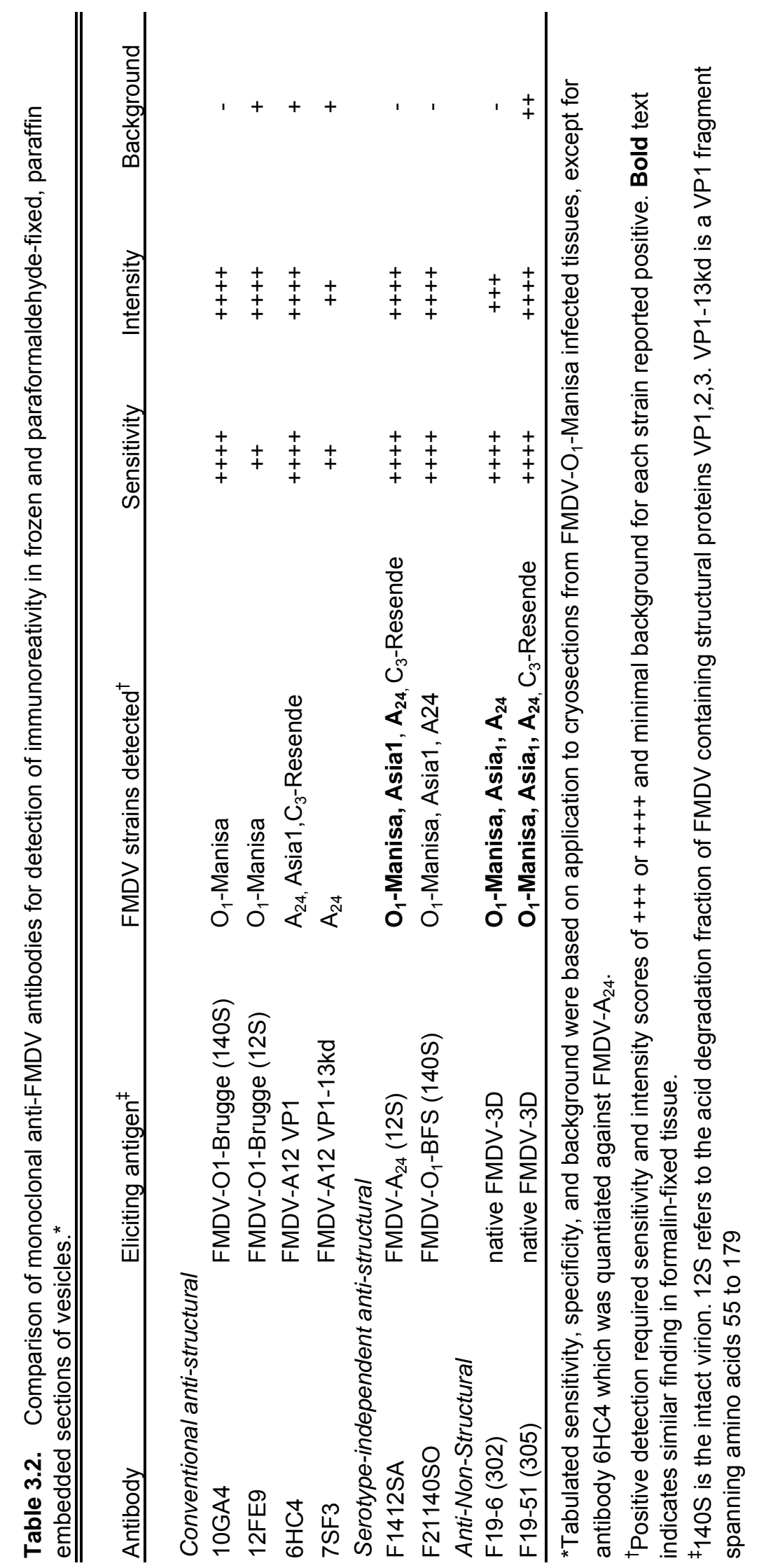




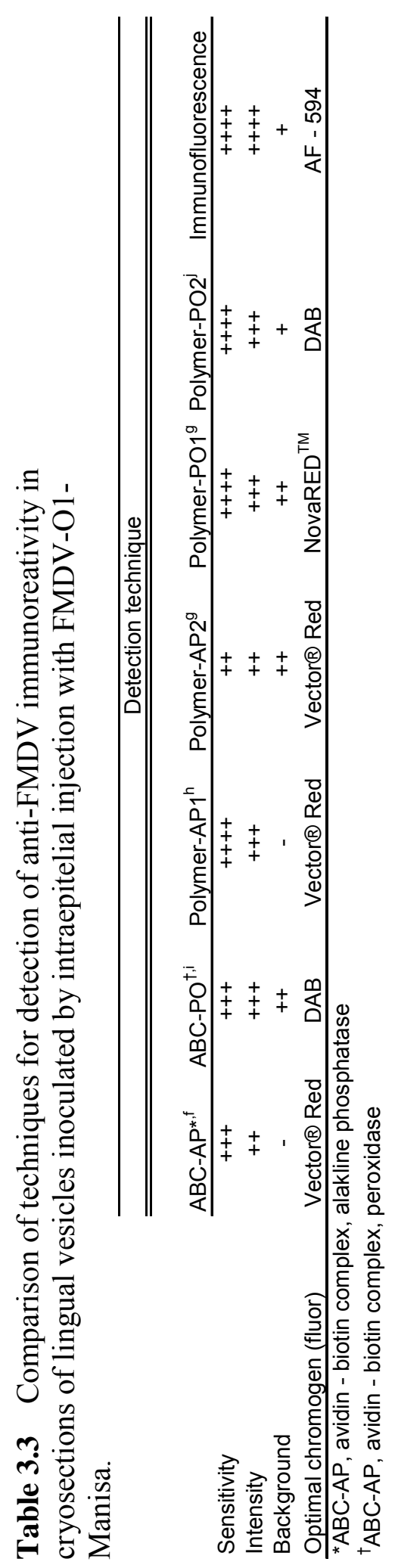




\section{Chapter 3 Figures}
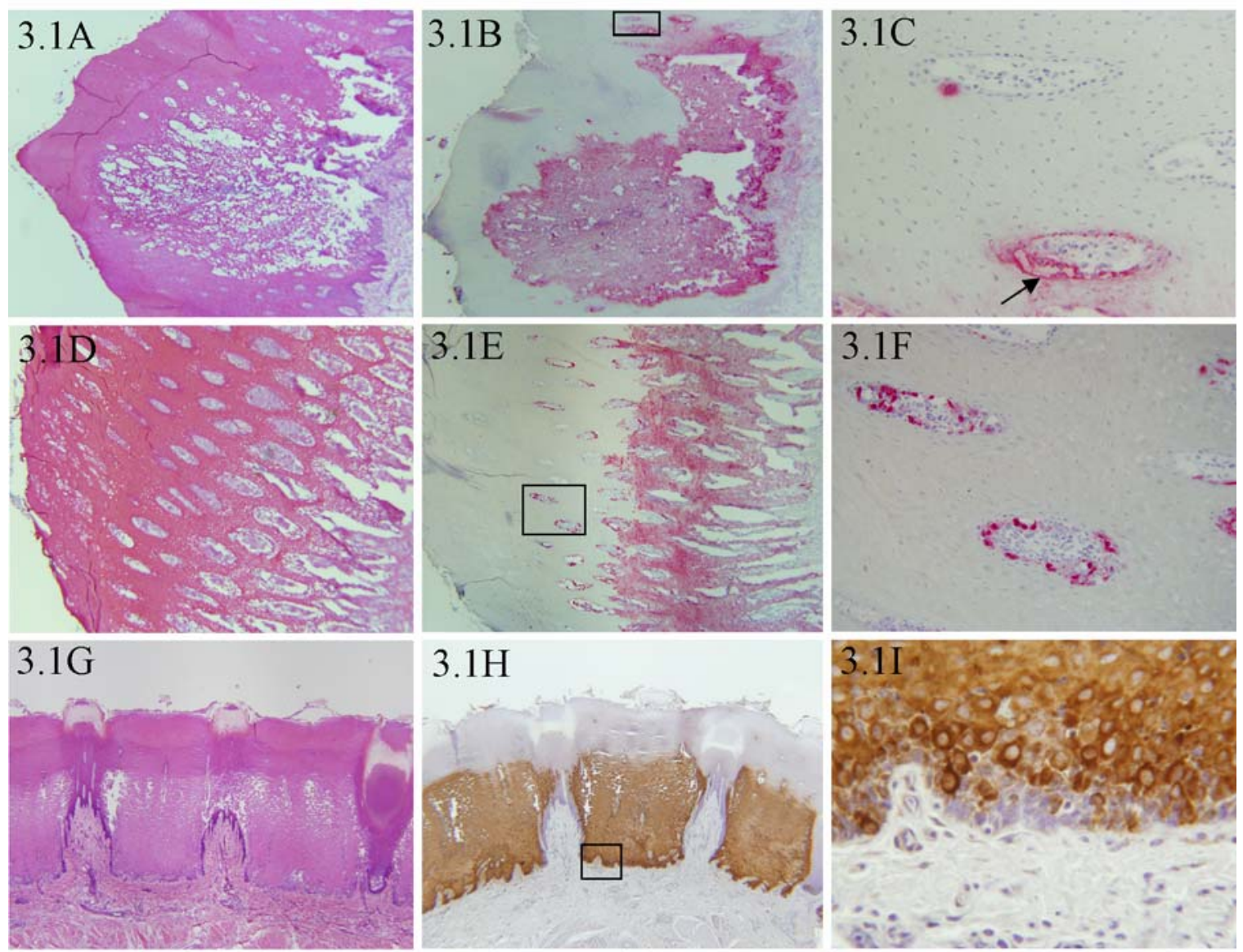

\section{$3.1 \mathrm{H}$}
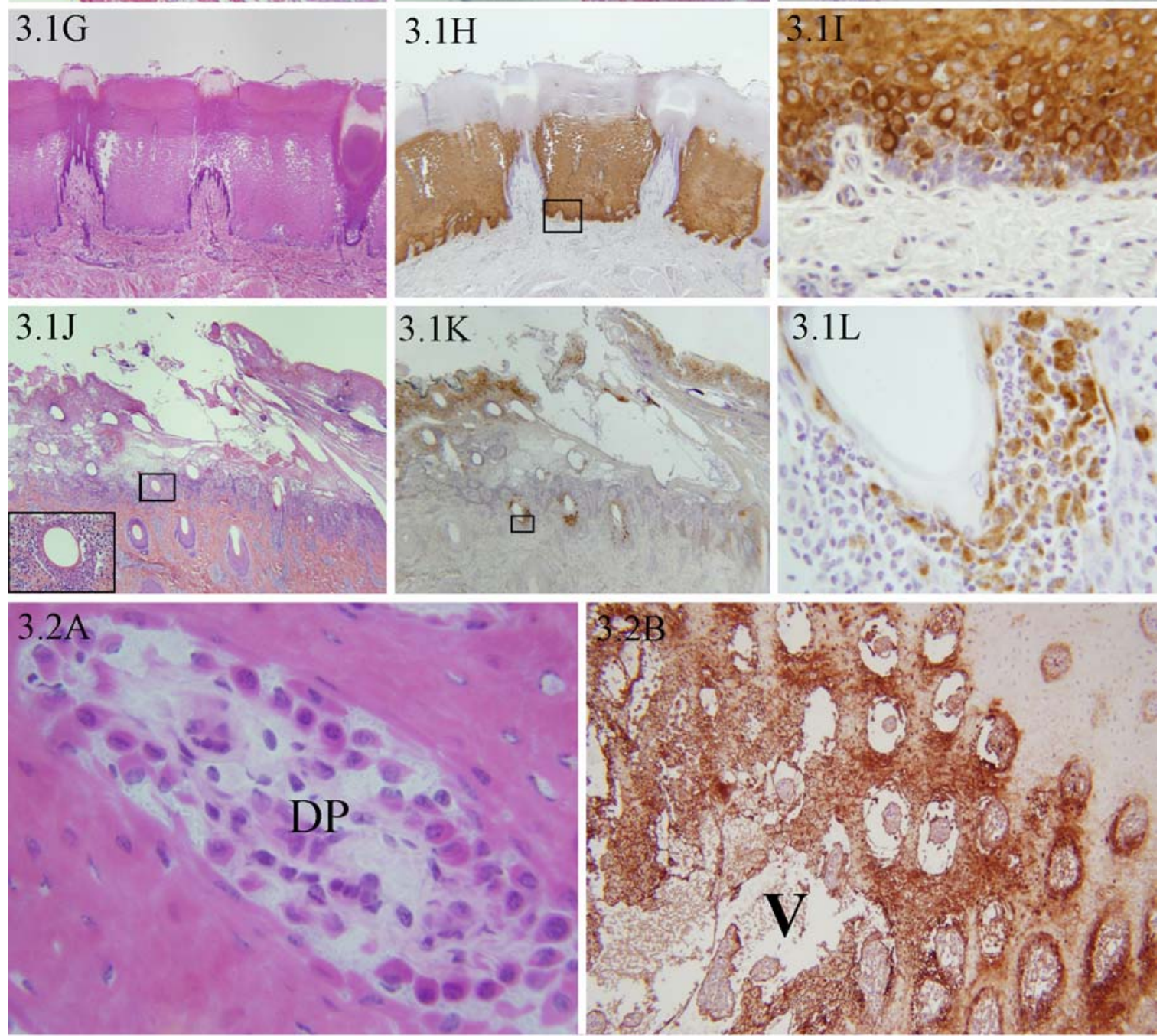
Figure 3.1. Light microscopy of FMD vesicles. 3.1A - F, cryosections. 3.1G - L, PLPfixed paraffin embedded. Column 1: Hematoxylin and eosin. Column 2: anti-FMDV immunohistochemistry, low magnification. Column 3: anti-FMDV IHC high magnification of region of interest identified in column 2 .

3.1A - C, Bovine 7200, lingual torus. Vesicle spanning strata basale - spinousum (3.1A) is strongly immunopositive (3.1B). 3.1C, At vesicle edge dermal papilla, immunopositive basal cells form an early suprabasilar microvesicle (arrow). Anti-FMDV structural Ab 10GA4, Micropolymer IHC-alkaline phosphatase. $\quad B a r=400 \mu \mathrm{m}(3.1 \mathrm{~A}, \mathrm{~B}) ; 50 \mu \mathrm{m}$ (3.1C).

3.1D - F, Pig 18566, snout. 3.1D, Epithelial degeneration and cavitation diffusely surrounding deep dermal papillae. Bar $=400 \mu \mathrm{m}$. 3.1E - F, Superficial to dense band of immunopositivity, numerous papillae have immunopositive cells peripherally and internally. Anti-FMDV serotype-independent structural Ab F1412. Micropolymer IHCalkaline phosphatase. Bar $=500 \mu \mathrm{m}(3.1 \mathrm{E}) ; 100 \mu \mathrm{m}(3.1 \mathrm{~F})$.

3.1G - I, Bovine 6100, tongue. 3.1G, Vesicle identified as region of rarefaction and pallor with minimal cavitation. Bar $=500 \mu \mathrm{m}$. 3.1H - I, Extensive immunoreactivity is strongest in basal cells. Anti-FMDV serotype-independent structural Ab F1412. Micropolymer IHC-peroxidase. Bar $=400 \mu \mathrm{m}(3.1 \mathrm{H})$; Bar $=30 \mu \mathrm{m}$ (3.1I).

3.1J - L, Pig 18566, junction of coronary band - haired skin. 3.1J, Vesicular cleft spans the entire section. Bar $=500 \mu \mathrm{m}$. 3.1J (inset), Suppurative mural folliculits at isthmus of several follicles. Bar $=20 \mu \mathrm{m}$. 3.1K, Immunoreactivity is strongest in superficial keratinocytes and follicular epithelium. Bar $=400 \mu \mathrm{m}$. 3.1L, Immunopositive follicular epithelial cells and immunonegative neutrophils. Anti-FMDV 3D Ab F19-6. Micropolymer IHC-peroxidase. Bar $=30 \mu \mathrm{m}$.

Figure 3.2. Dermal papillae (DP) at the periphery of FMD vesicles. 3.2A, steer 7200, cryosection of lingual torus. Acantholytic basal cells collapse into dermal papillary stroma. H \& E. Bar $=20 \mu \mathrm{m}$. 3.2B, steer 7200, PLP-fixed paraffin embedded, interdigital skin. Immunopositive cells surrounding papillae coalesce into expanding vesicle (V). Ab F19-6, IHC-micropolymer peroxidase. Bar $=200 \mu \mathrm{m}$. 

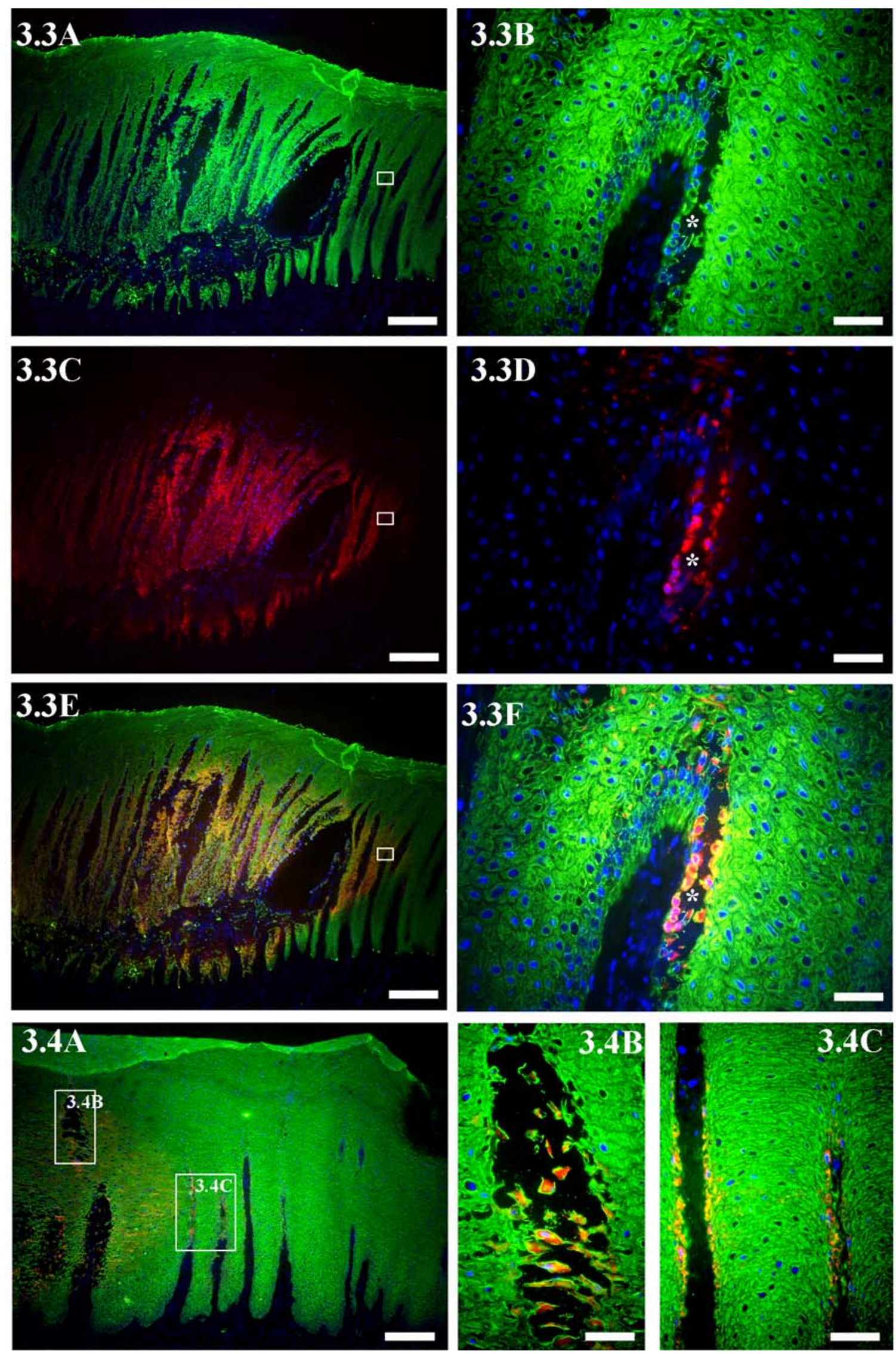
Figure 3.3. Steer 762, IF of lingual vesicle. 48hpa FMDV-O1-Manisa. Pancytokeratin (pCK) green, FMDV-3D red, colocalization yellow in merge, nuclei blue. Right column higher magnification of region of interest identified in left, low magnification image.

3.3A,C,E. FMDV colocalizes with pCK within the vesicle. Bar $=500 \mu \mathrm{m}$. 3.3B,D,F. At vesicle edge, a suprabasilar, microvesicular cleft $(*)$ has formed by dissociation of viruspositive papillary basal cells from overlying keratinocytes. Bar $=50 \mu \mathrm{m}$.

Figure 3.4. Steer 732, IF of periphery of lingual vesicle. 24hpi-IEL FMDV-O1-Manisa. Pancytokeratin ( $\mathrm{pCK}$ ) green, FMDV-3D red, colocalization yellow, nuclei blue. Right column higher magnifications of regions of interest identified in left, low magnification image. 3.4B, Maturing papillary microvesicle with acantholytic double positive cells filling the papillary space. 3.4C, At the leading edge of the vesicle, FMDV colocalizes with pCK only in intact papillary basal cells. Bar $=200 \mu \mathrm{m}$. (3.4A); Bar $=50 \mu \mathrm{m}$ $(3.4 \mathrm{~B}, \mathrm{C})$. 

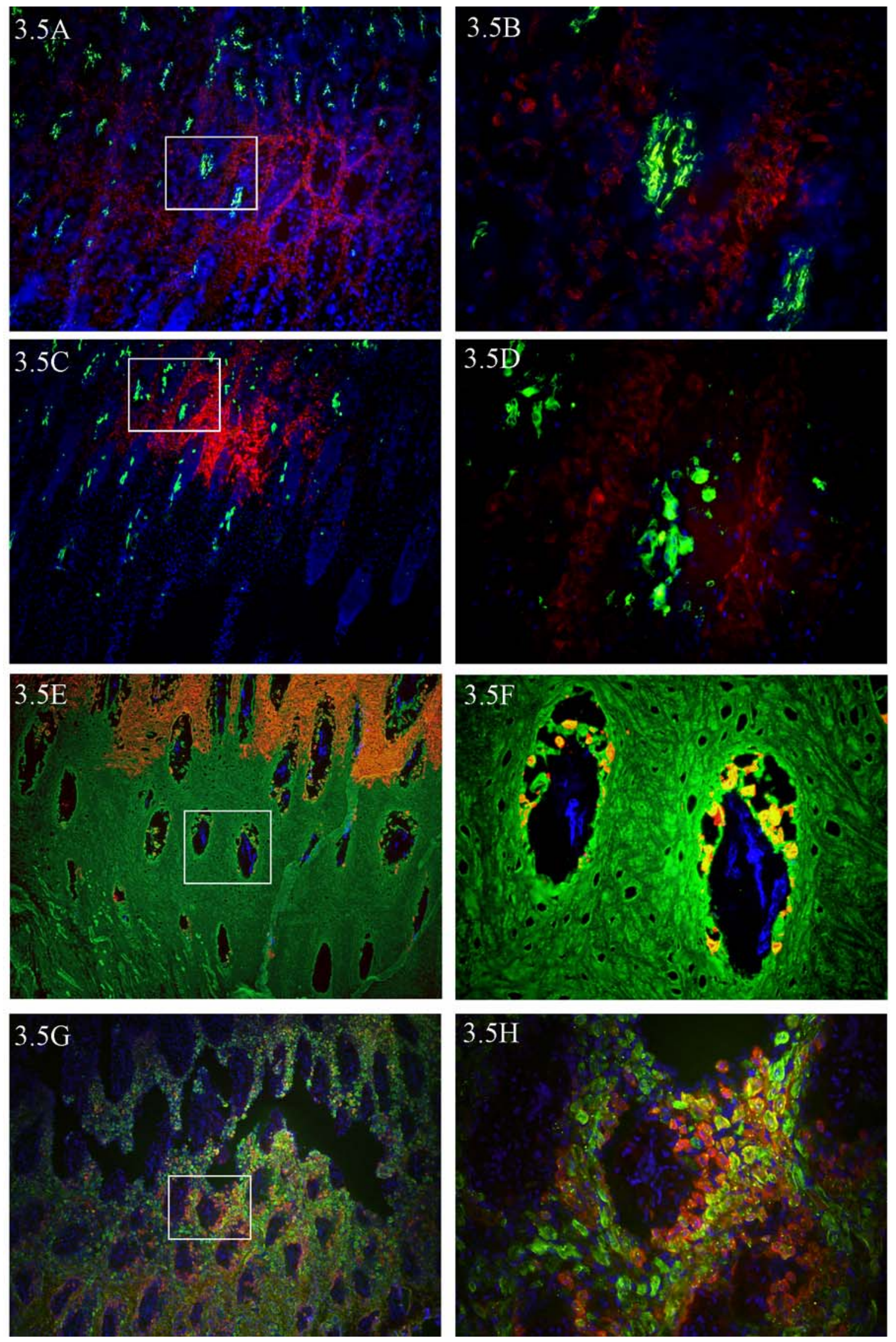
Figure 3.5. Pig 18566, IF of snout vesicle. 5dpi-IEHB FMDV-Asia1-A1. Right column higher magnification of area of interest identified in left, low magnification image. 3.5A B, S100 protein (green) localizes to dermal papillae, FMDV-3D (red) localizes to keratinocytes (not labeled), colocalization not present, nuclei blue. 3.5C - D, MHC-II (green) localizes to dermal papillae, FMDV-3D (red) localizes to keratinocytes (not labeled), colocalization not present, nuclei blue. 3.5E - F, Cytokeratin-14 (CK-14) green, FMDV-3D red, colocalization yellow/orange showing double positive keratinocytes degenerating and dissociating under suprabasilar cleft (*); MHC-II (blue) does not colocalize with FMDV. 3.5G - H, FMDV-3D green, FMDV-capsid red, colocalization yellow/orange, nuclei blue. Within epithelium, keratinocytes have variable colocalization of structural and non-structural antigens. Bar $=200 \mu \mathrm{m} .(3.5 \mathrm{~A}, \mathrm{C}, \mathrm{E}, \mathrm{G}) ; \mathrm{Bar}=50 \mu \mathrm{m}$ (3.5B, D, F, H). 

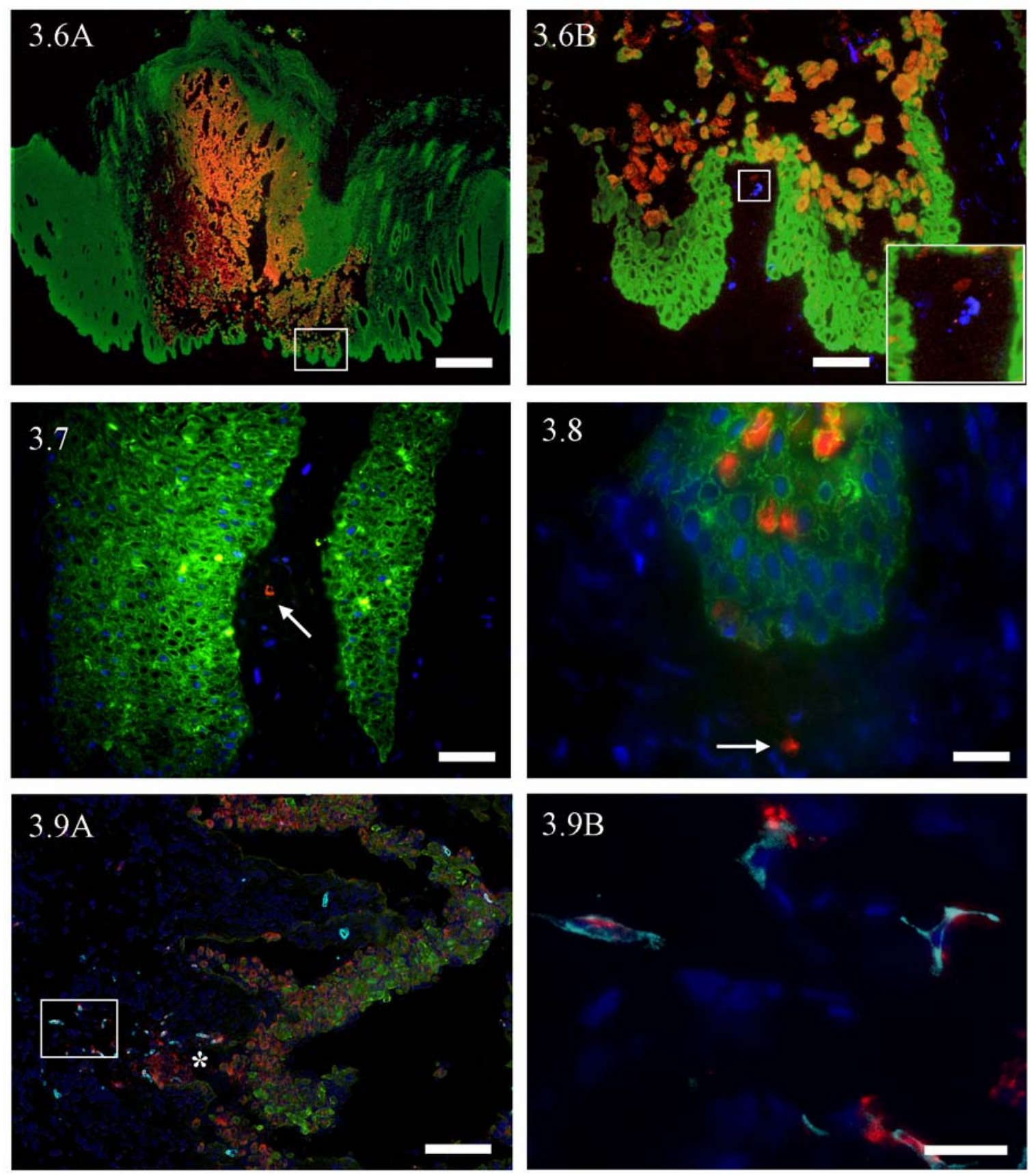

Figure 3.6. Steer 7200, IF of lingual vesicle. 48hpa FMDV-O1-Manisa. Pancytokeratin (pCK) green, FMDV-3D red, S100 blue, colocalization of FMDV with pCK is yellow/orange within vesicle acantholytic keratinocytes. 3.6B (inset) FMDV localizes in dermis in close proximity to S100 - positive cells. Bar $=500 \mu \mathrm{m}(3.6 \mathrm{~A})$; Bar $=50 \mu \mathrm{m}$ (3.6B).

Figure 3.7. Pig 871, IF of tissue subjacent to interdigital vesicle. 6 DPI FMDV-C3Resende. Pancytokeratin (pCK) green, FMDV-3D red, nuclei blue. FMDV-positive/pCKnegative cell within dermis (arrow). Bar $=50 \mu \mathrm{m}$.

Figure 3.8. Steer 732, IF of deep aspect of lingual vesicle. 24hpi-IEL FMDV-O1-

Manisa. Pancytokeratin (pCK) green, FMDV-3D red, colocalization yellow, nuclei blue. FMDV-positive/CK-negative cell within dermis (arrow). Bar $=20 \mu \mathrm{m}$. 
Figure 3.9. Steer 762, IF of interdigital vesicle. 48hpa FMDV-O1-Manisa.

Pancytokeratin (pCK) green, FMDV-capsid red, MHC-II aqua, nuclei blue. At region of deep ulceration (3.9A [*], several FMDV-positive cells (presumptive dendritic cells) within dermis are MHC-II positive. $\mathrm{Bar}=100 \mu \mathrm{m}$ (3.9A); $\mathrm{Bar}=20 \mu \mathrm{m}$ (3.9B). 


\title{
Sources and manufacturers
}

\author{
a. Sakura Finetek, Torrance, CA \\ b. Fisher Scientific, Pittsburgh, PA \\ c. Dako, Carpinteria, CA \\ d. Biocare Medical, Concord, CA \\ e. Sigma-Aldrich, St. Louis, MO \\ f. Vectastain ABC-AP, Vector Laboratories, Burlingame, CA \\ g. EnVision ${ }^{\mathrm{TM}} \mathrm{G} \mid 2$ System, Dako, Carpinteria, CA \\ h. MACH 3 Mouse AP Polymer, Biocare Medical, Concord, CA \\ i. Invitrogen, Camarillo, CA \\ j. ImmPRESS Anti-Mouse Ig (peroxidase), Vector Laboratories, Burlingame, CA \\ k. Vector Red Substrate Kit, Vector Laboratories, Burlingame, CA \\ 1. ImmPACT DAB Substrate, Vector Laboratories, Burlingame, CA \\ m. Vector NovaRED Substrate Kit, Vector Laboratories, Burlingame, CA \\ n. VMRD, Pullman, WA \\ o. Molecular Probes, Eugene, OR \\ p. Vector Laboratories, Burlingame, CA
}




\section{Chapter 3 References}

1. Alexandersen S, Zhang Z, Donaldson AI, Garland AJ: 2003 Jul, The pathogenesis and diagnosis of foot-and-mouth disease. J Comp Pathol 129:1-36.

2. Baxt B, Vakharia V, Moore DM, et al.: 1989, Analysis of neutralizing antigenic sites on the surface of type A12 foot-and-mouth disease virus. J Virol 63:2143-2151.

3. Brown CC, Meyer RF, Olander HJ, et al.: 1992 Jul, A pathogenesis study of foot-andmouth disease in cattle, using in situ hybridization. Can J Vet Res 56:189-193.

4. Brown CC, Piccone ME, Mason PW, et al.: 1996 Aug, Pathogenesis of wild-type and leaderless foot-and-mouth disease virus in cattle. J Virol 70:5638-5641.

5. Buckweitz S, Kleiboeker S, Marioni K, et al.: 2003, Serological, reverse transcriptasepolymerase chain reaction, and immunohistochemical detection of West Nile virus in a clinically affected dog. J Vet Diagn Invest 15:324-329.

6. Cornish TE, Stallknecht DE, Brown CC, et al.: 2001, Pathogenesis of experimental vesicular stomatitis virus (New Jersey serotype) infection in the deer mouse (Peromyscus maniculatus). Vet Pathol 38:396-406.

7. Durand S, Murphy C, Zhang Z, Alexandersen S: 2008, Epithelial Distribution and Replication of Foot-and-Mouth Disease Virus RNA in Infected Pigs. J Comp Pathol 139:86-96.

8. Frenkel HS: 1949, Histologic changes in explanted bovine epithelial tongue tissue infected with the virus of foot-and-mouth disease. Am J Vet Res 10:142-145.

9. Gailiunas P, Cottral GE: 1966, Presence and persistence of foot-and-mouth disease virus in bovine skin. J Bacteriol 91:2333-2338.

10. Gailiunas P: 1968, Microscopic skin lesions in cattle with foot-and-mouth disease. Arch Gesamte Virusforsch 25:188-200.

11. Gregg DA, Mebus CA, Schlafer DH: 1995, A comparison of three avidin-biotin complex immunoenzyme systems for detection of African swine fever virus antigen in paraffin-embedded tissues. J Vet Diagn Invest 7:17-22.

12. Haines DM, Clark EG, Dubovi EJ: 1992, Monoclonal antibody-based

immunohistochemical detection of bovine viral diarrhea virus in formalin-fixed, paraffinembedded tissues. Vet Pathol 29:27-32.

13. Hancock WW, Becker GJ, Atkins RC: 1982, A comparison of fixatives and immunohistochemical technics for use with monoclonal antibodies to cell surface antigens. Am J Clin Pathol 78:825-831.

14. Juleff N, Windsor M, Reid E, et al.: 2008, Foot-and-mouth disease virus persists in the light zone of germinal centres. PLoS ONE 3:e3434.

15. McLean IW, Nakane PK: 1974, Periodate-lysine-paraformaldehyde fixative. A new fixation for immunoelectron microscopy. J Histochem Cytochem 22:1077-1083.

16. Mohan MS, Gajendragad MR, Gopalakrishna S, Singh N: 2008, Comparative study of experimental Foot-and-Mouth Disease in cattle (Bos indicus) and buffaloes (Bubalis bubalus). Vet Res Commun 32:481-489.

17. Monaghan P, Gold S, Simpson J, et al.: 2005, The alpha(v)beta6 integrin receptor for Foot-and-mouth disease virus is expressed constitutively on the epithelial cells targeted in cattle. J Gen Virol 86:2769-2780.

18. Monaghan P, Simpson J, Murphy C, et al.: 2005, Use of confocal

immunofluorescence microscopy to localize viral nonstructural proteins and potential 
sites of replication in pigs experimentally infected with foot-and-mouth disease virus. $\mathrm{J}$ Virol 79:6410-6418.

19. O'Donnell V, Pacheco J, Gregg D, Baxt B: 2009, Analysis of foot-and-mouth disease virus integrin receptor expression in tissues from naive and infected cattle. J Comp Pathol 141:98-112, 2009.

20. Oem JK, Yeh MT, McKenna TS, et al.: 2008, Pathogenic characteristics of the Korean 2002 isolate of foot-and-mouth disease virus serotype $\mathrm{O}$ in pigs and cattle. $\mathrm{J}$ Comp Pathol 138:204-214.

21. Pacheco JM, Arzt J, Rodriguez LL: 2008, Early events in the pathogenesis of footand-mouth disease in cattle after controlled aerosol exposure. Vet J.

22. Prato Murphy ML, Forsyth MA, Belsham GJ, Salt JS: 1999, Localization of footand-mouth disease virus RNA by in situ hybridization within bovine tissues. Virus Res 62:67-76.

23. Ramos-Vara JA, Miller MA: 2006, Comparison of two polymer-based immunohistochemical detection systems: ENVISION+ and ImmPRESS. J Microsc 224:135-139.

24. Ramos-Vara JA, Kiupel M, Baszler T, et al.: 2008, Suggested guidelines for immunohistochemical techniques in veterinary diagnostic laboratories. J Vet Diagn Invest 20:393-413.

25. Sabattini E, Bisgaard K, Ascani S, et al.: 1998, The EnVision++ system: a new immunohistochemical method for diagnostics and research. Critical comparison with the APAAP, ChemMate, CSA, LABC, and SABC techniques. J Clin Pathol 51:506-511. 26. Seibold HR: 1963, A Revised Concept of the Lingual Lesions in Cattle with Footand-Mouth Disease. Am J Vet Res 24:1123-1130.

27. Stave JW, Card JL, Morgan DO: 1986, Analysis of foot-and-mouth disease virus type O1 Brugge neutralization epitopes using monoclonal antibodies. J Gen Virol 67 ( Pt 10):2083-2092.

28. Woodbury EL, Ilott MC, Brown CC, Salt JS: 1995, Optimization of an in situ hybridization technique for the detection of foot-and-mouth disease virus in bovine tissues using the digoxigenin system. J Virol Methods 51:89-93.

29. Yang M, Clavijo A, Li M, et al.: 2007, Identification of a major antibody binding epitope in the non-structural protein 3D of foot-and-mouth disease virus in cattle and the development of a monoclonal antibody with diagnostic applications. J Immunol Methods 321:174-181.

30. Yang M, Clavijo A, Suarez-Banmann R, Avalo R: 2007, Production and characterization of two serotype independent monoclonal antibodies against foot-andmouth disease virus. Vet Immunol Immunopathol 115:126-134.

31. Yilma T: 1980 Sep, Morphogenesis of vesiculation in foot-and-mouth disease. Am J Vet Res 41:1537-1542.

32. Zhang ZD, Kitching RP: 2001, The localization of persistent foot and mouth disease virus in the epithelial cells of the soft palate and pharynx. J Comp Pathol 124:89-94. 


\title{
Chapter 4
}

\section{A time-course investigation of the early pathogenesis of foot-and-mouth disease in cattle utilizing novel aerosol inoculation and immunolocalization techniques}

\begin{abstract}
In order to characterize the early events of foot - and - mouth disease virus (FMDV) infection in cattle subsequent to simulated natural exposure, sixteen steers were aerosolinoculated with FMDV and euthanized at various times [hours post aerosolization (hpa)]. Antemortem (serum, nasal swabs, and oral swabs) and postmortem (up to 40 tissues per animal) samples were collected from each steer and screened for FMDV by virus isolation and for FMDV RNA by real-time reverse transcription polymerase chain reaction (rRT-PCR). Tissues that tested positive for FMDV or viral RNA were examined by immunohistochemistry (IHC) and multi-channel immunofluorescence (MIF) microscopy. In previremic steers, FMDV was most consistently localized to nasopharyngeal tissues indicating this region as the most important site of primary viral replication. The earliest site of microscopic localization of FMDV antigens was the lymphoid follicle-associated epithelium of the mucosa - associated lymphoid tissue (PALT) of the nasopharynx at 6 hpa. At early time points after aerosol inoculation, viral antigens colocalized with cytokeratin-positive pharyngeal epithelial cells; intraepithelial FMDV-negative, MHCII/CD11c-double positive dendritic cells were present in close proximity to FMDV-positive cells. Onset of viremia coincided with marked increase of
\end{abstract}


viral loads in pulmonary tissues and substantial decrease of viral detection in nasopharyngeal tissues. These data indicate that subsequent to aerogenous exposure to FMDV, the temporally defined critical pathogenesis events are (1) primary replication in epithelial cells of the PALT crypts, (2) subsequent widespread replication in pneumocytes in the lungs which coincides with (3) the establishment of sustained viremia.

\section{Introduction}

Foot-and-mouth disease (FMD) is a highly contagious picornaviral disease affecting domestic and wild cloven-hoofed animals. ${ }^{2,13}$ Under natural transmission conditions, within and between herds of cattle, the etiologic agent, FMD virus (FMDV), is spread through inhalation of aerosolized virus, and under appropriate environmental conditions, virus-laden droplets may travel vast distances whilst maintaining infectivity. ${ }^{1,13,22}$

The pathogenesis of FMD in cattle has been experimentally investigated by numerous researchers ${ }^{1,4,6,7,14,15}$ however, a consensus still does not exist regarding many basic aspects of the early stages of infection. Most notably, the anatomic sites and cellular events involved in primary infection and the establishment of viremia are not well defined. Elucidation of these critical events and improved understanding of virus-host interactions have high probability to favorably impact the goal of improving efficacy of vaccines and biotherapeutic countermeasures to protect domestic livestock against FMDV. 
Early evidence that the respiratory tract was the natural route of infection implicated the nasal cavity ${ }^{14}$ or lungs ${ }^{10}$ as the sites of primary replication. Yet, as investigation proceeded, opinion on this subject diverged into two camps favoring either the nasopharynx $x^{2,7}$ or lungs ${ }^{4,6}$ as the primary infection site. A unique set of experiments performed in the 1970s effectively isolated the contributory roles of the upper and lower respiratory tract by placement of indwelling tracheostomy tubes in cattle. ${ }^{24}$ This work concluded that both the lungs and pharynx could similarly serve as portals for the establishment of systemic infection. The only studies to microscopically localize FMDV in the early (previremic) stages of infection utilized in situ hybridization and concluded that lungs supported infection earlier than the pharynx ${ }^{4,6}$ In consideration of the disparate findings across FMD pathogenesis studies it is necessary to remember that the various studies have utilized a broad range of serotypes and subtypes of FMDV which may have substantial differences in virulence and tissue tropism. Additionally, heterogeneity of inoculation systems and differences in sensitivity and/or specificity of virus detection methods may account for some disparity amongst the published studies.

Recent reports from our laboratory have described a novel method for aerosol inoculation of cattle with FMDV and trimodal systems for detection of FMDV in bovine tissues during the early stages of infection. ${ }^{3,18}$ In the current study, we utilize similar experimental systems to further characterize the distribution of FMDV in cattle during the previremic and early viremic phases of infection with the overall conclusion that subsequent to aerogenous inoculation of cattle, infection initiates in the nasopharynx, is promptly followed by pulmonary infection, and that the onset of viremia is coincident with increased viral load in the lungs and decreased virus in the nasopharynx. 


\section{Materials and methods}

Experimental animals, virus, and inoculation systems

Sixteen 9-18 month-old Holstein steers weighing 400-500 kg were obtained from an AAALAC-accredited experimental-livestock provider (Thomas-Morris Inc., Reisterstown, MD). For all experiments, animals were housed individually in a BSL-3 animal facility from time of inoculation until time of euthanasia. Experiments were terminated by euthanasia via intravenous barbiturate overdose at predetermined end points at 0.1 hours post aerosol inoculation (hpa; steer No. 1), 3 hpa (steer No. 2, 3), 6 hpa (steer No. 4, 5), 12 hpa (steer No. 6, 7), 24 hpa (steer No. 8-13), 48 hpa (steer No. 14, 15), 240 hpa (steer No. 16).

Virus inoculum consisted of a clarified, macerate of tongue epithelium harvested from two steers experimentally infected with the FMDV strain $\mathrm{O}_{1}$-Manisa as previously described. ${ }^{12,18}$ The inoculum was quantitated as bovine tongue infectious dose $50 \%$ $\left(\mathrm{BTID}_{50}\right)$. All steers were aerosol - inoculated with $10^{7}$ BTID $_{50}$ of FMDV-O FManisa as $_{1}$ previously described. ${ }^{18}$ Briefly, each steer was sedated with xylazine and fitted with a commercially available aerosol delivery system (Aeromask-ES, Trudell Medical, London, Ontario, Canada) which was placed over the muzzle. The mask was attached to a jet nebulizer (Whisper Jet, Vital Signs Inc., Totowa, NJ) which was subsequently attached to an air compressor which generated 25 psi of pressure. Aerosolization proceeded until the complete inoculum was expelled from the nebulizer cup $(10-15$ minutes). 


\section{Sample collection}

Antemortem sampling consisted of collection of whole blood in serum separation tubes, oral swabs, and nasal swabs. All animals were sampled prior to inoculation to ensure FMDV - free status and at several time points throughout the duration of the experiment which varied according to goals of the individual experiments. Swabs and serum tubes were transported from the animal room to the laboratory on ice and were immediately centrifuged for harvesting of serum, saliva, and nasal secretion. Samples were then stored at $-70{ }^{\circ} \mathrm{C}$ until time of processing.

Necropsies were performed immediately subsequent to euthanasia at predetermined time points, and tissue specimens were collected from oral cavity, nasal cavity, soft palate, pharynx, larynx, trachea, lungs, lymph nodes and skin (Table 4.1). Tissues collected from each animal varied depending upon the goals of individual experiments. Detailed descriptions of tissue designations and collection strategies has

been published previously. ${ }^{18}$ For each anatomically defined specimen, two $30 \mathrm{mg}$ tissue samples were aliquoted into separate screw-cap $1.5 \mathrm{ml}$ tubes and frozen immediately in liquid nitrogen for transfer within $2 \mathrm{~h}$ to a $-70{ }^{\circ} \mathrm{C}$ freezer in which they were stored until the time of processing. An adjacent specimen from each tissue was placed in a cryomold, embedded in Optimal Cutting Temperature Compound (OCT) (Sakura Finetek, Torrance, $\mathrm{CA}$ ), frozen on a bath of liquid nitrogen, and stored at $-70{ }^{\circ} \mathrm{C}$ for immunohistochemistry.

Foot and mouth disease virus RNA detection

Two samples of each tissue listed in Table 4.1 per animal were thawed and immediately macerated in a TissueLyser bead beater (Qiagen, Valencia, CA) as 
previously described. ${ }^{18}$ After maceration, $50 \mu \mathrm{L}$ of each sample was transferred to a $96-$ well plate (Thermo Scientific, Waltham, MA) containing $150 \mu \mathrm{L}$ lysis/binding solution. RNA was then extracted using Ambion's MagMax-96 Viral RNA Isolation Kit (Ambion, Austin, TX) on a King Fisher-96 Magnetic Particle Processor (Thermo Scientific, Waltham, MA). RNA was eluted in a final volume of $25 \mu \mathrm{L}$. Once extracted, $2.5 \mu \mathrm{L}$ of RNA was analyzed by real-time reverse transcription polymerase chain reaction (rRTPCR) on the ABI 7000 system (Applied Biosystems, Austin, TX) as previously described. ${ }^{8}$ Samples with cycle threshold $(\mathrm{Ct})$ values $<40$ were considered positive. The remaining macerated tissue was clarified at $1000 \mathrm{rpm}$ for $2 \mathrm{~min}$ at $4{ }^{\circ} \mathrm{C}$ and the supernatant was cleared of bacterial contamination using centrifuge tube filters (Spin-X, Costar, Corning, NY). Clarified and cleared samples were stored at $-70^{\circ} \mathrm{C}$ until virus isolation (VI) was performed.

In order to convert $\mathrm{Ct}$ values generated by rRT-PCR from experimental samples to RNA genome copies per mg, serial, 10-fold dilutions of in vitro synthesized FMDV RNA of known RNA concentration were analyzed by the rRT-PCR protocol described above. The equation of the curve of RNA copy vs. Ct value, further adjusted for average mass of tissue samples and dilutions during processing, was used for subsequent conversions. The Ct positivity cutoff of 40 corresponded to a detection threshold value of $2.26 \log _{10}$ FMDV RNA copies/mg (RNA/mg) of tissue. rRT-PCR results reported in Table 4.1 are the higher RNA/mg value of the two samples processed per tissue per animal. rRT-PCR results reported in Figure 4.1 are the mean $\log _{10}$ FMDV RNA copies $/ \mathrm{ml}(\mathrm{RNA} / \mathrm{ml})$ for all animals sampled at each time point. 
Foot-and-mouth disease virus isolation

Virus isolation was performed separately on the duplicate samples of each tissue on LFBK cells as previously described. ${ }^{18,25}$ Upon detection of cytopathic effect (CPE), FMDV-positivity was confirmed by rRT-PCR on cell culture supernatants. Samples in which no CPE was observed were amplified through three blind passages and the supernatants tested by rRT-PCR before they were deemed negative. Each VI result in Table 4.1 is reported positive if either or both duplicate samples per tissue were positive.

\section{Immunohistochemical and immunofluorescent localization of FMDV antigens}

Microscopic localization of FMDV antigens was performed in cryosections as previously described. ${ }^{3,18}$ Briefly, tissue sections were blocked for $2 \mathrm{~h}$ at $20^{\circ} \mathrm{C}$; primary antibodies were diluted in blocking buffer and applied to tissue sections for $18 \mathrm{~h}$ at $4{ }^{\circ} \mathrm{C}$. For IHC, specific anti-FMDV immunoreactivity was detected with a micropolymer alkaline phosphatase kit (Biocare, Concord, CA). For multichannel immunofluorescence (MIF), detection was performed with goat, anti-rabbit and isotype-specific, anti-mouse secondary antibodies labeled with AlexaFluor dyes (AF - 350, 488, 594, 647). Slides were examined with a wide-field, epifluorescent microscope, and images were captured with a cooled, monochromatic digital camera. Images of individual detection channels were adjusted for contrast and brightness and merged in commercially available software (Adobe Photoshop, CS2). Mouse monoclonal anti-FMDV antibodies against viral structural proteins were $10 \mathrm{GA} 4$ and $12 \mathrm{AF} 4^{23}$; anti non-structural protein antibodies were F19-6 and F19-51. ${ }^{27}$ Antibodies used to label cell markers in MIF experiments were mouse monoclonal anti-pancytokeratin plus (Biocare \#CM162), anti-bovine cytokeratin 
(Sigma \#C6909), anti-CD11c (VMRD \#BAQ153A),anti-MHCII (VMRD \#CAT82A), and anti-vimentin (Dako \#M0725), and Rabbit polyclonal anti-Von Willibrand factor (Dako \#A0082).

For each tissue screened by IHC, a duplicate, negative-control serial section treated with a mouse monoclonal anti-VSV-Indiana antibody of similar concentration was prepared. Additional negative control tissue sections were prepared from a steer that received a virus-free aerosol inoculum and was euthanized $24 \mathrm{hpa}$. Immunohistochemical and MIF labeling were considered positive when there was an intense cell-associated signal within the experimental tissue with the absence of such staining in the negative controls.

\section{Results}

\section{Inoculum detection controls}

For the purpose of determining if the FMDV screening techniques would detect residual inoculated virus, one aerosol-inoculated steer (No. 1) was euthanized immediately after inoculation ( $0.1 \mathrm{hpa})$ and was subjected to standard tissue collection and screening techniques as described for the other animals. All 28 tissues collected from this animal were VI-negative, and only a single tissue, proximal cranial lung, was positive by rRT-PCR $(2.56 \mathrm{RNA} / \mathrm{mg})$. This information confirmed that the inoculum reached as far as the lungs, and also strongly affirmed that any rRT-PCR and VI positive findings at subsequent time points represent FMDV replicated de novo. Based on the positive rRT-PCR finding for proximal cranial lung from steer No. 1, the frozen OCT embedded tissue specimen from this tissue was examined by IHC to similarly test for 
detection of inoculated virus. Forty serial sections were examined (alternating antiFMDV capsid and anti-FMDV 3D [polymerase] primary antibodies) with no detection of FMDV antigens in any section confirming that inoculum quantity was insufficient to be detected by IHC. Data generated from this animal are not included in subsequent analyses in the current study.

\section{Antemortem profiles of FMDV-infected cattle}

Neither vesicles nor fever (rectal temperature $\geq 40^{\circ} \mathrm{C}$ ) were observed in any previremic animals. The earliest detection of fever in any animal occurred at $60 \mathrm{hpa}$ in steer No. 16; this animal was febrile from 60 to 96 hpa with maximum body temperature of $41^{\circ} \mathrm{C}$ detected at $60 \mathrm{hpa}$. The three steers euthanized as $48 \mathrm{hpa}$ or later (viremic) all developed vesicles of one ( $n=2)$ or two $(n=1)$ interdigital clefts at 48 hpa (Fig. 4.1). One steer (No. 15) had subtle blanching of the epithelium of the lingual torus at $48 \mathrm{hpa}$, which was subsequently determined histologically to be an early vesicle. The one steer which survived $240 \mathrm{hpa}$ (No. 16) developed vesicles of tongue and all four interdigital clefts between $48-120 \mathrm{hpa}$. No other clinical signs of infection or gross lesions were detected in the animals which survived $0.1-48 \mathrm{hpa}$.

The aerosol inoculation system provided highly consistent patterns of viral shedding, viremia, and clinical signs across experimental animals; however some interanimal variation was observed. Antemortem data are presented as cumulative average $\log _{10}$ FMDV genome copy numbers/ml (RNA/ml) for all animals at each time point (Fig. 4.1). For oral swab samples, the quantity of FMDV RNA (inoculum) progressively decreased from $0.1-6$ hpa with de novo replicated virus first detected at 24 hpa and 
peaking at $72 \mathrm{hpa}$ at $8.17 \mathrm{RNA} / \mathrm{ml}$. Similarly, nasal swab samples showed gradual elimination of inoculum from 0.1 to 4 hpa with de novo replicated viral RNA beginning to increase at 6 hpa. However, unlike oral swabs, the viral RNA quantity never dropped below detection threshold before de novo replication was detected (Fig. 4.1). Also unlike oral swabs, the nasal shedding pattern showed two peaks at 12 and 72 hpa (5.22 and 8.92 $\mathrm{RNA} / \mathrm{ml}$ respectively) with an intervening trough. Maximum nasal and oral FMDV $\mathrm{RNA} / \mathrm{ml}$ occurred coincidently at 72 hpa with the nasal detection peak being slightly higher, but decreasing more precipitously relative to salivary samples.

The earliest detection of FMDV RNA in sera occurred at $22 \mathrm{hpa}$ in 1 steer. At 24 hpa, six of nine steers had RNA-positive sera, and at $48 \mathrm{hpa}$ the sera of all three steers sampled were FMDV rRT-PCR positive (Fig. 4.1). Detection of infectious FMDV in sera was delayed relative to RNA with a single VI-positive steer (1/9) at 24 hpi and the remaining three steers (3/3) becoming serum VI-positive by 48 hpa; viremia was defined by the detection of infectious virus in serum. Overall, FMDV RNA was detected in sera from $22-120 \mathrm{hpa}$, whereas viremia was only detected from $24-72 \mathrm{hpa}$.

Tissue-specific distribution of FMDV and viral RNA

Steers were euthanized at predetermined time points regardless of clinical progression of disease in individual animals. Sample collection schemes were predetermined and standardized with minor variation among individual animals based upon the expected stage of disease at the time of euthanasia (Table 4.1). A maximum of 40 anatomically distinct tissue specimens were collected per animal. Both steers euthanized at 3 hpa had more FMDV RNA - positive tissues in the nasopharyngeal / 
laryngeal sites (NP/L) (6 of 12 tissues; 50.0\%) than other anatomic regions (2 of 18 pulmonary tissues; 11.1\%) (Table 4.1). At this time point FMDV RNA quantities were generally low and no tissues contained infectious virus. The two highest quantities of FMDV RNA were detected in caudal dorsal soft palate $(2.92 \mathrm{RNA} / \mathrm{mg})$ and caudal dorsal nasopharynx (2.95 RNA/mg) of steer No. 2.

From six to twelve hpa, within the NP/L sites there were greater quantity of tissues positive for infectious FMDV (14/24; 58.3\%) and viral RNA (13/24; 54.2\%) relative to all other anatomic regions; at twelve hpa every NP/L tissue examined was positive by VI, rRT-PCR, or both. Within this time period, rRT-PCR and VI positivity percentages for pulmonary specimens were also increasing, but to a lesser extent than NP/L tissues. At the individual tissue-specific level, the greatest quantities of FMDV RNA between six and twelve hpa were detected in distal cranial lung (5.12 RNA/mg) and caudodorsal nasopharynx (4.9 RNA/mg) of steer No. 7 (12 hpa).

At $24 \mathrm{hpa}, 97.2 \%$ (35/36 at tissue level) of NP/L samples were positive for either FMDV RNA or infectious virus with $72.2 \%$ double (VI and rRT-PCR) positives. By contrast, $61.1 \%$ of pulmonary specimens (22/36 at tissue level) were VI or rRT-PCR positive with $36.1 \%$ double positivity. The highest quantity of FMDV RNA at $24 \mathrm{hpa}$ (7.3 RNA/mg) was detected within rostral dorsal soft palate of steer No. 9. The only positive findings (rRT-PCR or VI) from lymph nodes of previremic steers in the study were the hilar lymph node of steer No. 11 and the medial retropharyngeal lymph node of steer No. 12 which were VI positive at $24 \mathrm{hpa}$.

Both steers euthanized at 48 hpa were viremic at the time of euthanasia; as such, infectious FMDV and FMDV RNA detected in the tissues of these animals may have 
been present within and/or exterior to blood vessels in these tissues. Viral load was substantially decreased in the NP/L at 48 hpa relative to 24 hpa with $66.6 \%$ (8 of 12 tissues) positive by VI or rRT-PCR and 33.3\% double positives. By contrast, VI or rRTPCR positivity of the lungs from 48 hpa steers was increased relative to $24 \mathrm{hpa}$ with $77.8 \%$ (14 of 18 tissues) single positives and $27.8 \%$ double positive tissues. The greatest quantity of FMDV RNA detected in these animals was from the interdigital clefts of both steers (7.70 and $7.96 \mathrm{RNA} / \mathrm{mg})$ and the lingual torus of steer No. 15 (6.19 RNA/mg) all of which had grossly detected vesicles. Among non-lesional tissues collected from the 48 hpa steers, the greatest quantity of FMDV RNA was obtained from distal anterior lung of steer No. 15 (5.54 RNA/mg).

As the primary goal of these experiments was to characterize the involvement of various tissues as primary replication sites of FMDV, greater attention was focused upon the animals which had VI - negative sera at the time of euthanasia (Table 4.1). For these animals (all except steers Nos. 13-16), tissue - specific, cumulative positivity percentages (PP) were calculated for each tissue for rRT-PCR, VI, and combined rRT-PCR or VI. The PP was defined as: total positive results at tissue $X$ by modality $Y$ in previremic steers / total specimens of tissue $X$ examined by modality $Y$ in previremic steers. Thus, PP served as an indicator of the relative frequency of involvement of each tissue in previremic FMD in these animals. The PP index demonstrated that among previremic animals, the specimens most frequently positive for infectious FMDV or FMDV RNA were the tissues of the NP/L. Specifically, the only $100 \%$ PP value occurred for rRT-PCR or VI positivity in rostrodorsal nasopharynx. The next highest PP values (81.8\%) were only achieved in caudodorsal soft palate and caudodorsal nasopharynx. Overall, fifteen of 
eighteen PP values from NP/L were greater than all PP from other tissues. PP values from lung and ventral soft palate indicate lesser consistency of FMDV positivity relative to NP/L. Positivity percentages values from lymphoid tissues were uniformly low, with lingual tonsil having the highest overall PP in this tissue category.

Microscopic localization of FMDV antigens and phenotypic characterizations of associated cells

Inoculation to twelve hours post aerosol inoculation.

Despite numerous attempts, FMDV antigens could not be microscopically (immunohistochemically) identified in any of the rRT-PCR-positive tissues from the steers euthanized at $3 \mathrm{hpa}$. The earliest time point at which viral antigens were localized in situ was at 6 hpa within the rostrodorsal nasopharynx of both steers (Nos. 4 and 5) euthanized at this time point. Viral antigens were not localized in any other tissues from these animals despite screening of over 100 additional IHC slides from pulmonary and pharyngeal sites that were rRT-PCR or VI positive. In both steers, FMDV capsid antigen was similarly localized to microscopic epithelial crypts of the follicle associated epithelium (FAE) overlying pharyngeal mucosa associated lymphoid tissue (PALT; Figs. 4.2-4.3). Although the epithelial crypts were vaguely discernable by IHC/light microscopy (Fig. 4.2), the multichannel immunofluorescent (MIF) examination of a serial section clearly demonstrated that FMDV in these regions was intraepithelial rather than within subjacent lymphoid tissue (Fig. 4.3a). Furthermore, simultaneous labeling with CD11c and MHCII indicated that the FAE and subjacent lymphoid regions had diffuse distribution of cells positive for both of these antigens individually and as CD11c/MHCII 
double positives (presumptive dendritic cells(DCs)), Figs. 4.3b-d). Despite the presence of DCs in close proximity to FMDV antigens, virus colocalized exclusively with cytokeratin (CK) in these tissues. Rarely, individual cells containing FMDV antigens were identified in the subepithelial dome region immediately subjacent to antigenpositive crypts, however phenotypic characterization of these cells with various markers was not achieved.

At $12 \mathrm{hpa}$, the distribution of viral antigens in the nasopharynx was similar to that observed at 6 hpa with the exception that there was slightly greater intimacy of association between FMDV antigens and the DC markers CD11c and MHCII. However, colocalization of FMDV antigens with DC markers was not observed. The lungs of both steers euthanized at $12 \mathrm{hpa}$ (Nos. 6-7) had regional anti-FMDV immunoreactivity (Figs. 4.4 - 4.7). Steer No. 7 had numerous FMDV capsid and nonstructural antigen-positive cells within the distal segment of the cranial lung lobe (Figs. 4.5 - 4.7). In this animal, there were two distinct morphological variants of immunopositive cells when viewed by light microscopy: a squamous cell type associated with alveolar septa (type I pneumocyte; Fig. 4.5, insert a), and a polygonal cell type variably associated with alveolar septa or lumina (type II pneumocyte or alveolar macrophage; Fig. 4. 5, insert b). Multichannel IF labeling of this tissue indicated that both morphologic categories of FMDV-positive cells were additionally cytokeratin-positive (Fig. 4.6a, 4.7), vWFnegative (Fig. 4.7), vimentin-negative (Fig. 4.6b) confirming that infected cells were of epithelial histogenesis. However, throughout the alveolar parenchyma, vWF- and vimentin-positive cells were ubiquitously interspersed with cytokeratin-positive pneumocytes (Figs. 4.6b, 4.7). The other steer euthanized at $12 \mathrm{hpa}$ (No. 6) had 
antigenically and morphologically distinct pulmonary viral distribution. The distal segment of the middle lung lobe of this animal had a single, small focus of immunopositivity for FMDV 3D protein (Fig. 4.4) that was negative for capsid antigens. Unlike steer No. 7, FMDV-positive cells in this region were exclusively squamous.

Twenty-four hours post aerosol inoculation.

At 24 hpa, nasopharyngeal tissues had some of the same qualities described at 6 and $12 \mathrm{hpa}$, but with variations. Viral immunopositivity was similarly localized to FAE of PALT regions, but was less associated with crypt regions. Rather, FAE overlying large, expansive, cryptless regions were more commonly affected (Figs. 4.8 - 4.12). In such areas there were substantially greater quantities of FMDV-positive cells within the epithelium (Figs. 4.8 - 4.9) and the superficial and deep subepithelium (Figs. 4.9 - 4.12) relative to earlier time points. These cells were often positive for FMDV structural and non-structural proteins (Fig. 4.12). Within subepithelial lymphoid regions, small quantities of FMDV structural and non-structural protein-positive cells had morphologic and phenotypic (CK-/MHCII+/CD11c+) characteristics of DCs (Figs. 4.9 - 4.12). Additionally, concurrent labeling with anti-vWF antibody indicated that within lymphoid

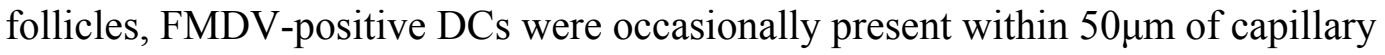
endothelia, but direct interaction between DCs and vascular cells was not observed in these areas. Microvesiculation (Fig. 4.8 - 4.9) and erosion (Figs. 4.8 - 4.11a) of nasopharyngeal FAE were rarely observed; in such regions, capillary endothelia (vWFpositive cells) were present within the disrupted epithelium immediately adjacent to FMDV-positive epithelial cells and DCs (Figs. 4.8 - 4.9). Intraepithelial vWF-positive 
cells were not observed in regions lacking erosion suggesting that this was a response to viral disruption of epithelial integrity.

Compared to $12 \mathrm{hpa}$, the lungs at $24 \mathrm{hpa}$ had more foci of immunopositive cells with a morphologic trend towards a greater quantity of polygonal versus squamous epithelial cell positivity (Fig. 4.13). Additionally, the CK/FMDV double positive polygonal cells were often free within alveolar lumina with deterioration of surrounding cytokeratin architecture.

Forty-eight hours post aerosol inoculation.

At 48 hpa there was a marked decrease of detection of FMDV immunopositive cells in the nasopharynx. Individual, and small clusters of, antigen-positive cells were present within the strata basale and spinosum of nasopharyngeal and laryngeal epithelia and lamina propria with no apparent predilection for FAE regions. A single cluster of FMDV-positive cells within the epiglottal epithelium of steer No. 14 was suggestive of a microvesicle. This steer, additionally, was the only animal in which FMDV antigens were identified within the palatine tonsil.

In contrast to the lesser quantity (relative to 6-24 hpa) of FMDV antigens localized to the upper respiratory tract, at 48 hpa there was substantially increased quantity of structural and non-structural FMDV antigens in pulmonary samples with multifocal, coalescing distribution (Figs. 4.14 - 4.15). Several tissues had regionally extensive fields spanning up to $2.0 \mathrm{~mm}$ of FMDV antigen-positive cells within alveolar parenchyma. Within these regions, alveolar septa were expanded by infiltrates of mixed leukocytes and proteinaceous material (fibrin). Cells containing FMDV antigens were 
round to polygonal with eccentric nuclei and were more frequently free within alveolar lumina or loosely associated with alveolar septa when examined by IHC-light microscopy (Fig. 4.14). However, when examined by MIF, these cells were nearly exclusively strongly CK-positive (Fig. 4.15). In these regions there were well demarcated transitions from the normal CK latticework pattern in regions lacking FMDV-positivity to disorganized CK clumping and dissociation of cells from septa in virus-positive regions. The pattern of MIF labelings also revealed that a subpopulation of FMDVpositive cells had somewhat greater association with alveolar septa than was detectable by light microscopy. Labelings for vimentin and vWF suggested that theses markers were present in a more normal architecture relative to the deterioration of the $\mathrm{CK}$ (pneumocytes) pattern. FMDV/CK double-positive cells were often directly adjacent to vWF-positive capillary endothelia (Fig. 4.15b). Overall, the pattern had strong similarities to the acantholytic degeneration seen in FMD vesicles.

\section{Discussion}

In considering the early pathogenesis of FMD in any species two critical issues have substantial translational relevance to development of vaccines and biotherapeutics. Identifying the primary site(s) of infection is foremost, as blocking these sites is the only method of achieving complete sterile protection. Identification of the mechanism of establishment of viremia is of secondary, but still substantial, importance. In most cases, blocking (or impairing) this process would substantially decrease shedding, transmission, and severity of clinical signs. Previous investigations of the early pathogenesis of FMD in cattle have implicated the nasopharynx $x^{7,15}$ and the lungs ${ }^{4,6,10}$ independently as sites of 
primary infection. A single study indicated that upper or lower respiratory tract can similarly serve as sites of primary infection and portals for systemic generalization of FMD ${ }^{24}$ Recent reviews have suggested that subsequent to natural aerosol exposure, FMDV replicates in the pharynx and establishes viremia by draining through the lymphatic system, but after experimental aerosol inoculation, viremia is established directly through the lungs. ${ }^{1,2}$ However, the primary experimental basis for these claims is not entirely clear. Another pathogenesis study implicated the nasal mucosa as the site of primary infection. ${ }^{14}$ Overall, the published literature does not provide enough information to allow a clear interpretation of the critical virus-host interactions associated with early FMDV infection of cattle.

The current study provides a more thorough description of the early events of experimental FMD in cattle than has been previously published. Additionally, the use of a controlled aerosol inoculation system has allowed a consistently repeatable method of exposure to virus while preserving the natural route of infection; high throughput techniques have facilitated screening of numerous tissues per animal and thus provided a highly detailed mapping of FMDV distribution.

Screening of tissues and swab specimens by rRT-PCR and VI indicated that there are tissue-specific, temporal trends regarding distribution of FMDV and viral RNA subsequent to aerosol inoculation. The period of 3 to $12 \mathrm{hpa}$ was generally dominated by amplification of virus in the nasopharyngeal and laryngeal (NP/L) tissues with a trend towards progressively higher levels of viral RNA and greater prevalence of VI positivity over time. Similarly, within the period of 4 to 12 hours, FMDV RNA detection from nasal swabs was increasing towards the first of two peaks. The temporal coincidence of 
these trends suggests that the RNA in nasal swabs in this period originated from FMDV replication in the NP/L tissues. At $24 \mathrm{hpa}$, FMDV and viral RNA were increasingly abundant in the pulmonary tissues with minimal change in the NP/L indicating panrespiratory distribution of virus associated with numerous foci of replication in both upper and lower respiratory tract. However, at 48 hpa, detection of FMDV by both screening tests was decreasing in NP/L tissues with further increase in the lungs. This coincided with the onset of viremia and the approach to the second peak in nasal swab RNA detection. Interpretation of the two peaks of the nasal swab FMDV RNA detection curve in the context of the tissue-specific rRT-PCR data suggests that there are distinct pharyngeal and pulmonary phases of FMDV release into the respiratory tract. Overall, the tissue-specific prevalence values for all previremic animals collectively indicates that the $\mathrm{NP} / \mathrm{L}$ are the most important sites of primary FMDV infection.

The rRT-PCR and VI data indicated that subsequent to aerosol inoculation, virus inoculum was distributed throughout the entire respiratory tract, yet immunolocalization of FMDV antigens indicated that primary infection was limited to specific regions of the nasopharynx and, somewhat later, the lungs. At early time points, tissues which were positive for FMDV by VI or rRT-PCR, but were IHC-MIF negative were interpreted as having virus or viral RNA on their superficial surfaces, but not having active infection and replication. Thus VI and rRT-PCR served as screening tests for infection at the tissue and cellular level (high sensitivity), whereas IHC-MIF functioned as a confirmatory procedures (high specificity). Overall, in the present study, the success of this screening and confirmation approach provided adequate efficacy of FMDV localization. 
The similar localization of FMDV antigens to the lymphoid follicle associated epithelium (FAE) of PALT crypts of the rostrodorsal nasopharynx in both steers euthanized at $6 \mathrm{hpa}$ demonstrated the importance of this region in the establishment of primary infection. The colocalization of FMDV antigens with cytokeratin and lack of colocalization with MHCII or CD11c in these tissues demonstrated that the first cells infected with FMDV are of epithelial origin. This is the first microscopic documentation of localization of FMDV to the respiratory tract of any aerogenously infected animal earlier than $24 \mathrm{hpa}$. Two previous works have demonstrated nasopharyngeal intraepithelial FMDV RNA in cattle by in situ hybridization at 5 days after contact exposure $^{20,26}$; however at this later phase of infection it is impossible to separate primary aerogenous from secondary hematogenous infection. The exclusive infection of PALT follicle associated epithelial cells in the context of pan-respiratory exposure to virus suggested that there are specific, intrinsic qualities of these cells which make them highly susceptible to infection. The caudal segment of the dorsal soft palate is anatomically aligned with the rostral dorsal nasopharynx and these two tissues were determined to be largely similar morphologically, phenotypically, and with regard to FMD pathogenesis within this study. The laryngeal tissues (epiglottis and larynx) are morphologically similar to the nasopharyngeal sites but with less MALT; this might explain the slightly decreased detection of virus in the former.

Though the nature of the susceptibility of the NP/L tissues remains elusive, possibilities include cell-specific expression of virus-specific receptors ( $\alpha \mathrm{V}$ integrins or other) and expression of other presently unidentified cellular factors by the susceptible cells or by other cells in the immediate microenvironment. Though $\alpha \mathrm{V} \beta 6$ and $\alpha \mathrm{V} \beta 3$ 
expression has been characterized in these tissues from uninfected cattle ${ }^{16,17}$, simultaneous localization with FMDV has not been described. The nearly diffuse epithelial distribution of $\alpha \mathrm{V} \beta 6$ described in one study ${ }^{17}$ combined with the multifocal distribution of primary FMDV infection (current work) suggest that the expression of integrins does not solely dictate cellular susceptibility to infection.

The FAE is an extremely active epithelium, and candidate cells which might affect the microenvironment include intraepithelial DCs, lymphocytes, and natural killer cells. Similarly, M-cells in these regions may directly facilitate infection by providing non-specific portals for entry of virus into the host via pinocytosis. Morphologic and phenotypic characterization of bovine PALT has indicated that such cells are present in the FAE to varying extents in FMDV-infected cattle and in the resting (naïve) state (Arzt, unpublished data). Additionally, physical characteristics of the FAE crypts may influence susceptibility to infection; it is possible that pooling of secretions in these regions allows increased time for adsorption of virions and thus increases efficiency of infection in a highly localized manner. Current efforts in the authors' laboratory are directed towards investigating these mechanisms.

Determining, the role of the lungs in early infection was less straightforward. Though viral RNA was detectable in pulmonary tissues at $3 \mathrm{hpa}$ and infectious virus at 6 hpa (similar to NP/L), the prevalence of VI and rRT-PCR positive samples was low at these time points compared to that in NP/L; additionally, viral antigens could not be detected in lungs until 12 hpa (i.e. 6 hours later than the nasopharynx). At least two hypotheses are supported by this contrast in the data describing processes in the NP/L and lung. It is possible that the viral RNA and infectious virus detected in the lungs prior to 
12 hpa represent foci which were in the process of establishing primary infection independent of infection of the nasopharynx, but with a relative lag (eclipse) period. Alternatively, it is possible that primary infection of the NP/L serves as a requisite phase in the establishment of pulmonary infection presumably by dose amplification of inoculated virus. In this scenario, the nasopharyngeally amplified virus would serve as an endogenously generated secondary aerosol delivered to the lungs via normal respiration. It is also possible that under conditions of natural (i.e. direct or indirect contact) exposure both infection scenarios are relevant with contributory roles determined by viral dose, aerosol droplet size and various aspects of virus host interactions.

Regardless of the contributory roles of lungs versus nasopharynx in the early pathogenesis of FMD in cattle, it is clear that the pulmonary epithelia are permissive to FMDV replication. Our trimodal identification of FMDV in distal lung segments of both steers euthanized at $12 \mathrm{hpa}$ (previremic) indicates the consistent role of the lungs in the early progression of FMD. This is consistent with previous works which localized FMDV RNA to alveolar septa in previremic FMD in aerosol inoculated cattle. ${ }^{4,6}$ In the present study, the morphologic localization of FMDV to alveolar septa combined with exclusive colocalization with cytokeratin in these regions suggests that pneumocytes are the most relevant cells supporting viral replication in the lungs. The morphologic variation of FMDV-positive cells (squamous versus polygonal) seen in the lungs of steer No. 7 likely represents a temporal and pathologic continuum with the squamous variant (type I pneumocyte) representative of early cellular infection that progresses to infection of cells with polygonal morphology (type II pneumocytes). Thus, the single, small (type I pneumocyte morphology) focus of anti-FMDV immunopositivity in middle lung lobe of 
steer No. 6 (Fig. 4. 4) is interpreted as an earlier stage relative to cranial lung specimen of steer No. 7 (Figs. 4.5 - 4.7). This concept is further supported by the increasing abundance of FMDV-immunopositve type II pnuemocytes at 24 and 48 hpa and by "conventional wisdom" on the subject of responses to insults by pulmonary epithelia. ${ }^{9}$ Rarely at 12 hpa colocalization of FMDV antigens and cytokeratin was identified within terminal bronchiolar epithelia indicating that these cells also are susceptible to infection, but with apparently lesser efficiency compared to pneumocytes.

The question of how viremia is established in FMD has substantial implications for ongoing and future development of FMD prophylaxis. It has been suggested previously that in bovine FMD the mechanism of establishment of viremia is that virus drains from the pharynx to the regional lymph nodes from which viremia is established. ${ }^{1,2}$ In the present study, the lack of detection of FMDV or viral RNA in lymph nodes draining the respiratory tract and oral cavity in the previremic and early viremic phases of FMD suggests that this is not the route of establishment of viremia within the current work's experimental conditions. A specific region's ability to serve as a portal for establishment of viremia is dependent upon local presence of virus in immediate proximity to blood vessels and upon a competent mechanism of movement of virions form the extravascular to the intravascular space. The transfer mechanism is a complex subject that was not addressed by the current study, but likely involves several molecular and cellular recognition events. However, in the current work, the requirement for intimate association of FMDV and blood vessels was shown to be met in previremic animals in tissues of the nasopharynx and lungs. 
As early as 12 hpa, FMDV-positive type I pneumocytes were present within alveolar septa which contained abundant vWF and vimentin - positive cells (i.e. capillary endothelia). This suggests that in the lungs FMDV would have a high likelihood of gaining access to the vasculature. However, at 24 hpa, FMDV was also present in close proximity to vWF-positive (endothelial) cells within the PALT epithelium and lamina propria. The intraepithelial capillaries in regions of erosion may represent a neovascular response to ongoing FMDV-induced epithelial injury. Additionally, small caliber intraepithelial blood vessels have previously been demonstrated within the normal reticular epithelium (FAE) of the bovine palatine tonsil which has many morphologic and phenotypic similarities to PALT ${ }^{19}$ The possibility that viremia may be established in the PALT is supported by the presence of these vessels associated with FMDV-positive epithelial cells and DCs. Overall, these findings are consistent with the earlier work demonstrating that the lungs or upper respiratory tract may independently serve as portals for systemic dissemination. ${ }^{24}$

An additional, salient consideration regarding the site of establishment of viremia is that in the time period in which viremia was established (24-48 hpa), viral load in the $\mathrm{NP} / \mathrm{L}$ was decreasing by all detection methods, whereas in the lungs virus was replicating to high genome copy numbers in cells which are in direct association with capillary endothelia. At the time of establishment of viremia, pulmonary quantities of FMDV, viral RNA, and structural and non-structural antigens were all increasing. Though these data do not conclusively establish a single responsible anatomic site for the establishment of FMDV viremia in cattle, interaction between processes in upper and lower respiratory 
tract regions are likely, and current efforts in the authors' laboratory are directed towards defining the relative contributory roles of these regions.

The FMDV-associated degenerative process observed in the lungs at 48 hpa has many microscopic similarities to the classic acantholytic degeneration described for vesicles caused by FMDV and other pathologic processes ${ }^{11,28}$; however, macroscopic lesions were not detected in the lungs. As is seen with keratinocytes in FMDV vesicles, the pneumocytes swell, lose association with adjacent structures, and dissociate into an expanding cavitary space. ${ }^{21,28}$ However, unlike a classic vesicle in which the morphologic characteristics of acantholysis are well defined and recognizable, this pulmonary “acantholytic-like degeneration" could easily be mistaken for an histiocytic alveolitis. The morphology of the acantholytic pneumocytes is similar to that of alveolar macrophages, and it is only the CK-positivity of these cells which confirms their epithelial histogenesis. An additional consideration on this subject is the relationship that this pulmonary process may have to the maintenance of high-titer viremia during acute FMD. Though it has previously been suggested that sustained FMDV viremia is maintained by viral replication in lesional and/or non-lesional skin ${ }^{1,5}$, this hypothesis has never been thoroughly elucidated. Several factors support the notion that the lungs may be important amplifiers of FMDV and may be responsible for maintaining high titer viremia including 1) the relatively high FMDV RNA/mg and large quantities of FMDV structural and non-structural antigens detected in the lungs of viremic cattle in this study, 2) the overall mass of the lungs, and 3) the extensive vascularity of lungs.

In conclusion, the data presented herein support a model for early FMDV infection of aerosol-inoculated cattle which includes the following key events: 1) primary 
replication in epithelial cells of the PALT crypts, 2) subsequent widespread replication in pneumocytes in the lung which coincides with 3) the establishment of sustained viremia. Current work in the authors' laboratory is directed towards similar investigation of additional serotypes and strains of FMDV and further elucidation of FMDV-host interactions in the early pathogenesis of FMD. 


\section{Chapter 4 Tables}

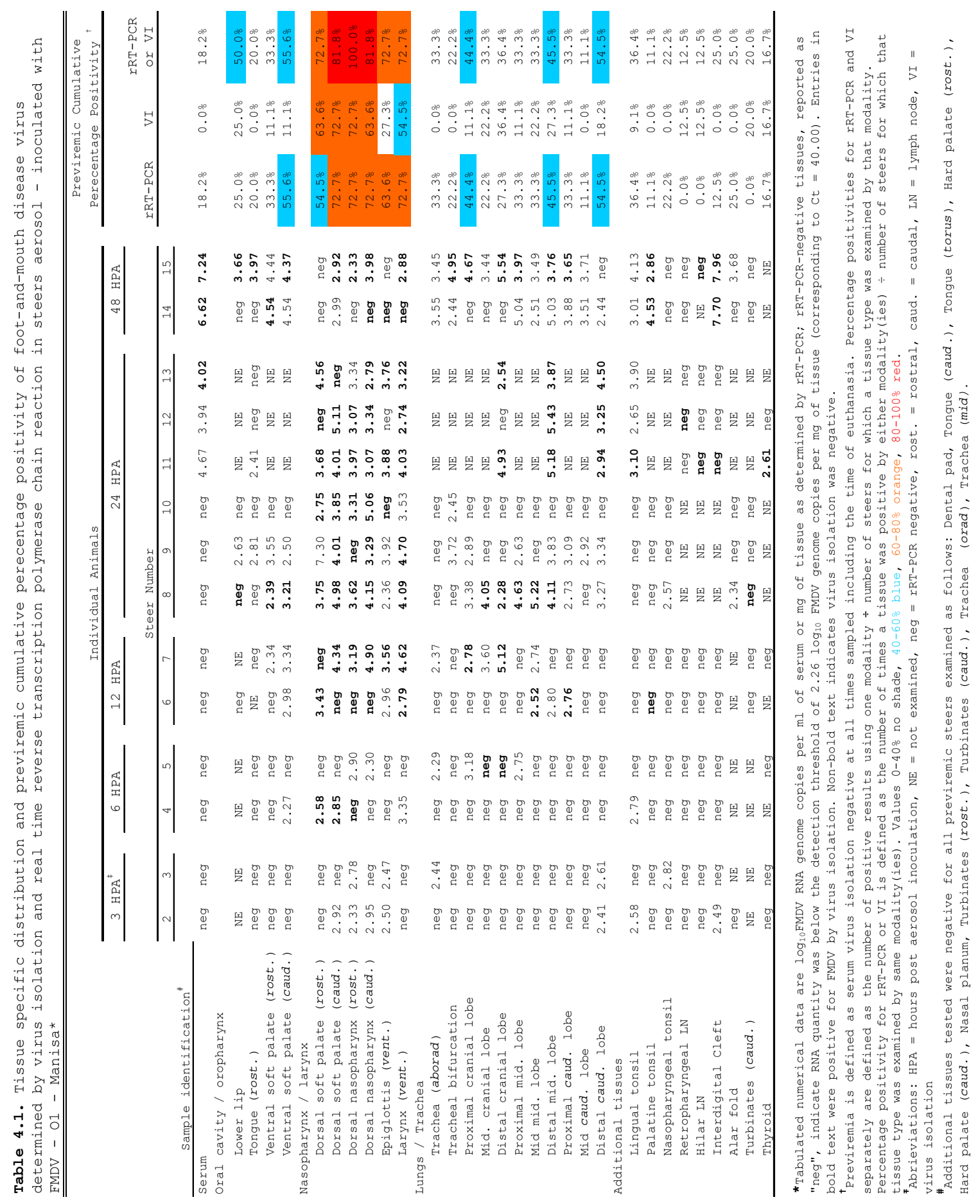




\section{Chapter 4 Figures}

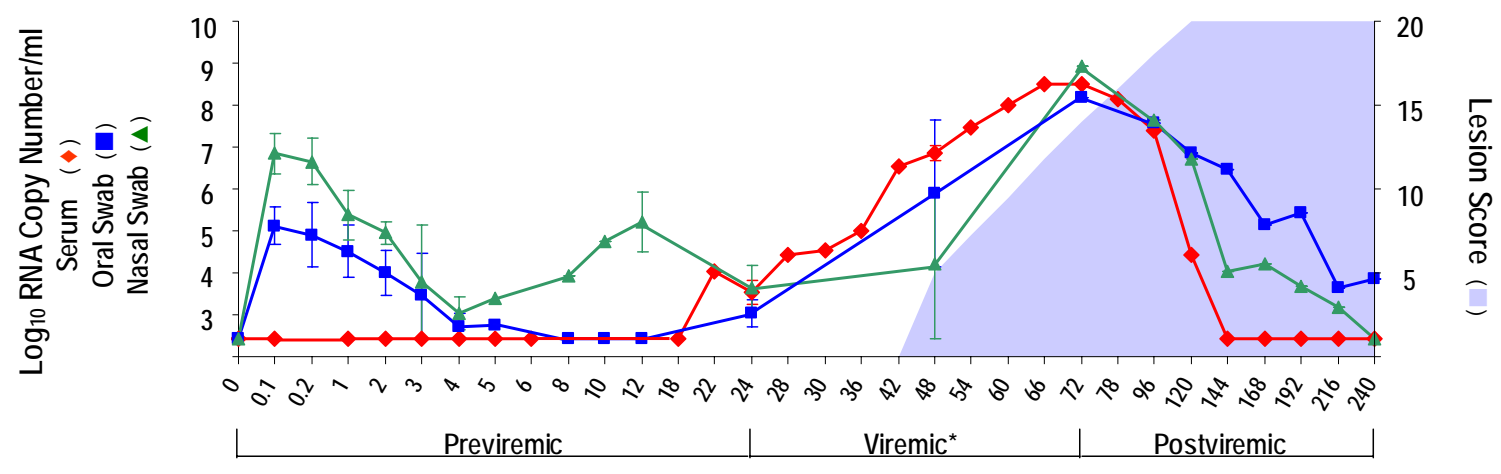

Hours post aerosol inoculation

Figure 4.1 Time course of FMDV RNA quantity ( $\log _{10}$ genome copy number $/ \mathrm{ml}$ ) determined by rRT-PCR in serum (red), nasal swab samples (green), and oral swab samples (blue) collected from steers aerosol-inoculated with FMDV-O 1 -Manisa. Each data point represents the mean $\pm \mathrm{SE}$ for all steers sampled at a given time (hours post aerosol inoculation). Lesion (vesicle) score was calculated by evaluating each foot and the head independently with 2 points assigned for a small $(\leq 1.0 \mathrm{~cm})$ vesicle and 4 points for a large vesicle. Viremia $(*)$ was defined by positive findings on serum virus isolation. $\mathrm{X}$-axis calibration not to scale. 

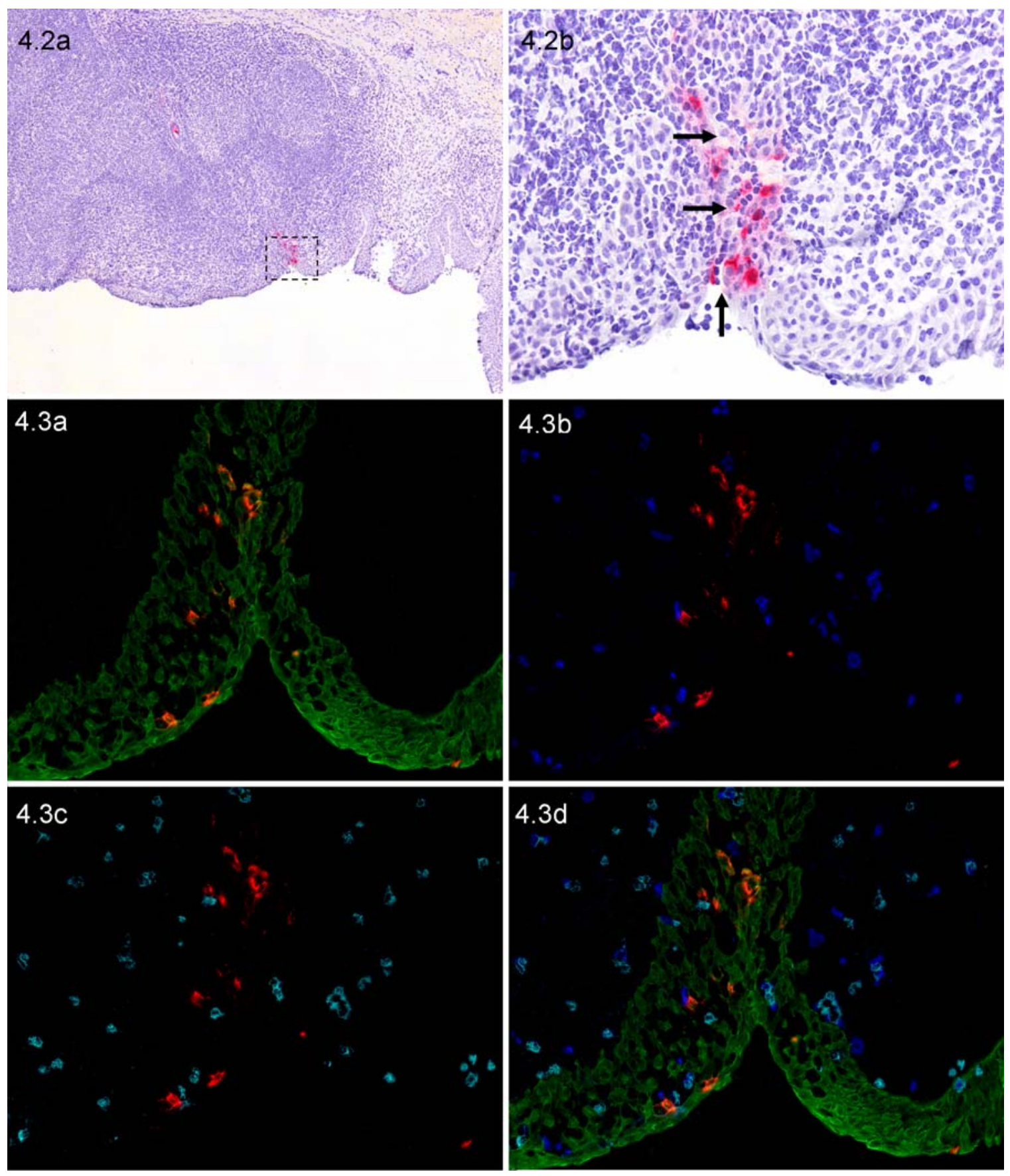

Figs. 4.2-4.3. Rostrodorsal nasopharynx, steer No. 4, 6 hours post aerosol inoculation with FMDV- $\mathrm{O}_{1}$-Manisa. Cryosections.

Fig 4.2a. Immunohistochemical localization of FMDV to epithelial crypt of mucosa associated lymphoid tissue (MALT). Anti - FMDV capsid monoclonal antibody. Micropolymer alkaline phosphatase. Gill's hematoxylin counterstain.

Fig 4.2b. Higher magnification of region of interest identified in Fig. 4.2a. FMDV antigens localize to crypt epithelium subjacent to crypt lumen (arrows). Anti - FMDV capsid monoclonal antibody. Micropolymer alkaline phosphatase. Gill's hematoxylin counterstain. 
Fig 4.3a. Multichannel immunofluorescence (MIF) of serial section of region of interest identified in Fig. 4.2a. Colocalization (orange) of FMDV capsid antigens (red) with pancytokeratin (green) - positive crypt epithelial cells. Anti - FMDV capsid and anti pancytokeratin monoclonal antibodies.

Fig 4.3b. Simultaneous MIF of specimen in Fig. 4.3a. MHCII (blue) - positive cells in close proximity to, but not colocalized with FMDV capsid (red) antigen. Anti - FMDV capsid and anti - MHCII monoclonal antibodies.

Fig 4.3c. Simultaneous MIF of specimen in Fig. 4.3a-b. CD11c (aqua) -positive cells in close proximity to, but not colocalized with FMDV capsid (red) antigens. Anti - FMDV capsid and anti - CD11c monoclonal antibodies.

Fig 4.3d. Merge of simultaneous MIF images from Fig. 4.3a-c. Intraepithelial MHCII (blue) and CD11c (aqua) positive cells (presumptive dendritic cells) are in close proximity to FMDV / pancytokeratin double - positive cells. Anti - FMDV capsid, anti pancytokeratin, anti - CD11c, and anti - MHCII monoclonal antibodies. 


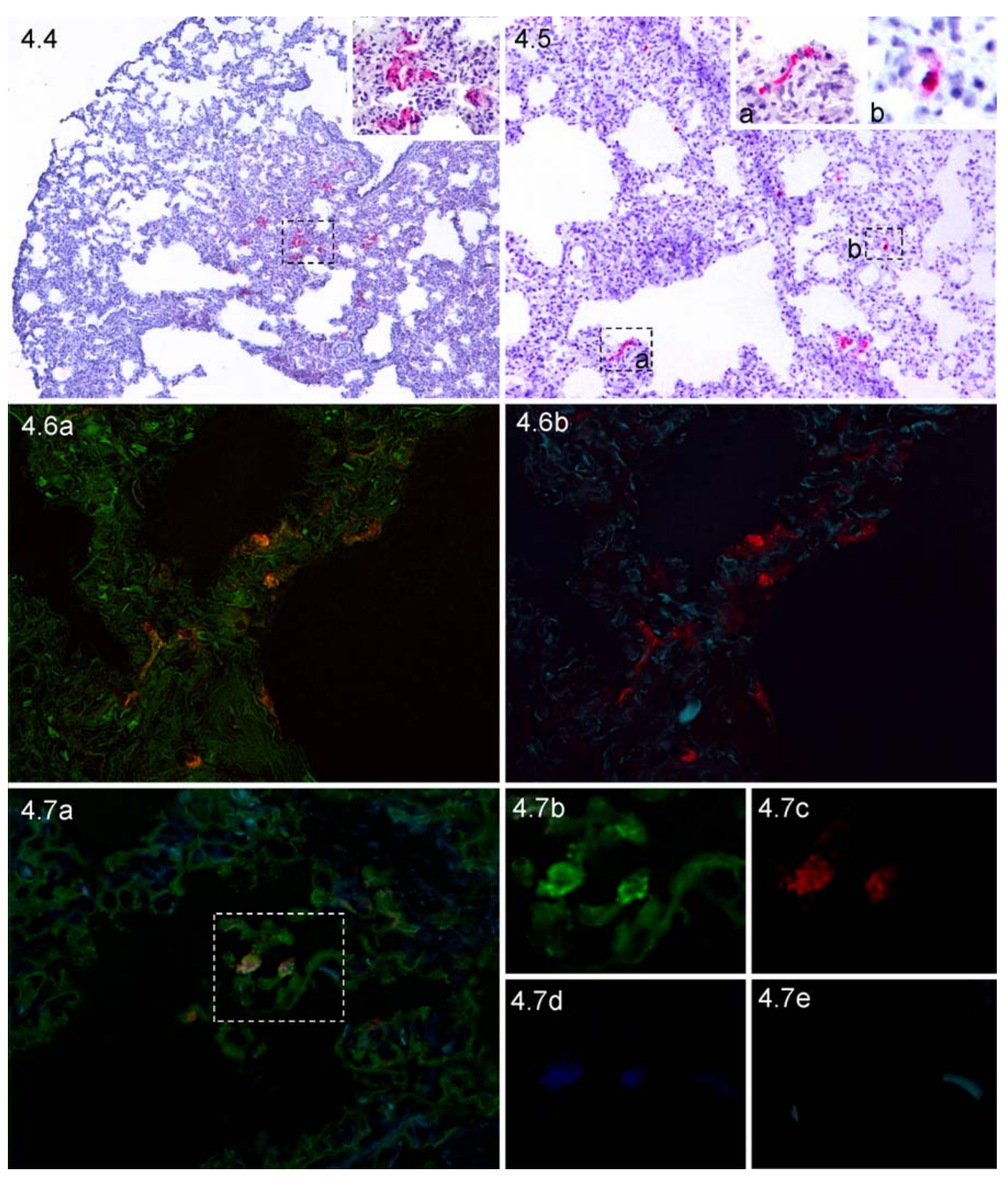

Figs. 4.4-4.7. Distal segments of lung lobes, 12 hours post aerosol inoculation with FMDV- $\mathrm{O}_{1}$-Manisa. Cryosections.

Fig 4.4. Middle lung lobe, steer No. 6. Focal region of anti-FMDV immunoreactivity with localization of antigen exclusively to alveolar septa (insert). Anti - FMDV-3D protein monoclonal antibody. Micropolymer alkaline phosphatase. Gill's hematoxylin counterstain.

Fig 4.5. Cranial lung lobe, steer No. 7. Immunohistochemical localization of FMDV antigen to squamous cells of alveolar septa (insert a) and polygonal cells of alveolar 
lumina (insert b). Anti - FMDV capsid monoclonal antibody. Micropolymer alkaline phosphatase. Gill's hematoxylin counterstain.

Fig 4.6a. Cranial lung lobe, steer No. 7. Multichannel immunofluorescence (MIF) of serial section of tissue shown in Fig. 4.5. Colocalization (orange) of FMDV capsid antigens (red) with pancytokeratin (green) - positive cells of alveolar septa. Anti FMDV capsid and anti - pancytokeratin monoclonal antibodies.

Fig 4.6b. Cranial lung lobe, steer No. 7. Simultaneous MIF of specimen in Fig. 4.6a. Vimentin (blue) - positive cells in close proximity to, but not colocalized with FMDV capsid (red) antigen. Anti - FMDV capsid and anti - vimentin monoclonal antibodies. Fig 4.7a. Cranial lung lobe, steer No. 7. Multichannel immunofluorescence (MIF) of serial section of tissue shown in Figs. 4.5-4.6. Triple colocalization of FMDV capsid (red) and FMDV 3D protein (blue) antigens with cytokeratin (green) in pneumocytes. vWF-positive capillary endothelial cells (aqua) are interspersed with pnuemocytes, and are negative for both FMDV antigens.

Fig 4.7b-e. Cranial lung lobe, steer No. 7. Higher magnification single channel views of region of interest identified in Fig 4.7a. Individual channels: Fig 4.7b. cytokeratin (green), Fig 4.7c. FMDV capsid (red), Fig 4.7d. FMDV 3D polymerase (blue), Fig 4.7e. vWF (aqua). 

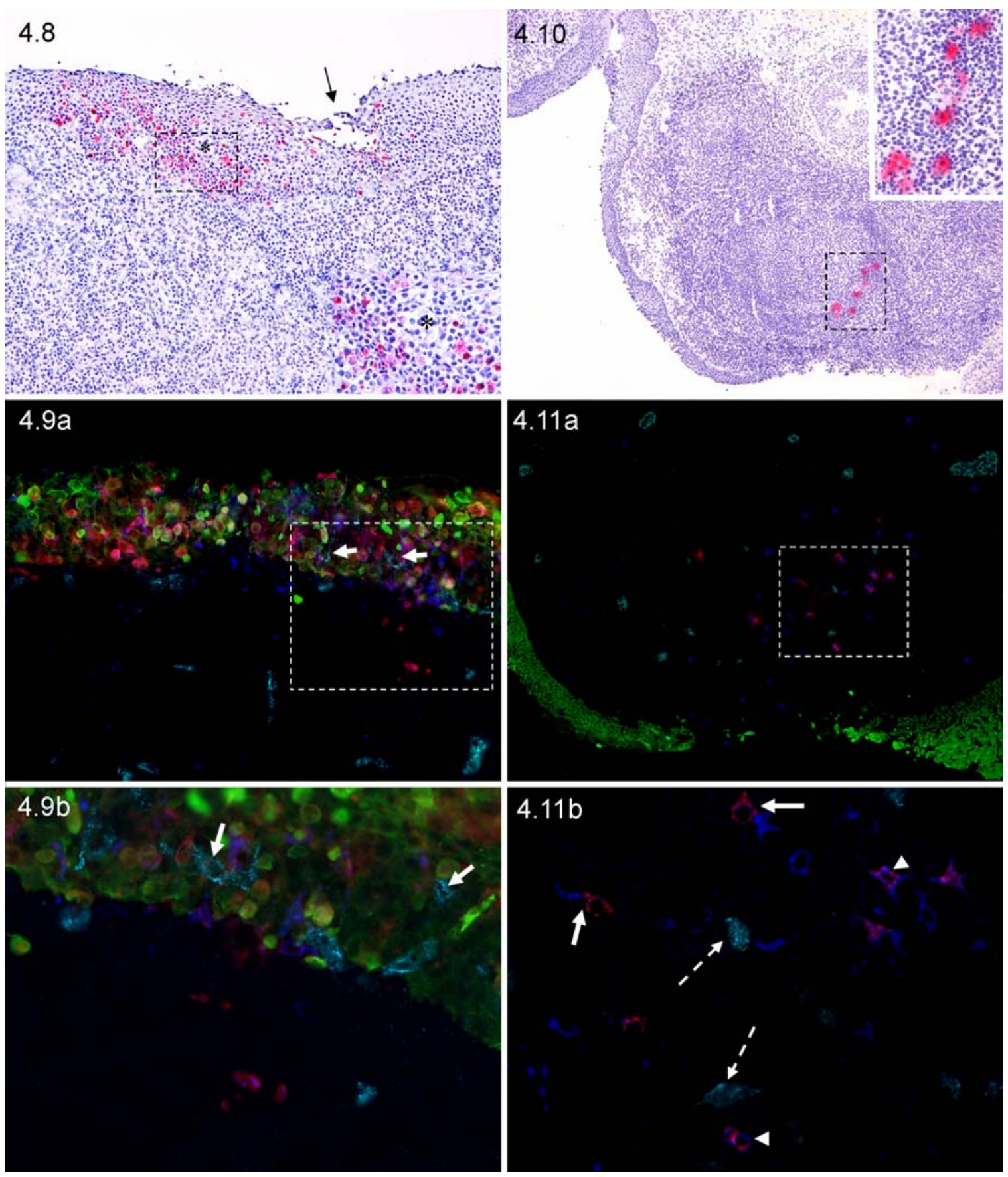

Figs. 4.8-4.11. Nasopharyngeal tissues, 24 hours post aerosol inoculation with FMDV$\mathrm{O}_{1}$-Manisa. Cryosections.

Fig 4.8. Caudodorsal soft palate, steer No. 11. Transepithelial immunohistochemical localization of FMDV to MALT epithelium and superficial lamina propria in a region of microvesiculation (*) and erosion (arrow). Anti - FMDV capsid monoclonal antibody. Micropolymer alkaline phosphatase. Gill's hematoxylin counterstain.

Fig 4.9a. Caudodorsal soft palate, steer No. 11. Multichannel immunofluorescence (MIF) of serial section of specimen in Fig. 4.8. Intraepithelial and subepithelial colocalization (purple) of FMDV capsid antigens (red) with MHCII (blue) - positive (presumptive) 
dendritic cells. Colocalization (orange) of FMDV capsid antigens (red) with cytokeratin (green) - positive epithelial cells. Von Willebrand antigen-positive (aqua) capillary endothelial cells are present within epithelium (arrows) and lamina propria in close proximity to FMDV-positive cells. Anti - FMDV capsid, anti-MHCII, anti-von Willebrand antigen, and anti - pancytokeratin monoclonal antibodies.

Fig 4.9b. Caudodorsal soft palate, steer No. 11. Higher magnification of region of interest identified in Fig 4.9a, multichannel immunofluorescence (MIF) of serial section of specimen in Fig. 4.8. Von Willebrand antigen-positive (aqua) capillary endothelial cells are present within epithelium (arrows) and lamina propria in close proximity to FMDVpositive cells. FMDV / MHCII individual and double positive cells are present within subepithelial lymphoid region. Anti - FMDV capsid, anti-MHCII, anti-von Willebrand antigen, and anti - pancytokeratin monoclonal antibodies.

Fig 4.10. Rostrodorsal nasopharynx, steer No. 12. Immunohistochemical localization of FMDV to lymphoid follicular dark zone of mucosa - associated lymphoid tissue (MALT). Anti - FMDV capsid monoclonal antibody. Micropolymer alkaline phosphatase. Gill's hematoxylin counterstain.

Fig 4.11a. Rostrodorsal nasopharynx, steer No. 12. Multichannel immunofluorescence (MIF) of serial section of specimen in Fig. 4.10. Colocalization (purple) of FMDV capsid antigens (red) with MHCII (blue) - positive dendritic cells. FMDV does not colocalize with cytokeratin (green) or von Willebrand antigen (aqua). Anti - FMDV capsid, antiMHCII, anti-von Willebrand antigen, and anti - bovine cytokeratin monoclonal antibodies.

Fig 4.11b. Rostrodorsal nasopharynx, steer No. 12. Higher magnification of region of interest identified in Fig. 4.11a. Multichannel immunofluorescence (MIF) of serial section of specimen in Fig. 4.10. Within a lymphoid follicle, FMDV antigens (red) are in close proximity to (arrows) and colocalize with (purple; arrowheads) MHCII (blue) positive cells. FMDV does not colocalize with von Willebrand antigen (aqua) positive endothelial cells (broken arrows). Anti - FMDV capsid, anti-MHCII, anti-von Willebrand antigen, and anti - pancytokeratin monoclonal antibodies. 

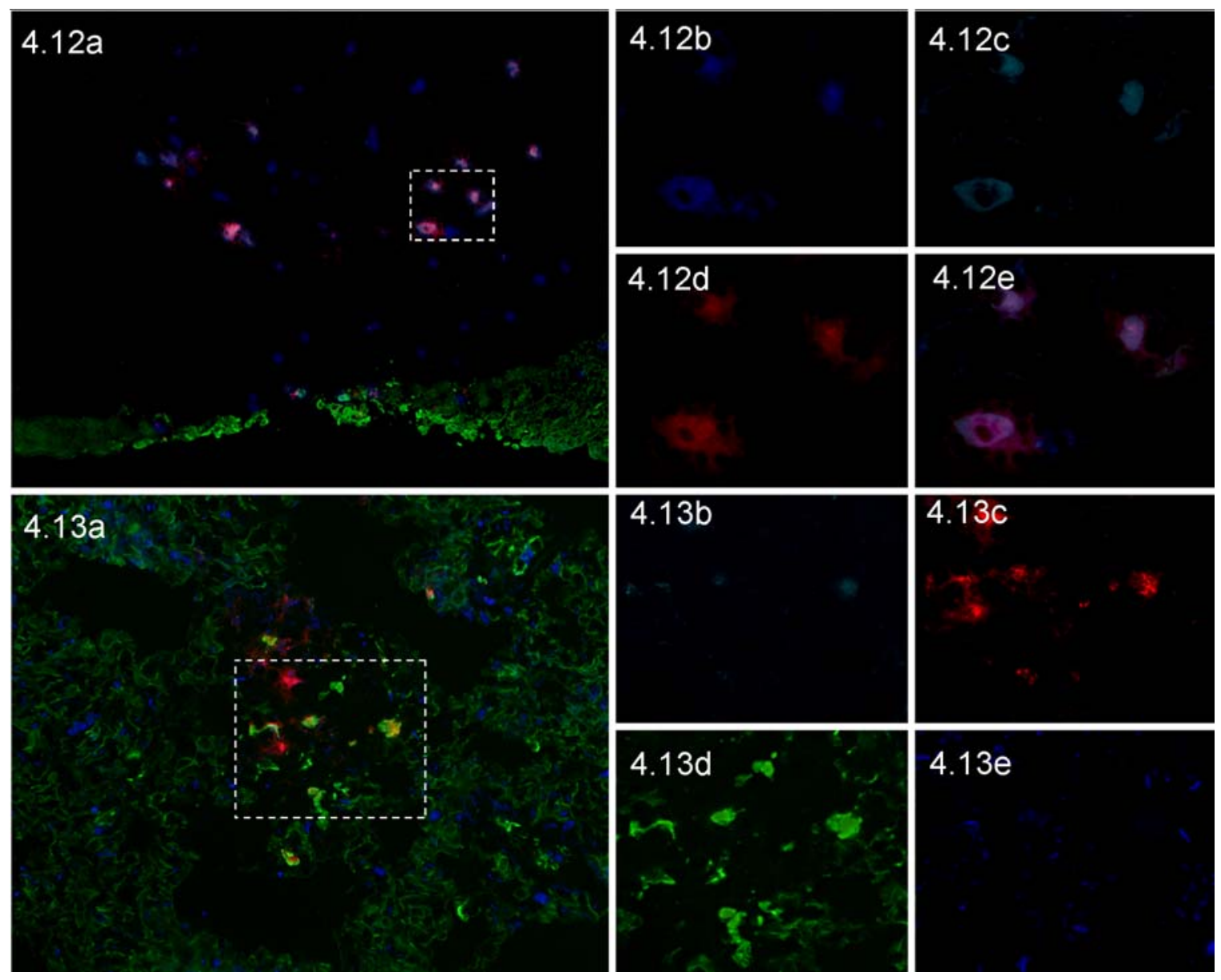

Figs. 4.12-4.13. 24 hours post aerosol inoculation with FMDV- $\mathrm{O}_{1}$-Manisa. Cryosections. Fig 4.12a. Rostrodorsal nasopharynx, steer No. 12. Multichannel immunofluorescence (MIF) of serial section of specimen in Figs. 4.10-4.11. Triple colocalization (pink) of FMDV capsid antigen (red), FMDV 3D polymerase antigen (aqua), and CD11c (blue) in dendritic cells. Surface epithelium is cytokeratin - positive (green). Anti - FMDV capsid, anti-FMDV 3D polymerase, anti-CD11c, and anti - pancytokeratin monoclonal antibodies.

Fig 4.12b-e. Rostrodorsal nasopharynx, steer No. 12. Higher magnification, single channel views of region of interest identified in Fig. 12a multichannel immunofluorescence (MIF) of serial section of specimen in Fig. 4.10-4.11. Fig 4.12b. CD11c (blue). Fig 4.12c. FMDV 3D polymerase (aqua). Fig 4.12d. FMDV capsid (red), Fig 4.12e. 4-channel merge.

Fig 4.13a. Caudal lung lobe, steer No. 13. Multichannel immunofluorescence (MIF). Triple colocalization (yellow) of FMDV capsid antigen (red), FMDV 3D polymerase antigen (aqua), and cytokeratin (green) in degenerating (acantholytic) pneumocytes. VWF antigen positive endothelial cells (blue) are interspersed with pneumocytes. Pneumocyte architecture is disrupted in focus of infection. Anti - FMDV capsid, antiFMDV 3D polymerase, and anti - pancytokeratin monoclonal antibodies. Anti-VWF polyclonal antibody. 
Fig 4.13b-e. Caudal lung lobe, steer No. 13. Higher magnification single channel views of region of interest identified in Fig. 4.13a multichannel immunofluorescence (MIF). Fig 4.13b. FMDV 3D polymerase (aqua). Fig 4.13c. FMDV capsid (red). Fig 4.13d. cytokeratin (green) Fig 4.13e. vWF (blue). 


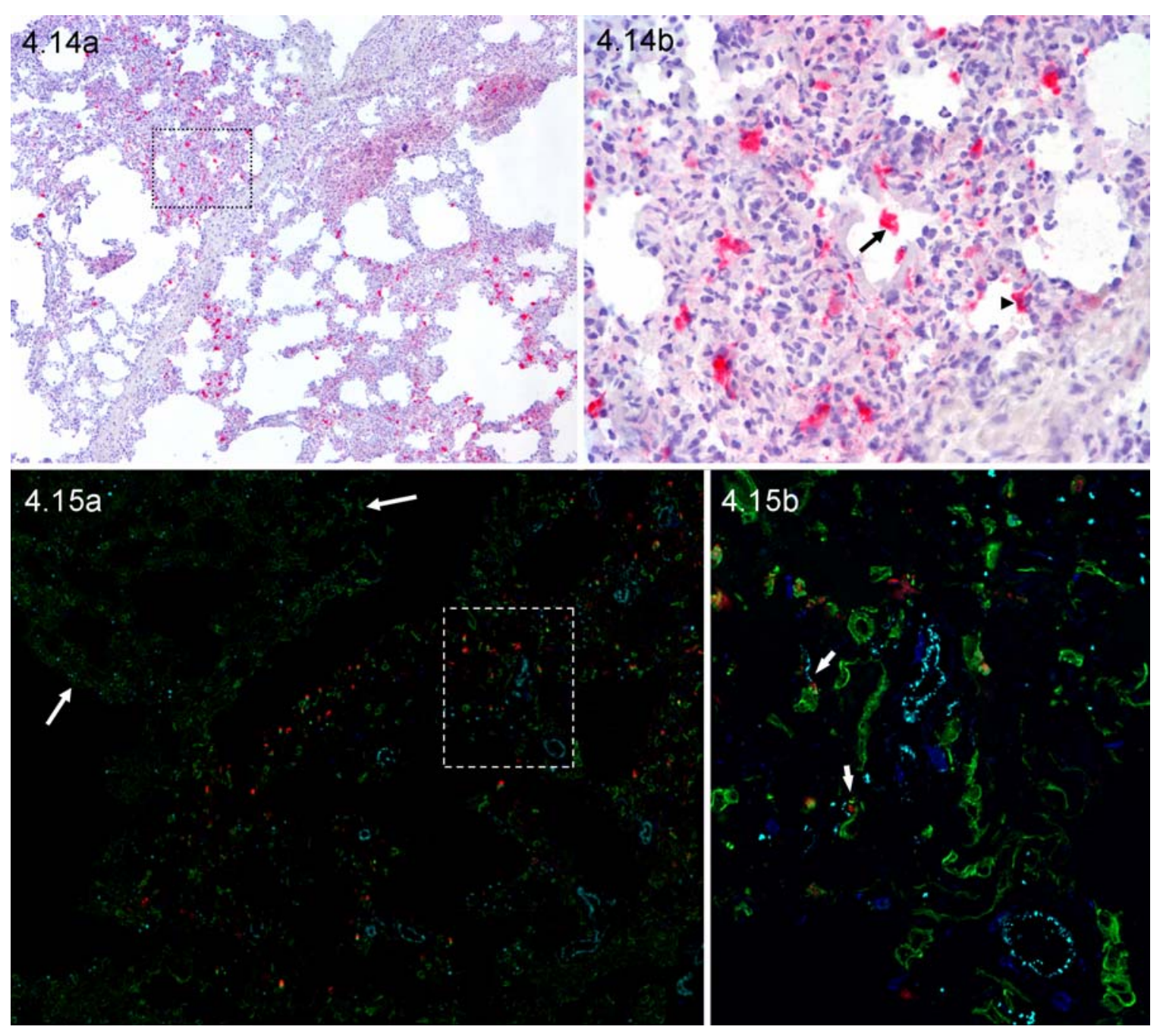

Figs. 4.14-4.15. Middle lung lobe, distal segment, steer No. 15, 48 hours post aerosol inoculation with FMDV- $\mathrm{O}_{1}$-Manisa. Cryosections.

Fig 4.14a. Regionally extensive distribution of anti-FMDV immunoreactive cells in a region of distortion of alveolar architecture. Anti - FMDV 3D polymerase monoclonal antibody. Micropolymer alkaline phosphatase. Gill's hematoxylin counterstain.

Fig 4.14b. Higher magnification of region of interest identified in Fig. 4.14a. AntiFMDV immunopositive cells are predominantly free within alveolar lumina (arrow) or adhered to septal walls (arrowhead). Alveolar septa are expanded and infiltrated by mixed leukocytes. Anti - FMDV 3D polymerase monoclonal antibody. Micropolymer alkaline phosphatase. Gill's hematoxylin counterstain.

Fig 4.15a. Multichannel immunofluorescence (MIF) of serial section of specimen in Fig. 4.14. FMDV antigen (red) colocalizes with pancytokeratin (green) - positive cells. Within FMDV/pancytokeratin double positive cells there is minimal subcellular colocalization. Normal pancytokeratin lattice pattern (between arrows) is extensively disrupted in FMDV-positive region and replaced by clumped pancytokeratin-positive cells with poorly defined intercellular associations. Anti-FMDV capsid, anti-von Willebrand antigen, and anti - pancytokeratin monoclonal antibodies.

Fig 4.15b. Higher magnification of region of interest identified in Fig. 4.15a, 
multichannel immunofluorescence (MIF) of serial section of specimen in Fig. 4.14a. FMDV/pancytokeratin double positive cells are in close proximity to vWF (aqua)positive capillaries (arrows) and vessels and MHCII (blue) -positive cells. Anti - FMDV capsid, anti-MHCII, anti-von Willebrand antigen, and anti - pancytokeratin monoclonal antibodies. 


\section{Chapter 4 References}

1. Alexandersen S, Mowat N: Foot-and-mouth disease: host range and pathogenesis. Curr Top Microbiol Immunol 288:9-42, 2005

2. Alexandersen S, Zhang Z, Donaldson AI, Garland AJ: The pathogenesis and diagnosis of foot-and-mouth disease. J Comp Pathol 129:1-36, $2003 \mathrm{Jul}$

3. Arzt J, Gregg DA, Clavijo A, Rodriguez LL: Optimization of immunohistochemical and fluorescent antibody techniques for localization of Foot-and-mouth disease virus in animal tissues. J Vet Diagn Invest 21:779-792, 2009

4. Brown CC, Meyer RF, Olander HJ, House C, Mebus CA: A pathogenesis study of foot-and-mouth disease in cattle, using in situ hybridization. Can J Vet Res 56:189-193, 1992 Jul

5. Brown CC, Olander HJ, Meyer RF: Pathogenesis of foot-and-mouth disease in swine, studied by in-situ hybridization. J Comp Pathol 113:51-58, 1995

6. Brown CC, Piccone ME, Mason PW, McKenna TS, Grubman MJ: Pathogenesis of wild-type and leaderless foot-and-mouth disease virus in cattle. J Virol 70:5638-5641, 1996 Aug

7. Burrows R, Mann JA, Garland AJ, Greig A, Goodridge D: The pathogenesis of natural and simulated natural foot-and-mouth disease infection in cattle. J Comp Pathol 91:599609,1981 Oct

8. Callahan JD, Brown F, Osorio FA, Sur JH, Kramer E, Long GW, Lubroth J, Ellis SJ, Shoulars KS, Gaffney KL, Rock DL, Nelson WM: Use of a portable real-time reverse transcriptase-polymerase chain reaction assay for rapid detection of foot-and-mouth disease virus. J Am Vet Med Assoc 220:1636-1642, 2002

9. Caswell J, Williams K. The respiratory system In: Jubb, Kennedy \& Palmer's Pathology of Domestic Animals, 5th Edition, Maxie MG, ed. 523-653. Saunders, St. Louis, MO, 2007

10. Eskildsen M: Experimental pulmonary infection of cattle with foot-and-mouth disease virus. Nord. Vet. Med 21:86-91, 1969

11. Frenkel HS: Histologic changes in explanted bovine epithelial tongue tissue infected with the virus of foot-and-mouth disease. Am J Vet Res 10:142-145, 1949

12. Golde WT, Pacheco JM, Duque H, Doel T, Penfold B, Ferman GS, Gregg DR, Rodriguez LL: Vaccination against foot-and-mouth disease virus confers complete clinical protection in 7 days and partial protection in 4 days: Use in emergency outbreak response. Vaccine 23:5775-5782, 2005

13. Grubman MJ, Baxt B: Foot-and-mouth disease. Clin Microbiol Rev 17:465-493, 2004 Apr

14. Korn G: Experimentelle untersuchungen zum virusnachweis im inkubationsstadium der maul-und klauenseuche und $\mathrm{zu}$ ihrer pathogenese. Archiv fur experimentelle veterinarmedizin

\section{1:637-649, 1957}

15. McVicar JW, J.H. G, Sutmoller P: Growth of foot-and-mouth disease virus in the bovine pharynx. Proceedings of the 74th Annual Meeting of the United States Animal Health Association 230-234, 1970

16. Monaghan P, Gold S, Simpson J, Zhang Z, Weinreb PH, Violette SM, Alexandersen $\mathrm{S}$, Jackson T: The alpha(v)beta6 integrin receptor for Foot-and-mouth disease virus is 
expressed constitutively on the epithelial cells targeted in cattle. J Gen Virol 86:27692780,2005

17. O'Donnell V, Pacheco JM, Gregg D, Baxt B: Analysis of foot-and-mouth disease virus integrin receptor expression in tissues from naive and infected cattle. J Comp Pathol 141:98-112, 2009

18. Pacheco JM, Arzt J, Rodriguez LL: Early events in the pathogenesis of foot-andmouth disease in cattle after controlled aerosol exposure. Vet J, 2008

19. Palmer MV, Thacker TC, Waters WR: Histology, immunohistochemistry and ultrastructure of the bovine palatine tonsil with special emphasis on reticular epithelium. Vet Immunol Immunopathol 127:277-285, 2009

20. Prato Murphy ML, Forsyth MA, Belsham GJ, Salt JS: Localization of foot-andmouth disease virus RNA by in situ hybridization within bovine tissues. Virus Res 62:6776,1999

21. Seibold HR: A Revised Concept of the Lingual Lesions in Cattle with Foot-andMouth Disease. Am J Vet Res 24:1123-1130, 1963

22. Sellers RF, Parker J: Airborne excretion of foot-and-mouth disease virus. J Hyg (Lond) 67:671-677, 1969 Dec

23. Stave JW, Card JL, Morgan DO: Analysis of foot-and-mouth disease virus type O1 Brugge neutralization epitopes using monoclonal antibodies. J Gen Virol 67 ( Pt 10):2083-2092, 1986

24. Sutmoller P, McVicar JW: Pathogenesis of foot-and-mouth disease: the lung as an additional portal of entry of the virus. J Hyg (Lond) 77:235-243, 1976 Oct

25. Swaney LM: A continuous bovine kidney cell line for routine assays of foot-andmouth disease virus. Vet Microbiol 18:1-14, 1988

26. Woodbury EL, Ilott MC, Brown CC, Salt JS: Optimization of an in situ hybridization technique for the detection of foot-and-mouth disease virus in bovine tissues using the digoxigenin system. J Virol Methods 51:89-93, 1995

27. Yang M, Clavijo A, Li M, Hole K, Holland H, Wang H, Deng MY: Identification of a major antibody binding epitope in the non-structural protein 3D of foot-and-mouth disease virus in cattle and the development of a monoclonal antibody with diagnostic applications. J Immunol Methods 321:174-181, 2007

28. Yilma T: Morphogenesis of vesiculation in foot-and-mouth disease. Am J Vet Res 41:1537-1542, 1980 Sep 


\section{Conclusions}

No scientific work is perfect. And, it is an unfortunate conundrum that no good scientific work should be completely definitive. This is because it is the nature of scientific investigation that answering one set of hypotheses, necessarily, leads to asking of new questions. Thus, the conclusion of every body of scientific work should include a consideration of the merits and shortcomings of, as well as the future directions indicated by, the current work. The work described in this dissertation has substantially contributed to the understanding of pathogenesis of FMD in cattle, and thus has fulfilled the intended goals. Though the presented information has intrinsic value as an addition to scientific knowledge, it is hoped that this knowledge will have an extrinsic legacy by being built upon by subsequent investigation. The discussion sections of the individual chapters thoroughly summarize and critique the relevant conclusions respectively. However, certain points are worthy of emphasis in this final dissertation conclusion.

As described in chapter one, historically, much effort has been exerted to determine the primary site(s) of infection of FMDV in cattle. The data presented herein provide the most thorough evidence supporting the critical importance of the nasopharyngeal epithelia as the primary sites of infection. Furthermore, the microscopic localization of FMDV antigens to the nasopharyngeal MALT crypts (demonstrated for the first time in this work) has important implications in understanding the pathogen-host interactions occurring at these sites. Similarly, the description of FMDV infection of 
pulmonary tissues suggests that early in infection there is interplay between processes in lung and pharynx that both precede the establishment of viremia.

The limitations of this work are disappointingly similar to those of earlier works on the same subject. As such, it should be noted that this did not occur by oversight, but rather due to intrinsic complications associated with the pathogen under investigation and the choice of experimental subject. Specifically, the seven serotypes and countless strains of FMDV create a seemingly insurmountable obstacle to "ultimate elucidation" of any aspect of the disease or its causal agent. Many features of FMDV are similar across strains, yet others may be distinct. As, such, interpretation of any data relating to FMDV must be made with awareness that the conclusions drawn are only directly relevant to the specific FMDV strain(s) used, and that extrapolation to other strains may or may not be legitimate or prudent. To address this point, the author of this dissertation and co-authors of constituent manuscripts have been conducting similar pathogenesis investigations in cattle using FMDV strain A24-Cruzeiro. It is expected that such work will be published in forthcoming manuscripts; however, it may be noted that at present, most aspects of pathogen-host interaction characterized thus far are similar between the two viruses. Thus, it seems likely that the findings described herein are similarly valid across at least two serotypes of FMDV.

Another group of limitations of this work derive from the combinatorial effects of the expense of experimentation in the natural host (cattle) and the logistical complexities of working within a BSL-3ag containment laboratory. Though there surely is an important place for FMDV research performed in tissue culture systems and rodent models, such approaches could never adequately simulate infection of the natural and 
intact host in vivo. Additionally, there is no practical manner of doing sophisticated work with FMDV in vivo without a containment facility; and work in such facilities has unique complications. The combined effect of these factors is that investigators must make do with smaller quantities of experimental animals compared to conventional research conditions. This often leads to resultant inability to conduct statistical analyses on the data generated.

Lastly, it should be mentioned that although the aerosol model developed within these pages provided a superb system with which to investigate FMD pathogenesis in vivo, the system is only a simulation of natural infection. And, it would be conveniently inappropriate to not mention that the events in natural infection could be different from those described herein. Yet, in the spirit of such complete disclosure and whilst in approach to the conclusion of this discourse, it also seems necessary to revisit the merits of the aerosolization system which include: (1) aerosol droplet sizes spanning the complete breadth of naturally generated infectious aerosols, (2) exposure of the entire respiratory tract to inoculum, (3) delivery of an infectious dose which simulates natural exposure, (4) ability to maintain consistency of exposure conditions across all experimental subjects, (5) ease of duplication at other research facilities due to commercial availability of all products, and, most importantly (6) close simulation of clinical FMD induced via contact and direct inoculation. It is hoped that future work will further confirm the similarities between contact and simulated natural (aerosol inoculation) infection with FMDV.

It is an inescapable reality that FMD is likely to remain the most important constraint to international trade of hoof stock and their derived products for some time. It 
is a plausible fantasy that in 100 years FMD will be eradicated from the face of the Earth. If the journey from today's reality to that version of tomorrow's fantasy is to take place, certain events must occur. Foremost, is the development of a new arsenal of rationally designed vaccines and biotherapeutics. The greatest failure of current vaccines is the inability to prevent primary infection in the nasopharynx, the mechanisms of which have been further unraveled in the current body of work. As such, it may be suggested (and hoped) that continuation of the efforts described herein may ultimately contribute to the global eradication of FMD. 